Old Dominion University

ODU Digital Commons

Civil \& Environmental Engineering Theses \&

Dissertations

Civil \& Environmental Engineering

Spring 2019

\title{
Sidestream RAS Fermentation for Stable Bio-P Combined with Short Cut Nitrogen Removal in an A/B Process
}

Lindsey Elise Ferguson

Old Dominion University, lindseyelise1112@yahoo.com

Follow this and additional works at: https://digitalcommons.odu.edu/cee_etds

Part of the Environmental Engineering Commons

\section{Recommended Citation}

Ferguson, Lindsey E.. "Sidestream RAS Fermentation for Stable Bio-P Combined with Short Cut Nitrogen Removal in an A/B Process" (2019). Master of Science (MS), Thesis, Civil \& Environmental Engineering, Old Dominion University, DOI: 10.25777/qeqm-2n59

https://digitalcommons.odu.edu/cee_etds/81

This Thesis is brought to you for free and open access by the Civil \& Environmental Engineering at ODU Digital Commons. It has been accepted for inclusion in Civil \& Environmental Engineering Theses \& Dissertations by an authorized administrator of ODU Digital Commons. For more information, please contact digitalcommons@odu.edu. 


\title{
WITH SHORT CUT NITROGEN REMOVAL IN AN A/B PROCESS
}

\author{
by \\ Lindsey Elise Ferguson \\ B.S. December 2017, Old Dominion University \\ A Thesis Submitted to the Faculty of \\ Old Dominion University in Partial Fulfillment of the \\ Requirements for the Degree of \\ MASTER OF SCIENCE \\ ENVIRONMENTAL ENGINEERING \\ OLD DOMINION UNIVERSITY \\ May 2019
}

Approved by:

Jaewan Yoon (Director)

Charles B. Bott (Member)

Gary Schafran (Member)

Mujde Unal (Member) 


\author{
ABSTRACT \\ SIDESTREAM RAS FERMENTATION FOR STABLE BIO-P COMBINED WITH SHORT \\ CUT NITROGEN REMOVAL IN AN A/B PROCESS \\ Lindsey Elise Ferguson \\ Old Dominion University, 2019 \\ Director: Dr. Jaewan Yoon
}

It is well known that soluble organic carbon (sCOD), especially in the form of volatile fatty acids (VFA), is critical to achieving reliable enhanced biological phosphorus removal $(\mathrm{EBPR})$ in biological nutrient removal (BNR) processes. Consistent and reliable EBPR in systems treating wastewaters deficient in SCOD may be accomplished by the addition of VFA and SCOD - rich fermentate produced by the fermentation of primary sludge, return / waste activated sludge (RAS / WAS), or other suitable carbon sources. The solids retention time (SRT) of fermenters being used to supplement carbon in sidestream EBPR processes must be controlled such that complex organics are hydrolyzed into simpler fractions, which are then converted into soluble organic carbon, including but not limited to short chain VFAs (i.e. SCVFA) via acidogenesis and acetogenesis, while also preventing methanogenesis from occurring (Skalsky and Daigger, 1995).

Perhaps the most widely employed sidestream EBPR processes involve sidestream RAS fermentation using several different configurations (J. Barnard et al., 2010; Vollertsen et al., 2006). These systems typically divert $5-30 \%$ of the RAS flow in an activated sludge process to an anaerobic, sidestream bioreactor, with hydraulic residence times (HRTs) in the range of $16-$ $48 \mathrm{~h}$. These HRTs may be reduced by the addition of supplemental carbon derived from the fermentation of a portion of the primary sludge. While there are several papers available in the literature detailing the operation and optimization of fermenters fed with primary sludge, little information is available about the performance of fermentation processes that employ sludge generated in high rate activated sludge (HRAS) systems. This study was carried out at a pilot plant operating an A/B type process and involved fermentation of a portion of the WAS from a HRAS A-stage process to add soluble carbon to a sidestream EBPR process receiving a portion of the RAS from B-stage. The goal was to achieve biological phosphorus removal and optimize 
performance in the sidestream reactor while utilizing supplemental carbon from the A-stage WAS fermenter. 
Copyright, 2019, by Lindsey Elise Ferguson, All Rights Reserved. 
This thesis is dedicated to Patrick Mills, Jennifer, Les, and Jacob Ferguson, my family. Without all their continued support I would not be where I am today. 


\section{ACKNOWLEDGEMENTS}

I would like to thank my committee members for providing their time, and knowledge in reviewing my thesis, as well as, for their patience and guidance on my research and editing of this manuscript.

I would like to extend my greatest thanks to my advisor Dr. Jaewan Yoon, who believed in my ability to succeed from my first course with him during my undergraduate studies. Dr. Yoon's untiring efforts deserve special recognition. He spent many hours dedicated to helping me succeed through his guidance, understanding, and encouragement.

Finally, I would like to thank my husband, Patrick, and my family. They shared the many tears shed and stress involved in my journey to completing my masters research. My husband and family continually supported me and reminded me of the reason I attempted this endeavor and my ability to complete it. I am forever grateful for such a loving support system. 


\section{NOMENCLATURE}

A/B - Adsorption/ Bio-oxidation

AD - Anaerobic Digestion

AMX - Anaerobic Ammonia Oxidation

ANOVA - Analysis of Variance

AS - Anaerobic Selector

AVN - Ammonia versus $\mathrm{NO}_{\mathrm{x}}$

Bio-P - Biological Phosphorus

BNR - Biological Nutrient Removal

BOD - Biochemical Oxygen Demand

C-Carbon

$\mathrm{C}: \mathrm{N}$ - Carbon to Nitrogen Ratio

CE - Chesapeake Elizabeth

CETP - Chesapeake-Elizabeth Treatment Plant

CEL - Central Environmental Laboratory

COD - Chemical Oxygen Demand

CSTR - Continually Stirred Tank Reactor

dGAO - Denitrifying Glycogen Accumulating Organisms

DO - Dissolved Oxygen

dPAO - Denitrifying Polyphosphate Accumulating Organisms

EBPR - Enhanced Biological Phosphorus Removal

GAO - Glycogen Accumulating Organisms

GLM - General Linear Model

GPM - Gallon Per Minute

HRAS - High-Rate Activated Sludge

HRSD - Hampton Roads Sanitation District

HRT - Hydraulic Residence Time 
MGD - Million Gallons per Day

MLE - Modified Ludzak-Ettinger

MLSS - Mixed Liquor Suspended Solids

MLVSS - Mixed Liquor Volatile Suspended Solids

MOV - Mechanically Operated Valve

MRT - Multiple Range Test

OP - Orthophosphorus

OHO - Ordinary Heterotrophic Organisms

ORP - Oxidation Reduction Potential

OrthoP - Orthophosphorus

$\mathrm{P}$ - Phosphorus

$\mathrm{P} / \mathrm{C}$ - Phosphorus release rate to COD uptake rate

PAO - Polyphosphate Accumulating Organisms

PBS - Polyphosphate Buffer Saline

PHA - Polyhydroxyalkanoates

PHB - Polyhydroxybutyrate

PHV - Poly-3-hydroxyvalerate

PID - Proportional Integral Derivative

PLC - Programmable Logic Controller

Poly-P - Polyphosphate

PVC - Polyvinyl Chloride

RAS - Return Activated Sludge

rbCOD - Readily Biodegradable Chemical Oxygen Demand

RPM - Rotations Per Minute

RUT - Residual Uptake Test

RWI - Raw Wastewater Influent

SAS - Statistical Analysis System

SBR - Sequencing Batch Reactor

SBPR - Sidestream Biological Phosphorus Removal

SCVFA - Short Chain Volatile Fatty Acid 
sCOD -Soluble Chemical Oxygen Demand

SND - Simultaneous Nitrification-Denitrification

SLR - Solids Loading Rate

SOR - Surface Overflow Rate

SRT - Solids Retention Time

SSRC - Sidestream RAS Fermentation Reactor with Supplemental Carbon Addition

TCA - Tricarboxylic Acid Cycle

tCOD - Total Chemical Oxygen Demand

TP - Total Phosphorus

TSS - Total Suspend Solids

UP - Unit Process

VFA - Volatile Fatty Acids

VSS - Volatile Suspend Solids

WAS - Waste Activated Sludge

WRRF - Water Resource Recovery Facility

WWTP - Wastewater Treatment Plant 


\section{TABLE OF CONTENTS}

Page

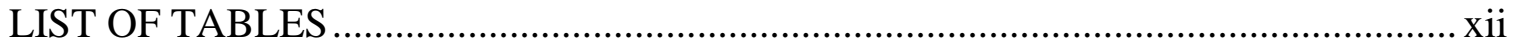

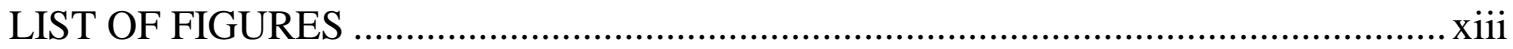

Chapter

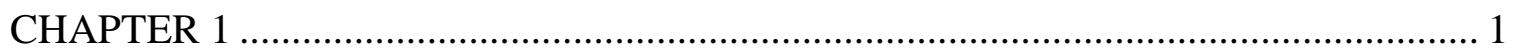

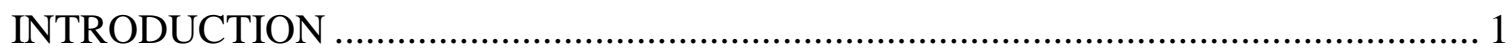

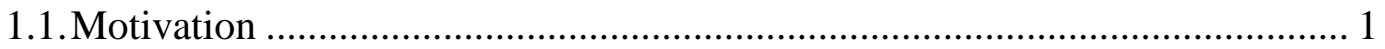

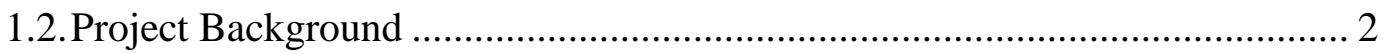

1.2.1.Operational Challenges .............................................................. 4

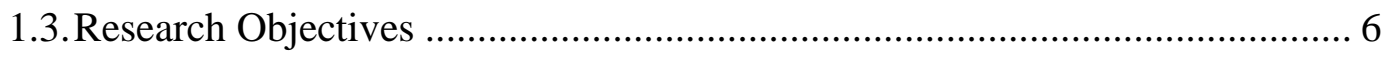

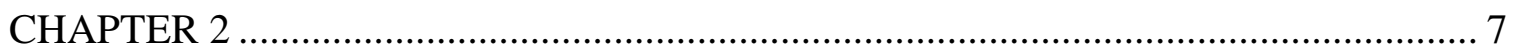

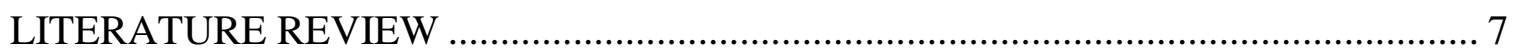

2.1.Enhanced Biological Phosphorus Removal................................................ 7

2.2.Important Microbial Processes In EBPR ................................................... 7

2.2.1.Difference between Accumulibacter and Tetrasphaera .................. 9

2.2.2.Are PAO and dPAO the Same Organism ................................... 10

2.3.Factors Affecting the Performance of EBPR Systems ................................. 11

2.4. Competition between PAOs and GAOs ..................................................... 12

2.4.1.Influent Carbon Effects ............................................................. 12

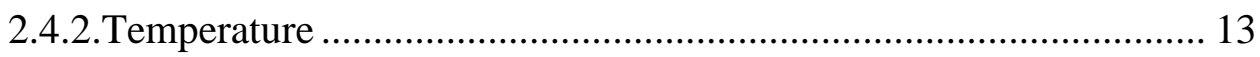

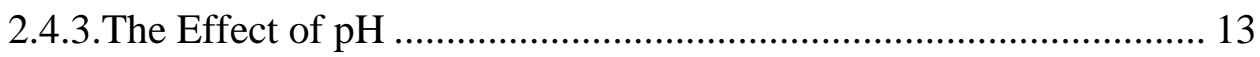

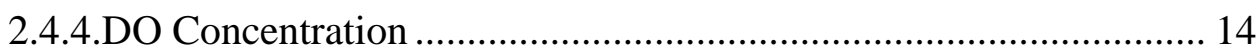

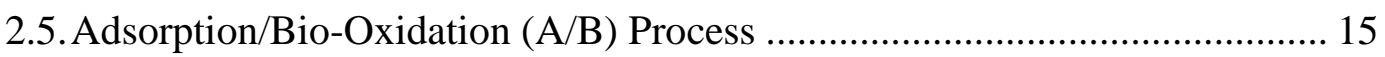

2.5.1.Primary Clarifier Effluent vs. A-stage Effluent ............................ 16

2.6.Primary Sludge Fermentation, Secondary Sludge Fermentation, WAS

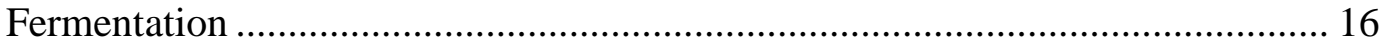

2.6.1.Primary Sludge Fermentation ................................................... 16

2.6.2.Secondary Sludge Fermentation ............................................ 17

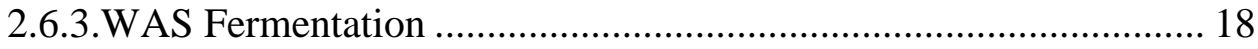


2.7. Conventional EBPR Leading to Sidestream EBPR....................................... 20

2.7.1.Sidestream Enhanced Biological Phosphorus Removal .................. 21

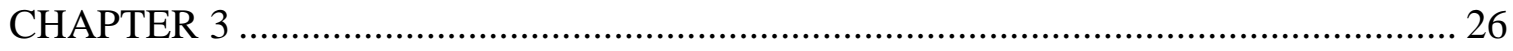

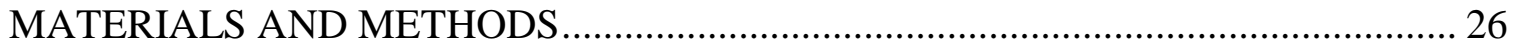

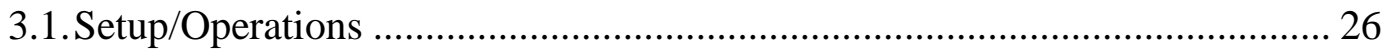

3.1.1.Preliminary Treatment ……………………….............................. 27

3.1.2.High-Rate Activated Sludge Process (HRAS-Control) .................... 28

3.1.3.B-stage AVN ............................................................................... 29

3.1.4.B-stage Sidestream Biological Phosphorus Removal Reactor ........ 31

3.2. Activity Measurements ............................................................................ 32

3.2.1.B-stage Polyphosphate Accumulating Organisms and Denitrifying

Polyphosphate Accumulating Organisms Rate Measurements ................ 32

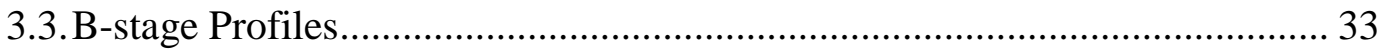

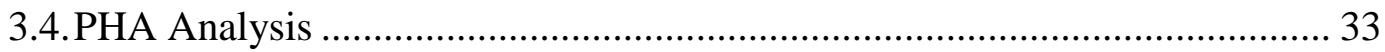

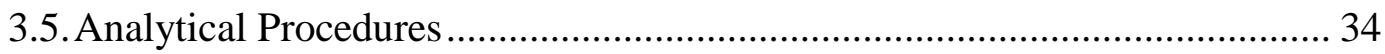

3.5.1.Ammonia Hach Test Kits............................................................... 34

3.5.2.Nitrite Hach Test Kits ................................................................... 34

3.5.3. Nitrate Hach Test Kits ................................................................. 34

3.5.4. Ortho-Phosphate Hach Test Kits .................................................... 35

3.5.5. Chemical Oxygen Demand Hach Test Kits ..................................... 35

3.5.6. Volatile Fatty Acid Hach Test Kits................................................. 35

3.6. Statistical Experimental Design................................................................ 35

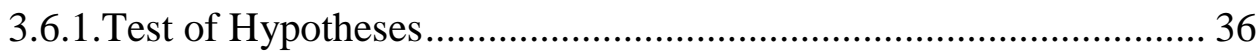

3.6.2. Validation of Data Distribution ....................................................... 37

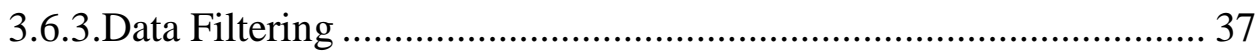

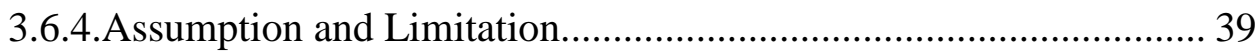

3.6.5.Experimental Design Methods......................................................... 39

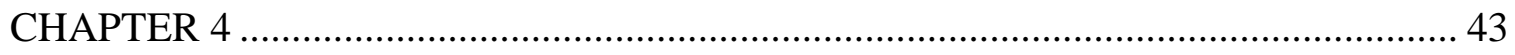

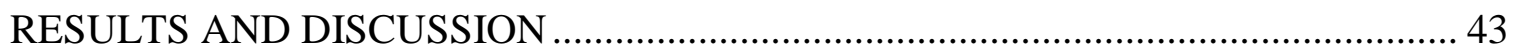

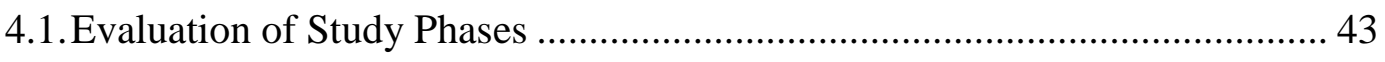

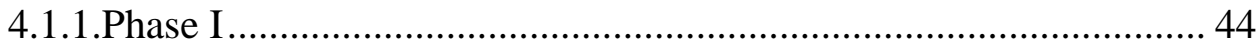

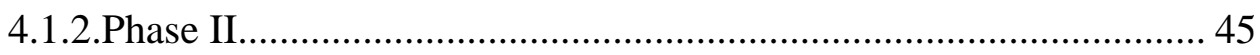

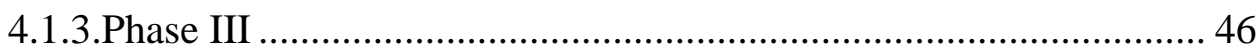

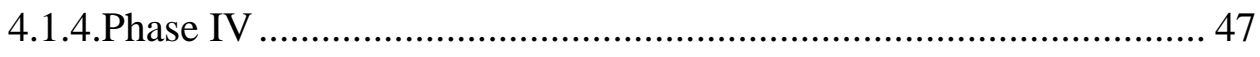

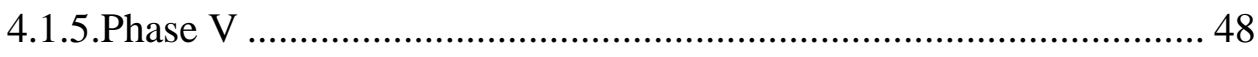




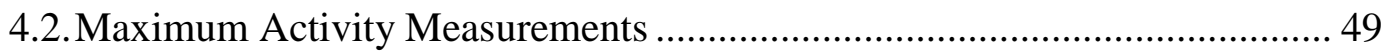

4.2.1.PAO and dPAO Maximum Rate Measurements .......................... 49

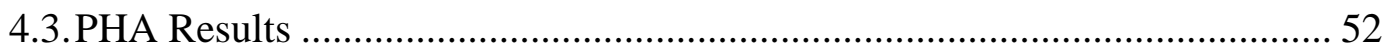

4.4.Fermenter and Thickener Performance ................................................... 57

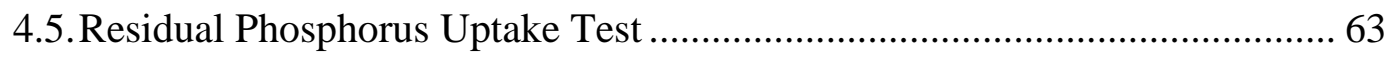

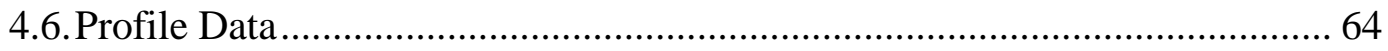

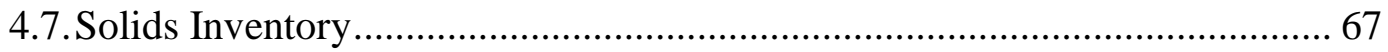

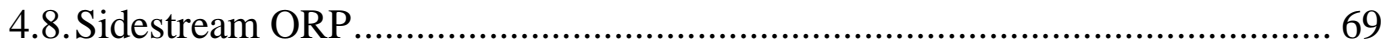

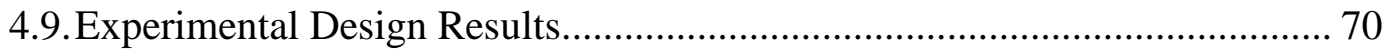

4.9.1.Identification of Contributing Control Variables in the System ...... 71

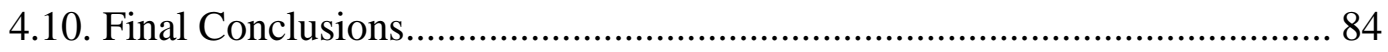

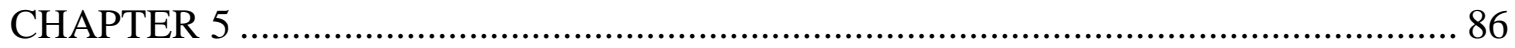

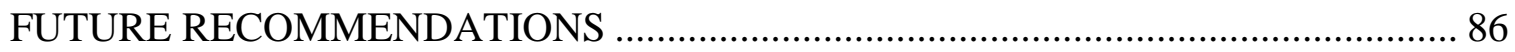

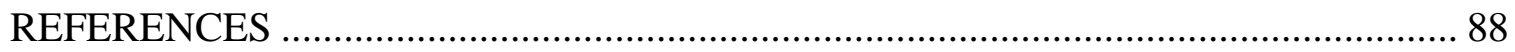

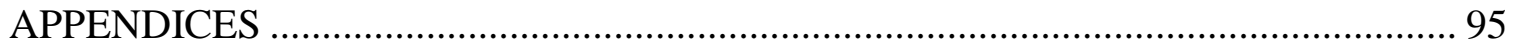

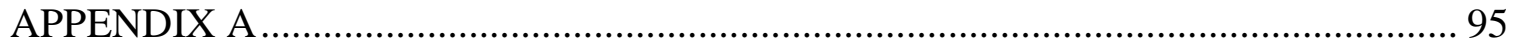

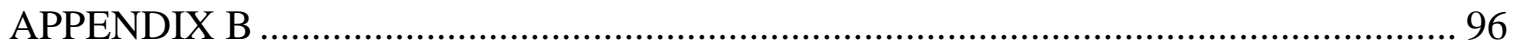

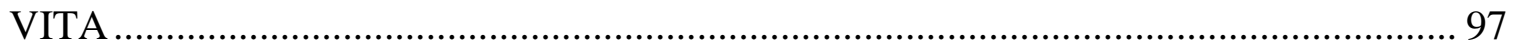




\section{LIST OF TABLES}

Table

Page

Table 2.1. Comparison of VFA Production from Sludge Sources. (Houweling et al., 2010) (Q.

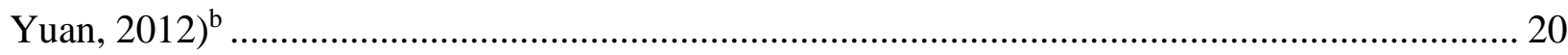

Table 3.1. Sidestream and Mainstream Mass Balance Expressions ....................................... 40

Table 3.2. Sidestream and Mainstream Generalized Linear Model Expressions ...................... 42

Table 4.1. Overview of Each Phase throughout the Study ..................................................... 43

Table 4.2. Phase I Operational Parameter Values..................................................................... 45

Table 4.3. Phases II Operational Parameter Values................................................................... 46

Table 4.4. Phase III Operational Parameter Values ................................................................ 47

Table 4.5. Phase IV Operational Parameter Values.............................................................. 48

Table 4.6. Phase V Operational Parameter Values ................................................................... 49

Table 4.7. Maximum Average Anaerobic Release Rate, Aerobic Uptake Rate, and................. 51

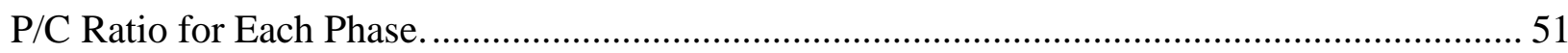

Table 4.8. Sidestream Unit Processes Broken into Ranges Based on Quartiles of the Data ....... 72

Table 4.9. Mainstream Unit Processes Broken into Ranges Based on Quartiles of the Data ...... 72

Table 4.10. GLM Model Validity on Contributional Collinearity by Independent Variables ..... 73

Table 4.11. Contributional Collinearity Independent Variables in Validated GLM Model ........ 74

Table 4.12. Summary Table for Duncan MRT Results ....................................................... 80 


\section{LIST OF FIGURES}

Figure

Page

Figure 1.1. Chesapeake-Elizabeth A/B Pilot Plant ........................................................... 5

Figure 2.1. PAOs Metabolism in Anaerobic, Anoxic, and Aerobic Conditions. (Q. Yuan, 2012;

Z. Yuan et al., 2012) 8

Figure 2.2. Full Scale Sidestream EBPR Process Configurations (Tooker et al., 2017)............. 22

Figure 2.3. Westbank Process Utilizing Sidestream Fermentation Reactor (J. Barnard et al., 2017) 23

Figure 3.1. Chesapeake Elizabeth A/B Pilot Plant.......................................................... 27

Figure 3.2. Location of Each Sensor in B-stage Process................................................ 30

Figure 3.3. Influent Feeding and Mixing Condition in the SBPR throughout the Study ........ 31

Figure 3.4. Stem and Leaf, Boxplot, and Normal Probability Plot........................................ 38

Figure 4.1. Operating Conditions throughout the Study ................................................. 44

Figure 4.2. Sidestream Operation with Mainstream Effluent OP Values throughout the Study .. 44

Figure 4.3. Overview of Maximum PAO and dPAO Bench Scale Activity Rates................... 51

Figure 4.4. Maximum PAO Rates Using Different Carbon Sources ........................................ 52

Figure 4.5. Profile data on Day 332 with PHA, OP, and sCOD ........................................... 54

Figure 4.6. Profile Data on Day 368 with PHA, OP, and sCOD .......................................... 54

Figure 4.7. Profile Data on Day 372 with PHA, OP, and sCOD .......................................... 55

Figure 4.8. Profile Data on Day 400 with PHA, OP, and sCOD ......................................... 55

Figure 4.9. Sample Days Comparing Maximum Anaerobic Release and Aerobic Uptake

Rates from Reactor 204 with PHA Concentration in the Anaerobic Selector............................ 56

Figure 4.10. Average VFA Fractionation Added to SBPR and Effluent OP Concentration ...... 57

Figure 4.11. Temperature, SRT, and pH of the A-stage WAS fermenter.............................. 58

Figure 4.12. tCOD, sCOD, and VFA Produced in the Fermenter ........................................5 58

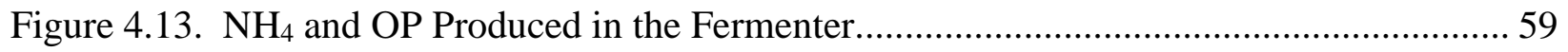

Figure 4.14. A-stage WAS Fermenter VFA Yield in Percent ............................................... 60

Figure 4.15. 2018 Average VFA Fractionation of the A-stage WAS Fermenter ..................... 61

Figure 4.16. Average Monthly Fermenter Temperature throughout the Study ........................ 62

Figure 4.17. Average Percent VFA Production from the Fermenter and B-stage Effluent OP... 62 
Figure 4.18. Residual Phosphorus Uptake Rate Test and Effluent OP Concentration ..... 63

Figure 4.19. Profile Graphs Depicting Influent, Effluent, and Last Aerated Reactor OP

Concentration..... 65

Figure 4.20. Profile Graphs Depicting the Four Aerated Reactor OP Concentrations ............... 65

Figure 4.21. B-stage Anaerobic Selector and SBPR sCOD Profile Grab Values...................... 65

Figure 4.22. Mainstream and Sidestream Solids Inventory Split ........................................ 67

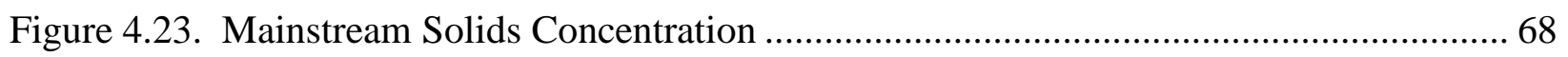

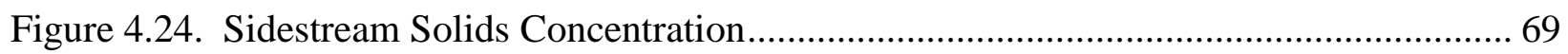

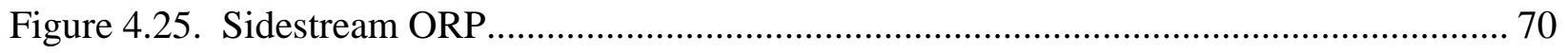

Figure 4.26. Duncan's MRT Grouping of EFF_Q and RAS_OP in Mainstream OP................ 75

Figure 4.27. Duncan's MRT Grouping of EFF_Q and RAS_OP for Mainstream NH4 as a

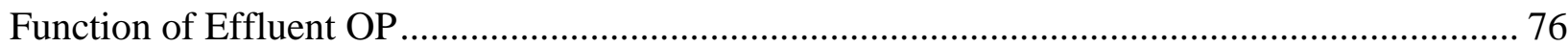

Figure 4.28. Duncan's MRT Grouping of RAS_NO3 for Mainstream NO3 ......................... 77

Figure 4.29. Duncan's MRT Grouping of RAS_OP, FERM_OP and SBPR_Q for Sidestream EFF_OP 78

Figure 4.30. Duncan's MRT Grouping of RAS_TSS, FERM_TSS and SBPR_Q for

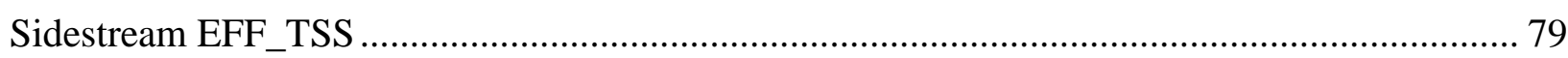

Figure 4.31. Sidestream Subgroup Models - Measured versus Predicted RAS OP Values .... 82

Figure 4.32. Mainstream Subgroup Models - Measured versus Predicted Effluent OP Values 82 


\section{CHAPTER 1}

\section{INTRODUCTION}

\subsection{Motivation}

As permit requirements become increasingly stringent for Phosphorus $(\mathrm{P})$ removal, the need for a more reliable phosphorus removal process from wastewater discharge is necessary. Among chemical precipitation, crystallization, and enhanced biological phosphorus removal (EBPR), the enhanced biological phosphorus removal (EBPR) process can be a reliable approach to removing $\mathrm{P}$ by subjecting microorganisms to first an anaerobic condition, and second to an anoxic/aerobic condition. This method of first subjecting microorganisms to an oxygen limited zone allows polyphosphate accumulating organisms (PAO) to store fermentation products, such as volatile fatty acids, into storage products while simultaneously releasing phosphorus. After the anaerobic zone, energy is produced by the oxidation of storage products, and polyphosphate storage within the cell increases. Storage products are metabolized and polyphosphate bonds form in the cells. Orthophosphate is then stored in the cell and removed from solution. This Enhanced Biological Phosphorus Removal (EBPR) process is beneficial compared to chemical P removal because it can decrease sludge volume production, reduce the impact on $\mathrm{pH}$, provide a secondary beneficial use for recovered P (e.g., struvite), and an overall reduction in cost (Metcalf and Eddy, 2003).

It is common that EBPR Water Resource Recovery Facilities (WRRFs) usually have a difficult time keeping the process stable; a backup chemical system is typically used to ensure the reduction of $\mathrm{P}$ to acceptable limits. EBPR processes that have periods of unstable $\mathrm{P}$ removal are generally caused by an insufficient amount of readily biodegradable influent carbon, PAO are competing against glycogen accumulating organisms (GAO) for carbon, and the inability to efficiently and consistently control the EBPR system (Metcalf and Eddy, 2003).

Increased process stability can be seen in systems with an adequate supply of readily degradable carbon compounds in the anaerobic zone (Tooker et al., 2017). This influent supply of readily degradable carbon to the anaerobic zone is crucial for a stable and effective biological 
phosphorus removal process to occur. Typically, a stable WRRF has a readily biodegradable chemical oxygen demand (rbCOD) to P ratio (rbCOD/P ratio) in the influent greater than 15 ( $\mathrm{J}$. Barnard and Abraham, 2006; Tchobanoglous et al., 2003). One way to ensure the proper $\mathrm{rbCOD} / \mathrm{P}$ ratio in the biological system influent is to provide an external carbon source. Fermentation of sidestream return activated sludge (RAS) is an alternative for improving EBPR process stability. The advantages of using a sidestream biological phosphorus removal (SBPR) process include: readily degradable carbon compounds in the influent that would have been used for EBPR can instead be used for denitrification, reduced odor production compared to primary sludge fermentation, and existing WRRFs can easily be renovated to institute this process (Tooker et al., 2017). Additional advantages for implementing sidestream bio-P processes instead of traditional EBPR processes include: the sidestream reactor having the ability to ferment RAS to make its own carbon source when influent volatile fatty acids (VFA) is low or accept fermentate as an external carbon source separate from the influent wastewater characteristics. The possibility of enriching PAO could give the competitive advantage over GAO allowing for better P removal.

Lastly, the sidestream bio-P process may be able to select for denitrifying PAO (dPAO), as well as, enrich Tetrasphaera more so than Accumulibacter (Tooker et al., 2017). This is significant because the dPAO could provide additional $\mathrm{P}$ uptake in the anoxic zone, while also performing denitrification. Tetrasphaera have the ability to ferment complex molecules while producing stored carbon, which could then be used by other PAOs, such as Accumulibacter, as a source of substrate. This is an important distinction between conventional EBPR and sidestream bio-P operation and reliability. The enrichment of Tetrasphaera in these deep anaerobic conditions gives the competitive advantage to PAOs allowing for a more stable and reliable process compared to traditional EBPR that lacks the diverse PAO population and the additional benefit of Tetrasphaera.

\subsection{Project Background}

Biological phosphorus removal achieved through the use of a sidestream RAS fermenter is a new topic of research that has recently begun in lab scale and pilot scale. In the 1970s and 1980s, it was discovered that many plants not designed for phosphorus $(\mathrm{P})$ removal were able to remove significant amounts of P. Barnard proposed the Phoredox process (J. Barnard, 1976), 
with an anaerobic zone up front, as well as, the Modified Bardenpho process. These two processes allowed for anaerobic zones at the beginning of the process configurations and flowsheets were implemented in a number of different treatment facilities. Some of these facilities were able to reduce total phosphorus (TP) to below $1 \mathrm{mg} / \mathrm{L}$, but the remaining facilities could not. From research by (Fuhs and Chen, 1975), the notion that certain organisms, such as Acinetobacter, were able to take up $\mathrm{P}$ after being fed acetic or propionic acid allowed for an explanation as to why some of these plants did not perform as well as others. This is because the collection systems in colder climates were not providing fermented influent wastewater to the plants. The end product of fermentation produces short chain fatty acids such as acetate and propionate, which was found to be a choice carbon source for phosphorus accumulating organisms (PAO).

With the knowledge that some influent wastewater lacks the much-needed volatile fatty acids (VFA) to achieve biological phosphorus removal, a different design for phosphorus removal was needed. In a pilot plant with a "dead zone", where fermentation was occurring and producing VFAs, J. Barnard (1985) discovered that even with influent wastewater not providing a VFA source to the anaerobic zone, biological phosphorus removal could still be achieved through the VFA entering the process through the deep anaerobic conditions of the "dead zone" (J. Barnard, 1985). The dead zone consisted of fermented mixed liquor that passed a small portion to the mainstream process. This discovery set the research for a sidestream RAS fermentation reactor in motion. If a small portion of RAS could be sent to a sidestream reactor and fermented to produce VFA, more stable biological phosphorus removal could be achieved, because the unstable influent wastewater characteristics would no longer be a limiting factor.

Full-scale facilities with sidestream biological phosphorus removal strategies have been in place for a number of years. Because there are still gaps in understanding the design and operation of sidestream biological phosphorus removal strategies, pilot and lab-scale research is needed. Pilot-scale research allows for different sidestream reactor designs and operating conditions to be tested, compared to the full-scale processes that do not have the ability to change operating configurations. A full-scale pilot study was performed to compare conventional EBPR processes and sidestream EBPR, specifically utilizing primary solids fermentation products as an external carbon source (Wang et al., 2018). 
This study took place at the A/B pilot located at the Hampton Roads Sanitation District (HRSD) Chesapeake-Elizabeth Plant located in Virginia Beach, VA. The High Rate Activated Sludge (HRAS) A-stage process made the research that much more challenging because of its very low readily biodegradable chemical oxygen demand (rbCOD). The little to no rbCOD and a solids retention time (SRT) too low for phosphorus accumulating organisms (PAO) to grow, meant there was a small chance for bio-P to occur. By using the information presented by $\mathrm{J}$. Barnard et al. (2017) and Tooker et al. (2017), a sidestream biological phosphorus removal (SBPR) reactor was implemented to accept a small portion of RAS and ferment it before returning it to the main stream process.

\subsubsection{Operational Challenges}

The largest operational challenge to overcome for this research was related to the amount of influent readily biodegradable carbon available for the PAOs in the SBPR. With little to no rbCOD entering the B-stage process, biological phosphorus removal could not be achieved. In an attempt to achieve biological phosphorus removal in an A/B treatment process, a sidestream RAS fermentation reactor (SBPR) was added (Figure 1.1). The size of the reactor also contributed to operational challenges. The size of the RAS fermentation reactor depends on the intended HRT, SRT, and the RAS mass split. In order to achieve a 12-14 hour HRT, which is needed for RAS fermentation ( $\mathrm{Li}$ et al., 2018), the reactor would need to be relatively large. In order to avoid building an oversized reactor large enough for an HRT of 14 hours or greater, the reactor was designed so that it could accept a small percentage of RAS, as well as, an external carbon source. The external carbon source going to the SBPR would provide additional VFA alongside any VFA produced from internal fermentation to ensure successful anaerobic metabolism of polyphosphate accumulating organisms (PAO). The SRT of the sidestream reactor is also important to consider. With a larger percent of RAS mass going to the SBPR to be fermented, the SRT needed to be longer in order to ferment particulate COD, where as if a smaller percent of RAS mass was going to the SBPR with a higher amount of external fermentate containing large amounts of soluble COD the SRT needed to be lower in order to ferment the soluble COD. The last major operational challenge came about with mixing in the SBPR. When the sidestream reactor was first built, it was designed based off the idea that a 
settled sludge layer in deep anaerobic conditions could achieve an environment where RAS fermentation with end products of VFA were produced as substrate for PAOs which could then proliferate and release polyphosphorus (poly-P) into solution. This design was meant to be operated with a short mixing time a couple of times a day. The mixing proved challenging to determine when to take samples, how to prevent gas entrainment in the sidestream reactor, as well as, preventing solids accumulation in the SBPR.

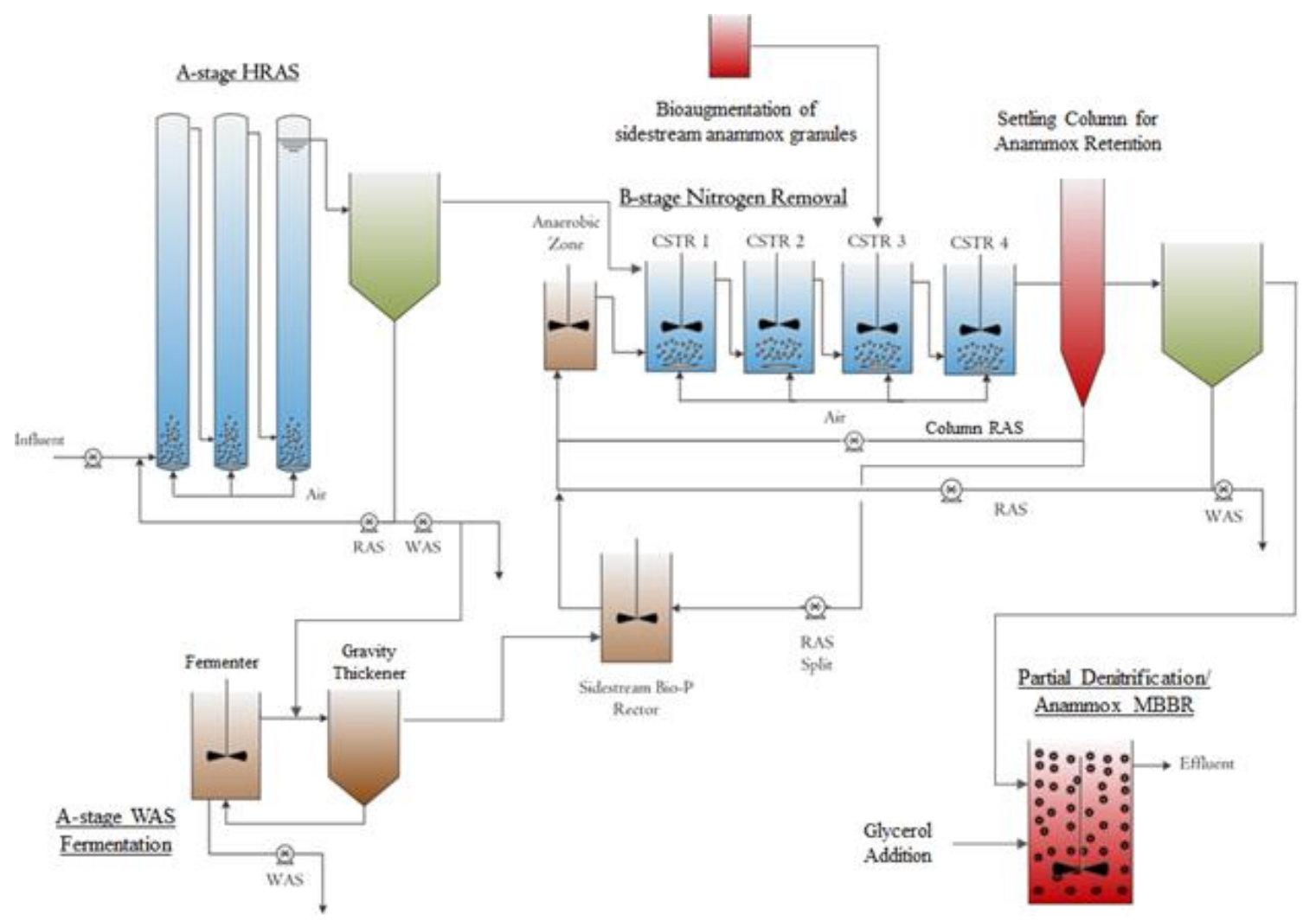

Figure 1.1: Chesapeake-Elizabeth A/B Pilot Plant 


\subsection{Research Objectives}

The objective of this study was to improve reliability of bio-P removal efficiency when influent VFA is low, with the hypothesis that $\mathrm{P}$ removal can be achieved in an A/B process with emerging concepts of sidestream bio-P (RAS fermentation) with or without the addition of externally produced fermentate. The tasks to achieve this objective consist of :

1. Understanding how variations in sidestream reactor operation influence the growth of PAOs and influence biological phosphorus removal in the mainstream.

2. Investigating the relative and key parameters involved in minimizing effluent OP.

3. Designing a pre-operational tool for future sidestream studies. 


\section{CHAPTER 2}

\section{LITERATURE REVIEW}

\subsection{Enhanced Biological Phosphorus Removal}

Enhanced biological phosphorus removal (EBPR) started around 1950 and has been continually researched since. This is an activated sludge process with the idea of utilizing bacteria within the process to incorporate phosphorus into the biomass. The biomass is then wasted along with the stored phosphorus. The enhanced biological phosphorus removal process centers on the idea of exposing a mixed microbial community to a cyclic environment of first an anaerobic and second an aerobic zone. When this cycle is repeated, the sludge is enriched with polyphosphate accumulating organisms. These organisms are responsible for releasing phosphorus and taking up carbon sources in the anaerobic zone as well as taking up phosphorus in the aerobic zone in excess of what they previously released. Enhanced biological phosphorus removal spans from high-rate, non-nitrifying plug-flow plants, to the Pho-Strip process, to a four-stage nitrogen removal process, to a two-stage nitrification/denitrification process ( $\mathrm{J}$. Barnard, 1985; Levin and Shapiro, 1965; Milbury et al., 1971). All of these processes exhibited biological phosphorus removal and were able to aid in the continued research of how to best operate a plant for EBPR.

\subsection{Important Microbial Processes In EBPR}

Polyphosphate accumulating organisms (PAO) are responsible for taking up phosphorus in the activated sludge system. PAOs have the ability to form energy rich storage compounds called polyphosphate (polyP) in excess of their normal cellular requirements under aerobic conditions, but only after exposure to an anaerobic zone first. In the anaerobic zone, PAOs utilize volatile fatty acids (VFAs) such as, acetate and propionate that have transferred into the cell by passive diffusion. Fermentative bacteria produce the VFA or it is brought in with the influent wastewater that was previously fermented in the sewage system. Once inside the cell, the VFA is activated to acetyl-CoA through ATP hydrolysis producing ADP. Simultaneously, the internal polyP is being hydrolyzed releasing phosphate from the cell. Polyhydroxyalkanoates (PHA), which is a carbon storage compound, is then synthesized from the acetyl-CoA using the 
reducing power generated from the metabolism of glycogen and the TCA cycle (Takashi Mino et al., 1987; Smolders et al., 1994). Depending on the type of environment PAOs are subjected to, the pathway for reducing equivalents for the anaerobic metabolism may vary. Meaning the glycolysis, full TCA cycle, or split TCA cycle could all be utilized (Martin et al., 2006).

In a downstream aerobic zone, the stored PHA is metabolized, providing energy and carbon for new cell growth. The oxidation of PHA provides the energy needed to form polyP bonds so that orthophosphate can be removed from solution into the cell. New cell growth also occurring from the oxidation of PHA allows for excess orthophosphate to be taken up due to the large amounts of polyP storage available (Oehmen et al., 2007).

Excess orthophosphate can also be stored inside the cell during anoxic periods. A fraction of PAOs called denitrifying polyphosphate accumulating organisms (dPAO) have the ability to couple denitrification with phosphorus uptake. This is made possible by the dPAO's ability to use nitrate or nitrite as an electron acceptor rather than oxygen (Kerrn-Jespersen and Henze, 1993; Kuba et al., 1993; Oehmen et al., 2010). The anoxic phosphorus removal occurs when nitrate and PHA-rich sludge are simultaneously present. This would occur when the anoxic zone is downstream of the anaerobic zone (Oehmen et al., 2007).
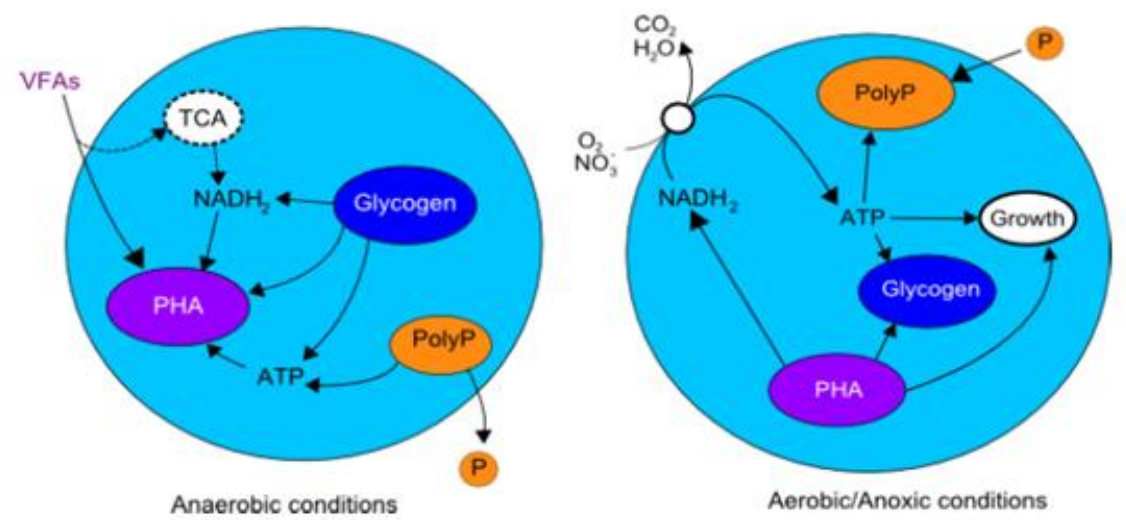

Figure 2.1: PAOs Metabolism in Anaerobic, Anoxic, and Aerobic Conditions. (Q. Yuan, 2012; Z. Yuan et al., 2012) 


\subsubsection{Difference between Accumulibacter and Tetrasphaera}

Accumulibacter are the well-known genus capable of performing the basic operation of EBPR in wastewater treatment facilities. Cycling activated sludge biomass anaerobically and aerobically allows for PAOs to take up orthophosphate. Anaerobically, carbon substrates, usually acetate and propionate, are used to synthesize PHA. The hydrolysis of polyphosphate and the oxidation of glycogen provide energy for the synthesis of PHA. This PHA is then oxidized in the aerobic or anoxic zone for new cell growth as well as the additional uptake of orthophosphate. It has been noted that the accepted Accumulibacter PAO is not able to ferment during the anaerobic phase (Kang and Noguera, 2014). Accumulibacter have been divided into two major types, with one of these types showing the ability to denitrify during anoxic times (Flowers et al., 2009).

Tetrasphaera have begun to be known as the putative PAO. This meaning that they show similar characteristics to Accumulibacter and are prevalent in full-scale EBPR plants, sometimes in larger quantities than their counter parts (Kong et al., 2005; Nielsen et al., 2010).

Tetrasphaera have proven capable of also taking up phosphate aerobically but have not proven to form intracellular PHA anaerobically as a storage compound in all but one species analyzed (Kristiansen et al., 2013). Tetrasphaera have been found to be able to ferment glucose due to their proven ability to not be able to take up acetate or other carbon sources after nine hour incubation periods, but have been able to take up glucose after nine hours and presumably ferment that glucose (Nguyen et al., 2011). Regardless of the manner in which Tetrasphaera are storing carbon sources anaerobically, anaerobic uptake of a form of substrate such as glycogen is required for later $\mathrm{P}$ uptake in the aerobic zone (Nguyen et al., 2011). Some Tetrasphaera have shown to be capable of taking up VFA, but not all, and those that have the ability to take up VFA do not cycle polyP, effectively rendering them useless to removing orthoP (J. Barnard et al., 2017). Even though Tetrasphaera have not been known to utilize VFA in an effective manner for taking up orthoP like Accumulibacter, they are able to produce VFA during fermentation that could be used by other PAOs. This production of VFA through fermentation in deeper anaerobic conditions could allow for Accumulibacter to grow alongside Tetrasphaera. An additional capability of Tetrasphaera is their ability to denitrify as well as take up orthophosphate in an 
anoxic zone. Utilizing nitrate or nitrite as an electron acceptor rather than oxygen while taking up orthophosphate has proven to be a shared characteristic of Tetrasphaera, and the IA clade of Accumulibacter. This trait along with the ability to ferment makes Tetrasphaera a versatile bacterium. Environmental conditions that may favor one bacteria over the other consist of the availability of certain carbon sources such as glucose and the ability to ferment with a longer anaerobic residence time (Nguyen et al., 2011). Overall, it seems that Accumulibacter and Tetrasphaera are both PAOs that occupy different environmental niches and can work together to coexist.

\subsubsection{Are PAO and dPAO the Same Organism}

There has been much debate about whether dPAOs are the same organism as PAOs. Recent research on Accumulibacter showed that when sludge acclimated to oxygen as the electron acceptor and then changed to nitrate the organisms present were able to take up phosphorus after a short adaptation period, while sludge acclimated to nitrate as the electron acceptor and then changed to oxygen were able to take up phosphorus immediately (Zeng et al., 2002). This indicates that Accumulibacter were able to take up phosphorus anoxically with coupled denitrification, as well as, aerobic uptake of phosphorus. Continued research on the Accumulibacter genome showed that the gene for nitrate reductase was not present; however, the gene for nitrite reductase was present (Martin et al., 2006). This indicates that in simultaneous nitrogen and phosphorus removal systems, another organism is responsible for nitrate reduction. Once nitrate is reduced, the Accumulibacter are able to carry out denitrification and phosphorus removal. The other organism that is responsible for nitrate reduction could be a different clade of Accumulibacter that has been found to be able to use nitrate as an electron acceptor or Tetrasphaera (Flowers et al., 2009). In recent research by (Kristiansen et al., 2013), the genome for nitrate reduction to nitrite was detected in all Tetrasphaera species. This indicates that Tetrasphaera may be providing the reduction of nitrate to nitrite for Accumulibacter to couple partial-denitrification and phosphorus removal as well as Tetrasphaera performing full denitrification and phosphorus removal.

Earlier research showed that denitrifying polyphosphate accumulating organisms and non-denitrifying polyphosphate accumulating organisms are both considered Accumulibacter, however they occupy different niches (Kerrn-Jespersen and Henze, 1993). Accumulibacter with 
Rod-type morphology have been seen to have the ability to denitrify as well as take up phosphorus. Accumulibacter with cocci-type morphology were not able to couple denitrification and phosphorus removal in anoxic conditions, however, they were able to take up phosphorus in aerobic conditions (Oehmen et al., 2007). Denitrifying PAO and non-denitrifying PAO seem to both be Accumulibacter that occupy different sub-groups with their respective phenotypic characteristics (Carvalho et al., 2006). PAO and dPAO seem to be the same organism with the ability to take up phosphorus aerobically and anoxically, however, depending on the wastewater characteristics, and carbon sources available, it may be a combination of Accumulibacter and Tetrasphaera working together to perform EBPR. Generally, with more diverse influent organic substrates, Accumulibacter PAOs can account for 9-24\% of the total microbial community in full-scale wastewater treatment plants, with 40-69\% being Accumulibacter and the rest are other forms of PAOs (He et al., 2008).

\subsection{Factors Affecting the Performance of EBPR Systems}

Some factors that could affect the performance of an EBPR system include the amount and variability of substrates in the influent, the amount of nitrate returned to the anaerobic zone, as well as DO concentrations. The variability and amount of substrates in the influent refers to the amount of readily degradable carbon compounds in the anaerobic zone. This is a very important parameter to obtain stable and effective biological phosphorus removal. A typical $\mathrm{rbCOD} / \mathrm{P}$ ratio in the influent of a stable WRRF is greater than $15 \mathrm{mg} / \mathrm{L}$ (Tchobanoglous et al., 2003). Another indicator of a plant's ability to perform EBPR is the VFA/P ratio. The VFA concentration needed in the influent feed is based on the amount of rbCOD that will also be present and available to be converted to VFA in the anaerobic zone. This ratio should be in the range of 4-16mg VFA/ mg P removed (J. Barnard and Abraham, 2006; Curto, 2001), where the lower end of the range will be sufficient if there is enough rbCOD in the influent to be converted to VFA, and the higher end of the range will be needed if there is not sufficient rbCOD present in the influent. There are other factors that play a role in determining the feasibility of EBPR, but if these ratios are met, the likelihood of achieving EBPR is higher. Nitrate in the anaerobic zone generally cause a problem with EBPR performance. This is because other ordinary heterotrophic organisms (OHO) and denitrifiers are able to take up the carbon available in the anaerobic zone providing competition for PAOs anaerobic metabolism. High DO concentrations around 4.5- 
$5 \mathrm{mg} / \mathrm{L}$ have shown to negatively affect the ability to take up $\mathrm{P}$ while lower DO concentrations around 2.5-3mg/L have shown a higher affinity to take up P (Griffiths et al., 2002). Lower DO concentrations around $0.5-1.5 \mathrm{mg} / \mathrm{L}$ are being examined more closely because of the ability to perform simultaneous nitrification/denitrification (SND) (Lemaire et al., 2006), as well as allowing PAO populations to outcompete GAO populations (Carvalheira, Oehmen, Carvalho, Eusebio, et al., 2014). These lower DO values have shown an increase in PAO population. This indicates that a lower DO can be used to perform EBPR, which will help in aeration costs as well as removing nitrogen.

\subsection{Competition between PAOs and GAOs}

Glycogen Accumulating Organisms (GAO) were first reported in 1985 as a potential competitor for PAOs because they are able to take up VFA under anaerobic conditions, however they are not able to accumulate polyphosphate and take up orthophosphate under aerobic conditions (Fukase et al., 1985). The GAO biochemical pathway takes up carbon and converts it to PHA anaerobically, which is similar to PAOs, however the source of energy for GAOs is different than PAOs since they are not able to cycle polyP. GAOs rely on glycogen as the primary source of energy and reducing equivalents, whereas PAOs rely on polyP (Oehmen et al., 2007). During the aerobic phase, GAOs oxidize PHB and PHV for biomass growth, and glycogen replenishment (Oehmen et al., 2007). Because GAOs are able to take up acetate in the anaerobic zone, and do not cycle polyP, they are not able to take up orthophosphate in the aerobic phase, which means they are a direct competitor for carbon in the anaerobic phase for PAO and do not provide the benefit of orthophosphate uptake in the aerobic phase.

\subsubsection{Influent Carbon Effects}

Influent carbon plays a role in determining if there will be a more prevalent GAO population. PAO and GAO metabolism is effected by the type of carbon source made available to them (Oehmen et al., 2006; Oehmen, Yuan, et al., 2005). PAO have the ability to utilize acetate or propionate with similar kinetic rates (Oehmen et al., 2006; Oehmen, Yuan, et al., 2005). Two different GAO populations have been seen to be able to take up either acetate or propionate with similar kinetic rates to the Accumulibacter, but both types are not able to take up acetate and propionate (Oehmen et al., 2006; Oehmen, Yuan, et al., 2005). Because 
Accumulibacter are able to take up acetate and propionate at similar kinetic rates and efficiencies, it seems the best way to outcompete GAO is to have a combined acetate and propionate feed (Chen et al., 2005; Chen et al., 2004).

\subsubsection{Temperature}

Temperature has proven to play a role in selecting for either a PAO or GAO dominated population in activated sludge. Higher temperatures have correlated with a higher GAO presence, and lower temperatures have shown a higher PAO presence. Multiple studies have proven that temperatures above 20 degrees Celsius favor GAOs and below 20 degrees Celsius favor PAO populations (Lopez-Vazquez et al., 2009; Panswad et al., 2003) (Erdal et al., 2003). Lower temperatures correlate to a slowed rate for kinetic activity. In the case of PAOs, phosphorus release and uptake rates did decline at lower temperatures, however, these lower temperatures did induce a change in population from GAO to PAO (Brdjanovic et al., 1998). A study done by (Panswad et al., 2003) showed that an increase in P release rate occurred at higher temperatures simultaneously with a decrease in P uptake rate. Based on Brdjanovic et al. (1998) findings, the stoichiometry of PAOs is not correlated with temperature dependence. Based on this, a higher fraction of GAO to PAO population observed at higher temperatures would provide an explanation for the increased $\mathrm{P}$ release and decreased $\mathrm{P}$ uptake. Overall, improved EBPR performance has been seen with decreasing temperatures (Oehmen et al., 2007). The PAO community is dominant over GAO fractions in these colder temperatures, and accounts for the enhanced EBPR performance at many wastewater treatment facilities (Erdal et al., 2003).

\subsubsection{The Effect of pH}

The effect of $\mathrm{pH}$ on PAO outcompeting GAO has been studied and used in batch tests (Oehmen et al., 2007). Higher $\mathrm{pH}$ values, greater than 8.0, have shown to support a larger PAO fraction (Carvalheira, Oehmen, Carvalho, and Reis, 2014). This is because at higher ambient pH levels, the anaerobic P release rate increases (Liu et al., 1996; Smolders et al., 1994). Smolders et al. (1994), under the assumption that internal $\mathrm{pH}$ of the cell remains the same, found the $\mathrm{pH}$ gradient increases simultaneously with an increase in electrical potential difference across the cell. This concludes that more energy is required for acetate to be taken into the cell at higher $\mathrm{pH}$ values. Filipe et al. (2001c) discovered that for $\mathrm{pH}$ between 6.5 and 8.0 is 
independent of acetate uptake, glycogen degradation, and PHA accumulation rates for PAOs. This is consistent with Smolders et al. (1994) findings indicating that the ability to utilize VFA is not hindered by the higher $\mathrm{pH}$ levels. Additional studies by Filipe et al. (2001a) showed aerobic $\mathrm{P}$ uptake rates were inhibited at $\mathrm{pH}$ levels less than 6.5. This information leads to the consensus that PAOs operate better under higher $\mathrm{pH}$ levels.

GAO dominant populations show the opposite results of PAOs when it comes to acetate uptake at higher $\mathrm{pH}$ values. GAOs are not able to account for an increased energy demand at higher $\mathrm{pH}$ levels because they do not have the ability to utilize polyP like PAOs can (Oehmen et al., 2007). This means that GAOs struggle to take up acetate and meanwhile are consuming more glycogen (Oehmen et al., 2007). A study performed by Filipe et al. (2001c) showed that PAOs are capable of taking up VFA faster above a pH of 7.25, whereas GAOs are capable of taking up VFA faster below a $\mathrm{pH}$ of 7.25. Thus, $\mathrm{pH}$ values may be a significant factor that influences the size of the two populations. Oehmen, Vives, et al. (2005) showed results of increased PAO population over GAO populations when the $\mathrm{pH}$ was increased to 8 as well as improved $\mathrm{P}$ removal. Overall, $\mathrm{pH}$ plays a large role in selecting for PAO or GAO population and should be considered when evaluating process performance.

\subsubsection{DO Concentration}

DO in WRRFs is being examined more closely as a tool to enhance aerobic orthophosphate uptake and provide a competitive advantage to PAO outcompeting GAO. Carvalheira, Oehmen, Carvalho, Eusebio, et al. (2014) performed a study in which two sequencing batch reactors (SBRs) were enriched with PAOs and GAOs respectively. These two SBRs were operated at different DO concentrations to determine the effect the DO played on the microbial population within each reactor, as well as the $\mathrm{P}$ uptake rates. The maximum DO concentration tested was $8 \mathrm{mg} \mathrm{O} 2 / \mathrm{L}$ and the minimum was $0.6 \mathrm{mg} \mathrm{O} 2 / \mathrm{L}$. Results from the study showed that when reducing the DO concentration from $8 \mathrm{mg} \mathrm{O} 2 / \mathrm{L}$ to $2 \mathrm{mg} \mathrm{O} 2 / \mathrm{L}$ in the PAO dominated reactor, the abundance of Accumulibacter increased from 71 to $90 \%$ while the GAO population of Competibacter decreased from 20 to $<1 \%$ (Carvalheira, Oehmen, Carvalho, Eusebio, et al., 2014). In addition to the increased PAO population, the P release to VFA uptake ratio increased from 0.33 P/VFA to 0.56 P/VFA after the decrease in DO concentration (Carvalheira, Oehmen, Carvalho, Eusebio, et al., 2014). This is in accordance with the known 
literature phosphorus release to VFA uptake ratio of 0.5 indicating a PAO dominated population (Smolders et al., 1994). The aerobic HRT of the system was also studied as a potential factor in PAO and GAO competition. The same study by Carvalheira, Oehmen, Carvalho, Eusebio, et al. (2014) showed that an increased aerobic HRT causes secondary release of P as an energy source for cell maintenance once PHA degradation is complete. This reduced the amount of polyP available for VFA uptake in the anaerobic zone, causing reduced P uptake later in the aerobic zone. This continued cycle of extended aeration would decrease the polyP content of PAOs overtime and allow for more VFA to be available for GAOs, causing an increased GAO dominated population (Carvalheira, Oehmen, Carvalho, Eusebio, et al., 2014). Overall, higher aeration, either through increased DO concentrations or aerobic HRTs proves harmful to the PAO dominated population.

\subsection{Adsorption/Bio-Oxidation (A/B) Process}

The adsorption/bio-oxidation process (A/B process) was developed in the 1950s (Ullrich and Smith, 1951). The goal was to develop a cost-effective treatment process that maximized carbon recovery to produce energy through biogas and reduce nutrient concentrations. This process was designed with two consecutive stages. The first stage is a highly loaded activated sludge process with a clarification step for carbon removal. The second stage is a biological oxidation and nutrient removal step with a lower F/M ratio. A typical A-stage loading is 2-

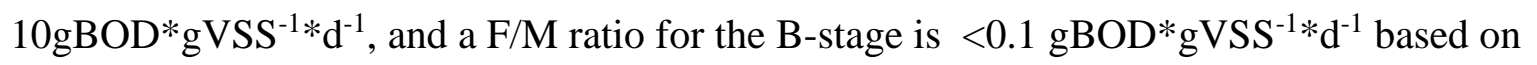
findings from (Sancho et al., 2019). The loading to A-stage is higher because the process operates at a lower HRT, SRT, and DO to capture more C (Carbon) in the biomass rather than it being mineralized. A-stage's goal is to use biological, physical, and sometimes chemical methods to capture $\mathrm{C}$ in the particulate and colloidal form into the sludge and redirect that to an anaerobic digester (AD) for energy recovery (Meerburg et al., 2015). A-stage is capable of achieving removal efficiencies under optimum operating conditions of 70-80\% of total COD, $30 \%$ soluble COD, and 80-95\% of suspended solids (de Graaff et al., 2016). Because of the high removal efficiency for TSS/COD in A-stage, there is insufficient $\mathrm{C}$ for conventional denitrification processes (Wan et al., 2016). However, other processes that require less carbon for nitrogen removal would do well in the B-stage step, such as short-cut nitrogen. 


\subsubsection{Primary Clarifier Effluent vs. A-stage Effluent}

Carbon fractionation found in the WAS and effluent of an A-stage process differs from that of a primary clarifier. Total COD removal of $70-80 \%$ can be achieved in an A-stage process (de Graaff et al., 2016), where as a primary clarifier can achieve total COD removal of 10-24\% (Metcalf and Eddy, 2003). This is an important parameter to consider when the downstream BNR process requires low influent COD. Shortcut nitrogen removal processes such as partial nitritation/deammonification and nitritation/denitritation require carbon to nitrogen $(\mathrm{C}: \mathrm{N})$ ratios of 0-5:1 and 5-8:1 respectively compared to full nitrogen removal processes performing nitrification/denitrification that require a $\mathrm{C}: \mathrm{N}$ ratio of 8-15:1 (Yang et al., 2014). Because the B-stage nitrogen removal step requires a smaller $\mathrm{C}: \mathrm{N}$ ratio, utilizing an A-stage process instead of a primary clarifier would be more beneficial for the treatment process. Additional concerns with utilizing a primary clarifier instead of an A-stage process are related to the amount of biomass produced in B-stage as well as energy production. Because a primary clarifier captures less COD in the WAS, a larger percent of COD is sent to B-stage and harnessed for biomass production. This increases the required aeration capacity and tank volume (Meerburg et al., 2015; Trzcinski et al., 2017). Additionally, the COD captured in the WAS of A-stage produces more energy after being sent to an anaerobic digester compared to a primary clarifier (Rahman $e t$ al., 2017).

\subsection{Primary Sludge Fermentation, Secondary Sludge Fermentation, WAS Fermentation}

\subsubsection{Primary Sludge Fermentation}

Production of VFA on plant site through the use of primary sludge fermentation is a common practice worldwide (Munch and Koch, 1999). Operational parameters for primary sludge fermenters are SRT, HRT, and $\mathrm{pH}$. The SRT controls the group of organisms found inside of a fermenter. A longer SRT will allow methanogens to grow while a shorter SRT may wash out the fermentative bacteria. Because fermenting bacteria are temperature-dependent, a SRT of 3 to 5 days in the warmer months, and a SRT of 4 to 8 days during the colder months should be followed for optimal fermenter operation (WEF, 2006). The HRT is used to fine-tune the operation of a fermenter based on the primary sludge-pumping rate. The $\mathrm{pH}$ of a fermenter is important in helping prevent methanogenesis from occurring. Methane formers are known to 
prevail at neutral $\mathrm{pHs}$. Operating a fermenter at a $\mathrm{pH}$ below 6.5 allows acid formers to prevail because they are less sensitive to lower pHs (Rabinowitz, 2011). Primary sludge has been fermented in five different configurations: Activated primary sedimentation tanks, complete mix fermenter, single-stage static fermenter/thickener, two-stage mixed fermenter/thickener, and unified fermentation and thickening fermenter (Rabinowitz, 2011). In a study operated by Rabinowitz (1985), primary sludge fermenters at temperatures between 18 and 22 degrees Celsius with a SRT between 2 and 10 days found that 90 percent of the short chain volatile fatty acids produced were acetic and propionic acids. A study by Elefsionitis and Oldham (1994) found that acetic, propionic, and butyric acids accounted for 45, 31, and 9 percent, respectively, of the SCVFAs produced in the primary sludge fermenter. Overall, the majority of the SCVFAs produced in fermenters when operated at optimal conditions are acetic and propionic acids. Even though primary sludge fermenters have the ability to produce the needed VFA for BNR processes, they are not always reliable. Numerous treatment plants with primary sludge fermenters have seen the mass of VFA produced is often below what is required for efficient phosphorus and nitrate removal (Thomas et al., 2003). This occurs because large flat sewer systems have longer residence times and increased temperatures, which lead to decreased VFA production potential in the primary sludge fermenters.

\subsubsection{Secondary Sludge Fermentation}

Secondary sludge fermentation consists of a portion of mixed liquor or RAS being fermented to form readily biodegradable COD (rbCOD) or SCVFAs and then returned to the mainstream BNR process to enhance biological phosphorus removal (Rabinowitz, 2011). Secondary sludge fermenters are usually completely mixed, or intermittently mixed reactors. These reactors are designed in the main process, or if using the RAS, in a sidestream process. In 1985, J. Barnard (1985) discovered that mixed liquor fermentation was taking place in a "dead zone" within the MLE process, and adding sufficient VFA to the post-anoxic zone which resulted in phosphorus release of over 30mg/L as P (J. L. Barnard and Kobylinski, 2014). This discovery along with other observations of phosphorus removal occurring at plants not specifically designed for BPR were able to achieve this through turning off mixers or air at the beginning of plug-flow processes, and determine that mixed liquor or RAS fermentation could facilitate EBPR (J. L. Barnard and Kobylinski, 2014). Another example of mixed liquor 
fermentation from Clark and Neethling (2009) showed by switching off a mixer in one of two anaerobic zones, fermentation in the reactor occurred and was able to send enough SCVFAs to achieve phosphorus removal from $8 \mathrm{mg} / \mathrm{L}$ to $0.5 \mathrm{mg} / \mathrm{L}$.

RAS fermentation can be applied at any BNR process, but is generally used in plants with secondary treatment processes, and no primary clarifiers. Lamb (1994) developed a patented process where a portion of RAS is pumped to a sidestream fermentation zone, and the effluent from the fermentation zone is sent to the anaerobic zone providing the VFA source for EBPR. Based on Lamb's patented process, Stroud and Martin (2001) upgraded the South Cary, North Carolina, plant to a four-stage Bardenpho process with RAS fermentation. The plant was able to reduce TP to below 1mg/L (Stroud and Martin, 2001).

In almost all plants achieving phosphorus removal through secondary sludge fermentation have happened by accident, or through operators attempting to improve phosphorus removal based on J. Barnard et al. (2010) findings. Secondary sludge fermentation is a better alternative to primary sludge fermentation because odorous primary sludge fermenters would no longer be needed, corrosion from fermentation would be avoided, and blockages with pumping the higher concentration solids would no longer be a problem (J. Barnard et al., 2010).

\subsubsection{WAS Fermentation}

Another option for utilizing substrates already at wastewater treatment facilities other than secondary sludge fermentation is waste activated sludge (WAS). Fermenting WAS is different than primary fermentation because of the available substrate to be fermented. In primary sludge there are higher concentrations of easily biodegradable organic polymers (proteins, lipids, carbohydrates) and, in WAS there is mostly bacterial mass, which allows for shorter hydrolysis and fermentation times in primary sludge (Q. Yuan, 2012). The primary sludge is able to be hydrolyzed and fermented in a much shorter amount of time than WAS because WAS must perform cell lysis before it is able to be hydrolyzed and fermented (Turoviskiy and Mathai, 2006). Research on WAS fermentation at a 5 day SRT, similar to the primary fermentation, showed average VFA yields at 0.07g VFA/g COD (Q. Yuan, 2012). When comparing these results with primary sludge fermentation, they were within the same 
range of VFA yield. These results did conclude that a longer SRT of 10 days is required to achieve roughly the same VFA yield efficiency.

Another substrate that can be used for fermentation is A-stage WAS. This is the waste activated sludge coming from a high rate A-stage process. This would be used in an A/B process where the A-stage is operated as a high rate adsorption step followed by a bio-oxidation step. This process was used in this project to divert the largest amount of carbon possible in the Astage, and subsequently send a small amount of carbon to the B-stage in order to perform shortcut Nitrogen removal. The carbon that was diverted in the A-stage can be recovered for energy in a digester later in the process. Similarly, to the primary WAS, the A-stage WAS sludge would contain mostly bacterial mass compared to primary sludge where there would be a lot of organic polymers and less organisms, so there is likely to be more available soluble COD in the primary sludge than in the A-stage WAS sludge. Similar to the case when using primary WAS, the SRT of the fermenter would need to be longer to achieve higher VFA yields. The VFA results would be similar to the primary WAS VFA yield results. Another consideration when utilizing this form of substrate would be the amount of ammonium and phosphorus released during fermentation and put back into the system with the VFA enriched fermentate. Both primary sludge fermentation and A-stage WAS fermentation are expected to release phosphorus and nitrogen into the liquid phase because of the higher concentration of bacterial mass. This was demonstrated in a study done by Danesh and Oleszkiewicz (1997) where primary sludge was co-thickened with WAS and fermented. This would drive the nutrient loading up in the mainstream BNR process. This form of fermentation has not been studied in depth with only one other A-stage fermentation study performed so far. The study performed by (Cagnetta et al., 2016) evaluated key parameters that affect the fermentation of HRAS. The study showed that the initial BOD of the sludge appeared to be the key in determining the yield produced from A-stage sludge. The maximum VFA production found from fermenting A-stage sludge was $141 \mathrm{mg} \mathrm{C} \mathrm{g}^{-1} \mathrm{VSS}_{\text {fed }}$ at a $\mathrm{pH}$ of 7 (Cagnetta et al., 2016). This is similar to VFA yield found from fermenting primary sludge which expects to produce a VFA yield of $0.15 \mathrm{~kg}$ VFA measured as COD per kg of TSS (Oldham and Abraham, 1994).

Fermenting A-stage WAS is a completely novel idea. Fermenting A-stage WAS in the project was the solution to accomplishing biological phosphorus and nitrogen removal together. 
The goals of the overall project at the Chez-Liz pilot plant consisted of operating an A/B process where the HRAS diverted as much $\mathrm{C}$ as possible to be able to send a smaller amount of $\mathrm{C}$ to the B-stage process for shortcut nitrogen removal. Also, the C diverted to the A-stage WAS was fermented in an A-stage WAS fermenter and sent additional VFA and COD to the sidestream biological phosphorus removal reactor. The fermented WAS that was not utilized for sidestream EBPR could be sent to an AD for energy recovery. Overall, the use of an A/B process and fermenting A-stage WAS allowed for carbon addition to the B-stage nitrogen removal and sidestream EBPR processes to be controlled and optimized.

Table 2.1. Comparison of VFA Production from Sludge Sources. (Houweling et al., 2010) (Q. Yuan, 2012) $)^{\mathrm{b}}$

\begin{tabular}{|l|l|l|}
\hline $\begin{array}{l}\text { Primary Sludge } \\
\text { Fermentation }\end{array}$ & WAS Fermentation & $\begin{array}{l}\text { Secondary Sludge } \\
\text { Fermentation }\end{array}$ \\
\hline $\begin{array}{l}0.55-0.9^{\text {a }} \\
\text { Kg VFA per kg bCOD } \\
\text { applied }\end{array}$ & $0.07 g$ VFA/g COD & $\begin{array}{l}\text { b.09-0.14 } \\
\text { Kg VFA per kg bCOD }\end{array}$ \\
\hline
\end{tabular}

\subsection{Conventional EBPR Leading to Sidestream EBPR}

The idea for a sidestream biological phosphorus removal reactor started with the first sign of accidental phosphorus removal observed in many conventional EBPR USA plants in the early 1970s (Milbury et al., 1971). These plants were operating in a high rate plug-flow process to prevent nitrification. These plants were seeing a release of phosphorus at the beginning of the plug-flow reactors. The reason for this was suggested to be because of the inability to properly aerate the inlet of the plug-flow reactor (Milbury et al., 1971). Because of these accidents, (Levin and Shapiro, 1965) created the Pho-Strip process. This process stripped the phosphorus from the sludge by sending 100 percent of the return activated sludge (RAS) to an anaerobic thickener. The RAS was then sent to the mainstream where it recombined with influent 
wastewater. The PAO were then able to replenish their phosphorus reserves, as well as, accumulate phosphorus in the aeration zone.

In work done by Fuhs and Chen (1975), the need for VFA in the influent to the plant of the Pho-Strip process was realized. When nitrates were produced in the aeration basin, it prevented the formation of VFA. Without VFA in the anaerobic zone, the PAOs did not have a carbon source to readily take up. This work led J. Barnard (1985) to realize that mixed liquor fermentation was occurring in a dead zone in a pilot plant he was operating. This mixed liquor fermentation was providing the necessary VFA needed for phosphorus release in a second anoxic zone, as well as, unexplained phosphorus uptake in the reaeration zone. Barnard (1985) also realized this dead zone was receiving a small portion of the mixed liquor, only 7 percent. This small amount of unmixed sludge had a long enough retention time to be able to ferment and provide sufficient VFA for phosphorus release.

Conventional EBPR process configurations all utilize the anaerobic/aerobic metabolism of polyphosphate accumulating organisms. These process configurations can successfully perform EBPR, however, these treatment configurations rely on the influent wastewater containing a high enough concentration of VFA which can be variable (J. Barnard and Abraham, 2006; Gu et al., 2008). An alternative to the conventional EBPR process configurations that can provide a stable VFA source is the sidestream EBPR process.

\subsubsection{Sidestream Enhanced Biological Phosphorus Removal}

The findings fromJ. Barnard et al. (2010); Fuhs and Chen (1975); Levin and Shapiro (1965) encouraged an alternative method for improving EBPR process stability. This process includes a sidestream anaerobic reactor capable of biological sludge hydrolysis and fermentation, where the effluent of the sidestream reactor is returned to the mainstream biological process. There are many full-scale plants operating with this type of sidestream system. These processes send a portion of the RAS or mixed liquor to a sidestream anaerobic reactor where either retention times are long enough for mixed liquor fermentation before being sent back to the mainstream, or a shorter retention time is held with external carbon being added to the reactor (Tooker et al., 2017). The important design factor is that there is enough stable VFA being produced in the sidestream reactor or added to the sidestream reactor to achieve phosphorus 
release and VFA uptake. Even though there are about 80 full-scale facilities operating with sidestream EBPR processes, they are still at their infancy in terms of understanding how to design and operate a stable EBPR plant with a sidestream EBPR reactor. The most common design configurations for sidestream EBPR consist of: sidestream RAS fermentation, sidestream RAS fermentation with supplemental carbon addition, sidestream mixed liquor suspended solids fermentation, and unmixed in-line mixed liquor suspended solids fermentation (Tooker $e$ t al., 2017). These six configurations for sidestream EBPR implemented at full-scale facilities can be seen in the figure below.
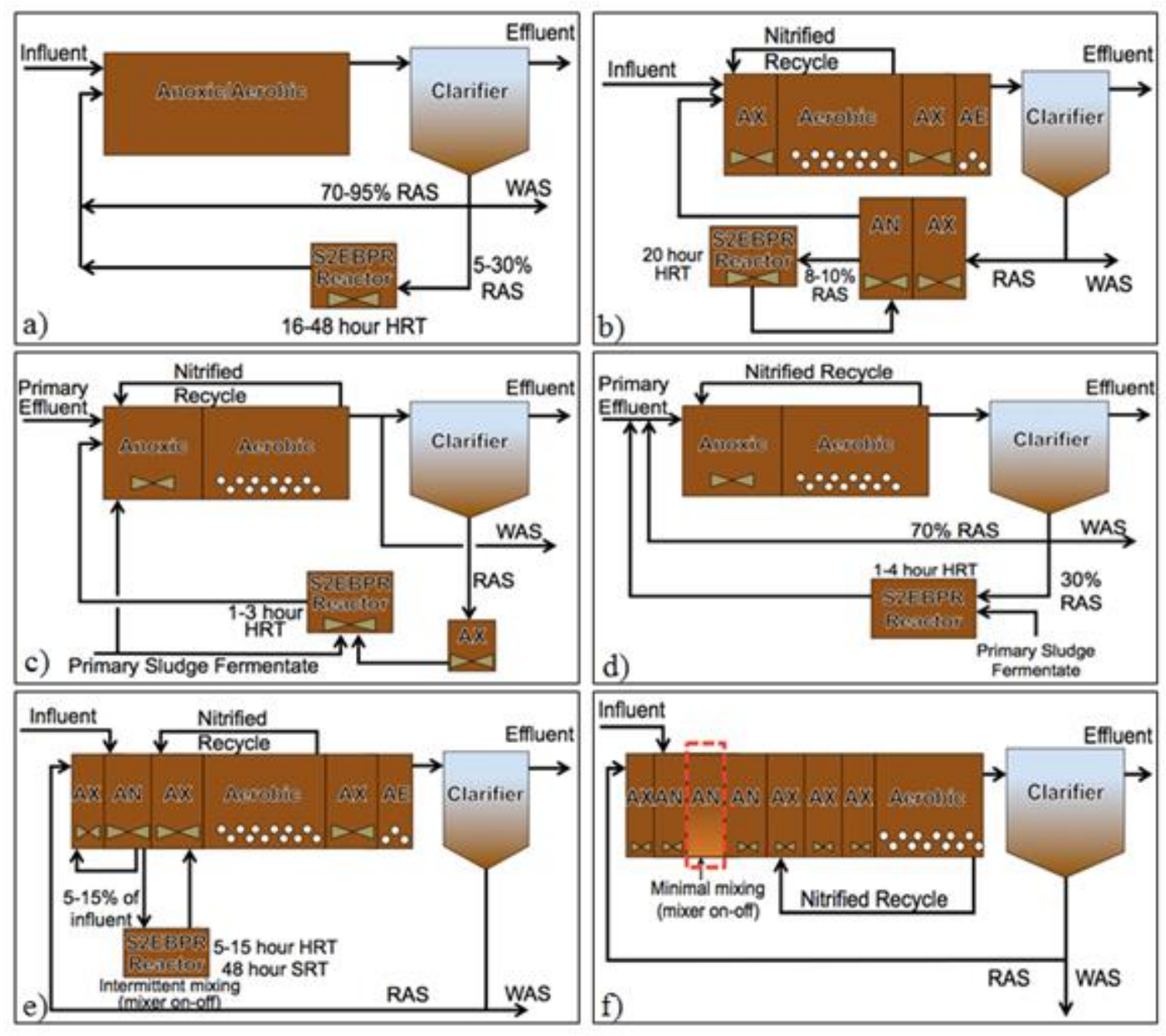

Figure 2.2: Full Scale Sidestream EBPR Process Configurations (Tooker et al., 2017) 


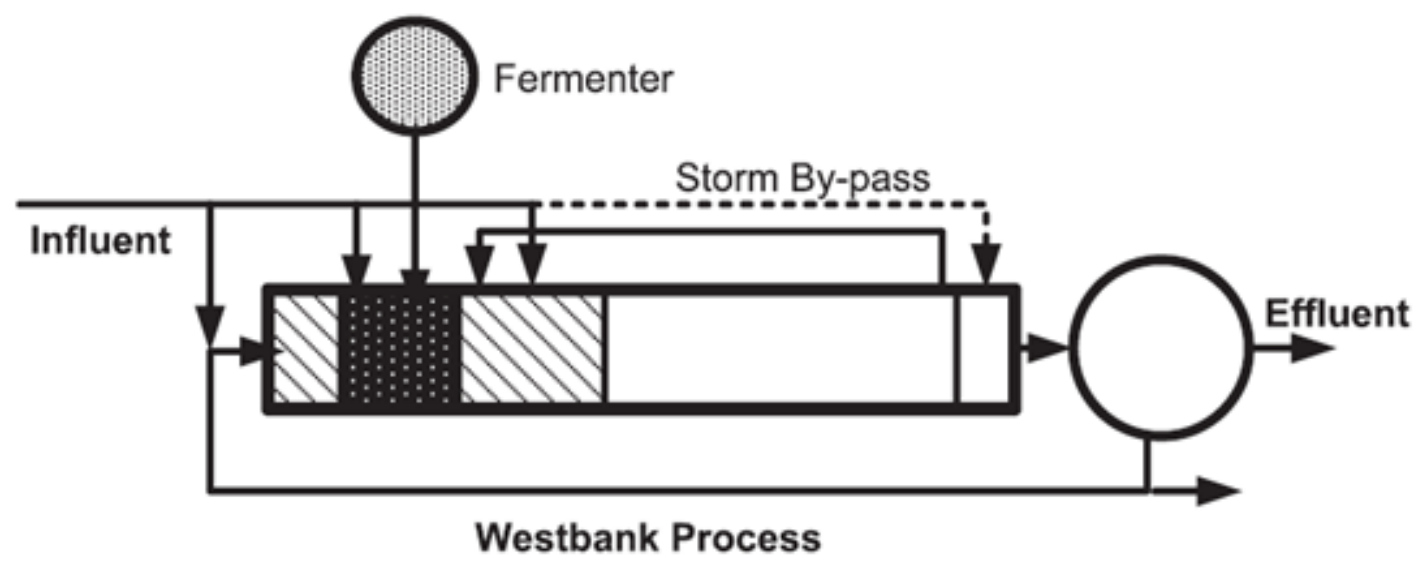

\section{$\square$ Anoxic Anaerobic $\square$ Aerobic}

Figure 2.3: Westbank Process Utilizing Sidestream Fermentation Reactor (J. Barnard et al., 2017)

The most common sidestream configuration is sidestream RAS fermentation, which is in use in Denmark and the UK, shown in Figure 2.2a above. This configuration sends a small portion, 5-30\% of the RAS to a sidestream reactor where the hydraulic retention time is between 16 and 48 hours (Andreasen et al., 1997; Vale et al., 2008; Vollertsen et al., 2006). This process allows for fermentation of the RAS to occur in the reactor for VFA production. In Figure 2.2b, a modified sidestream RAS configuration sends all the RAS to an anoxic and then anaerobic tank before sending 8-10\% of the RAS to a sidestream reactor with an HRT of 20 hours. This configuration is in use at the South Cary, North Carolina plant (Stroud and Martin, 2001). Figure 2.2c shows a sidestream RAS fermentation reactor with supplemental carbon addition (SSRC). This configuration is in use at Westside Regional Facility in West Kelowna, British Columbia (Stevens et al., 2015). The sidestream RAS fermentation reactor with supplemental carbon addition passes all the RAS through an anoxic reactor before sending all the RAS and primary sludge fermentate to a sidestream reactor with an HRT of 1-3hours. Figure 2.2d shows a modified SSRC configuration where $30 \%$ of the RAS is passed to a sidestream reactor with primary fermentate with an HRT in the reactor of 1-4hours. This configuration is in use at the 
Robert W. Hite facility in Denver, Colorado (Carson, 2012). Figure 2.2e shows a sidestream mixed liquor suspended solids fermentation configuration. This process diverts $5-15 \%$ of the anaerobic mixed liquor to a sidestream reactor with an HRT of 5-15 hours with the effluent being sent back to the anoxic zone of the mainstream. This process is in use at the Cedar Creek facility in Olathe, Kansas (Kobylinski et al., 2013). Lastly, Figure 2.2f shows an unmixed in-line MLSS fermentation configuration where a portion of the anaerobic zone in the mainstream process reduces mixing or completely stops mixing to allow fermentation to occur in the reactor. This configuration has been implemented in plants located in Colorado, Nevada, and Minnesota ( $\mathrm{J}$. Barnard et al., 2010). The Westbank process (Figure 2.3) is another example of a sidestream EBPR process. This process fermented primary sludge before sending the fermenter supernatant to the anaerobic zone to supply VFAs. A portion of the primary effluent was passed to the anaerobic zone to avoid diluting the VFA feed, and the rest was sent to the anoxic zone. This plant also sent the RAS through a pre-anoxic zone for denitrification to avoid sending nitrate to the anaerobic zone. This plant is in operation at the Westside Regional plant in British Columbia, Canada (J. Barnard et al., 2017).

All the sidestream EBPR process configurations are similar in that they send the influent to the anoxic zones of the system. This allows for denitrification to occur so there is minimal nitrate present in the anaerobic zone, giving the anaerobic metabolism of the PAOs the best chance for VFA uptake and phosphorus release. This is different than the conventional EBPR process configurations where the influent was sent to the anaerobic zones. This could have been providing competition for PAOs anaerobic metabolism, as well as diluting the VFA feed leading to less stable operation (J. Barnard et al., 2017).

Sidestream EBPR still has many knowledge gaps in understanding why these process configurations work more reliably than conventional EBPR processes. These knowledge gaps consist of a lack of design and operating guidance related to: the proportion of RAS or MLSS diverted to the sidestream, SRT and HRT in the sidestream, and mixing regime, as well as, the VFA production and phosphorus release, and dominant microbial population in the sidestream (Tooker et al., 2017). These are all still unknown factors affecting the further implementation of sidestream EBPR processes. This project worked to answer some of those questions by running 
a pilot study on a sidestream EBPR process. The specifics of how this project was operated will be discussed further in the methodology section. 


\section{CHAPTER 3}

\section{MATERIALS AND METHODS}

\subsection{Setup/Operations}

This study took place at the A/B pilot located at the Hampton Roads Sanitation District (HRSD) Chesapeake-Elizabeth (CE) Plant located in Virginia Beach, VA (Figure 3.1). The CE pilot is a two-stage biological treatment process with the Adsorption step preceding the Biooxidation process. The raw influent wastewater was taken from the main CE plant after screening and degritting. This influent wastewater fed the high rate A-stage process, which was followed by intermediate clarification. The A-stage process consisted of two trains in parallel with the ability for one train to be the control and the other to have varied operational conditions. In this study no A-stage experiments were performed so only one train was used as a constant. The A-stage effluent was the influent for the B-stage nitrogen removal step. The B-stage process was operated under ammonia versus $\mathrm{NO}_{\mathrm{x}}\left(\mathrm{NO}_{\mathrm{x}}\right.$ equals nitrate plus nitrite) AVN control, which uses online in-situ $\mathrm{DO}, \mathrm{NH}_{4}, \mathrm{NO}_{2}$, and $\mathrm{NO}_{3}$ sensors to control the aerobic duration in the CSTRs to maintain equal effluent $\mathrm{NH}_{4}$ and $\mathrm{NO}_{x}$, and consisted of a sidestream biological phosphorus removal reactor. 


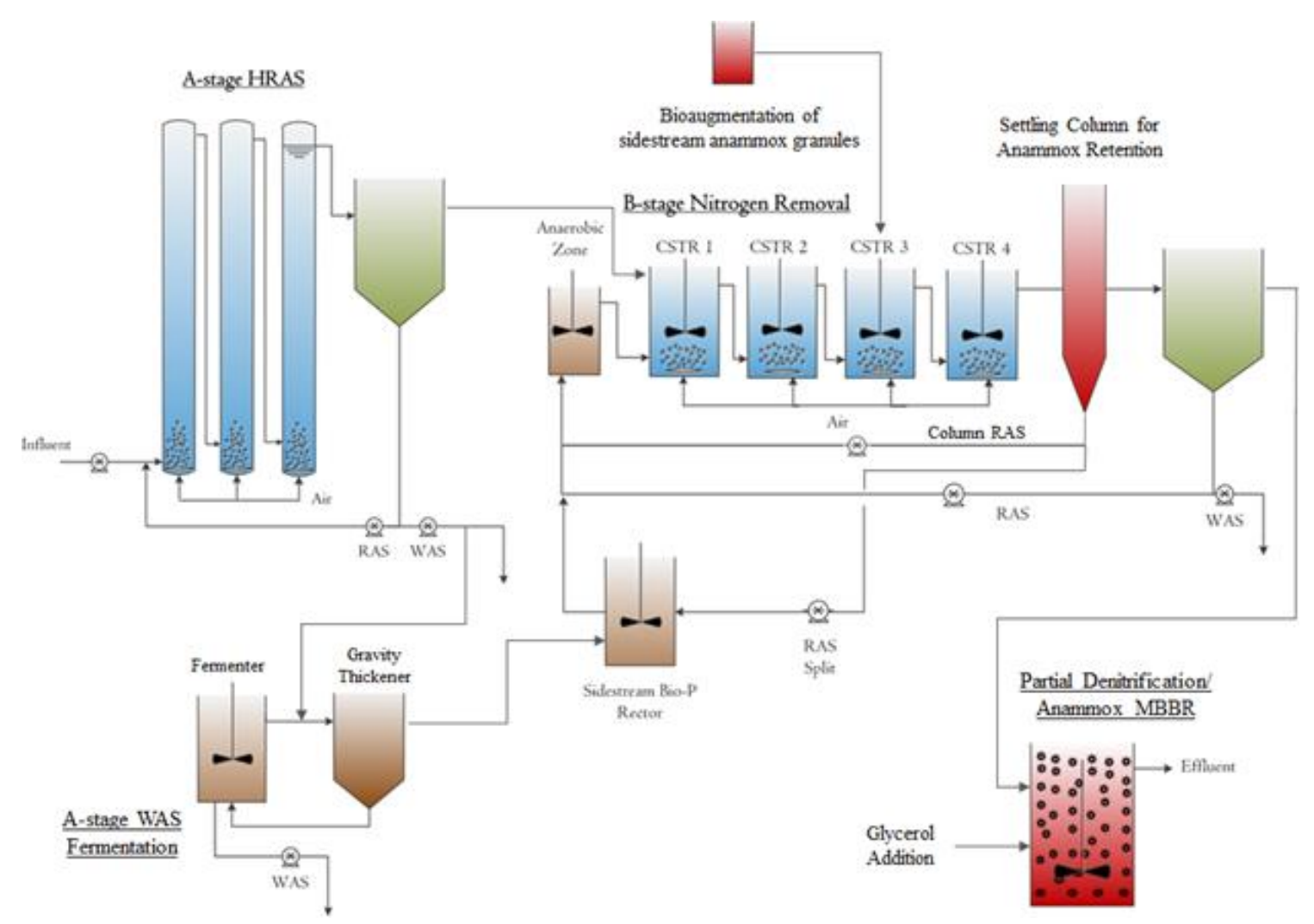

Figure 3.1. Chesapeake Elizabeth A/B Pilot Plant

\subsubsection{Preliminary Treatment}

Preliminary treatment was performed in the main CE plant first before being pumped to the pilot plant. The raw water influent (RWI) first went through $6 \mathrm{~mm}$ fine screens and a forced vortex grit removal process. The CE plant's preliminary treatment facility was not very efficient which caused the pilot to have its own grit removal step. The influent to the CE pilot was sent to a 150-gal tank where a variable speed mixer was used to keep particulate and colloidal organic matter in suspension but to settle out any grit remaining after the CE plant preliminary treatment. An overflow from the tank to a floor drain allowed for oil and grease on the top of the tank to be continuously removed, and the accumulated grit on the bottom of the tank was removed once a week by draining and cleaning the tank. The RWI was then fed through a basket screen with $2.4 \mathrm{~mm}$ pores into a 150 -gal temperature control tank using a progressive cavity pump. The temperature control tank also utilized a variable speed mixer and contained two submersible 
heaters, as well as a finned-tube coil. The finned-tube coil circulated cool water through it with the help of a water-cooled water chiller to achieve a temperature-controlled wastewater. A thermocouple in the temperature control tank provided constant readings of the temperature in the tank to a programmable logic controller (PLC). The temperature in the tank was regulated by a user set point in the PLC. The PLC was set to regulate the temperature control tank to 20 degrees Celsius by utilizing the heater or chiller depending on the incoming wastewater. This allowed for temperature-controlled wastewater throughout the A- and B-stage processes.

\subsubsection{High-Rate Activated Sludge Process (HRAS-Control)}

The HRAS process was constructed with three vertical PVC pipes operated in series, supported at the bottom with a volume of 45 gal each, a total HRT of 40 minutes, and an SRT of 8 hours. Compressed air was sent through a membrane disc diffuser in the bottom of each reactor to maintain a dissolved oxygen (DO) setpoint. A Hach-Insite IG FDO optical DO sensor was in the middle reactor to monitor the DO. A PID controller was utilized in conjunction with a MOV on the compressed air line to maintain the DO setpoint. Large-bubble mixing was utilized in these tall vertical reactors. The last reactor overflowed by gravity to a cone bottom clarifier with a target solids loading rate (SLR) of $4.5 \mathrm{~kg}^{*} \mathrm{~m}^{-2} * \mathrm{hr}^{-1}$ and a surface overflow rate (SOR) of $0.7 \mathrm{~m}^{3} \mathrm{~m}^{-2} \mathrm{hr}^{-1}$ with a $3000 \mathrm{mg} / \mathrm{L}$ MLSS setpoint at $100 \% \mathrm{RAS}$ rate. The influent to the clarifier fed into a vertical inlet submerged inside a center well, which helped with slowing the influent hydraulic energy. The clarifier had a scraper mechanism at the top of the clarifier cone that rotated at $0.25 \mathrm{rpm}$ to achieve better solids compaction at the bottom of the clarifier. The SRT was controlled using a programmable digital peristaltic pump that wasted from the underflow of the clarifier.

A 55-gal storage tank for the overflow of the clarifier effluent was used as the feed tank for B-stage influent. This tank utilized a constant speed mixer and a progressive cavity pump was used to pump influent to B-stage.

\subsubsection{HRAS WAS Fermenter and Thickener}

The HRAS WAS fermenter and thickener were designed based on the current A-stage HRT and operating parameters. The fermenter is a 50-gal circular reactor with a variable speed mixer to ensure completely mixed conditions. The Thickener is a 90-gal cone bottom clarifier 
with a SOR of $0.0136 \mathrm{~m}^{3} \mathrm{~m}^{-2} \mathrm{hr}^{-1}$. The SRT of the fermenter was optimized to 5 days with the waste rate from the bottom of the fermenter equal to $32.2 \mathrm{~L} /$ day. The A-stage WAS feeds into the gravity thickener at a rate of $132 \mathrm{~mL} / \mathrm{min}$. The RAS rate on the gravity thickener is $100 \%$ feeding into the fermenter. The liquid overflow from the gravity thickener flows into a 5-gal bucket, which then feeds fermentate to the SBPR.

\subsubsection{B-stage AVN}

The B-stage nitrogen removal step was made up of four equally sized completely stirred tank reactors (CSTR) in series, with each reactor equal to $150 \mathrm{~L}$ totaling $600 \mathrm{~L}$. In addition to this, there is a 57L anaerobic selector in front of the CSTRs and a cone bottom clarifier for the effluent and RAS. In one phase of the study, the effluent from the four CSTR's was flowing into a settling column that selected for anammox granules via surface overflow rate (SOR) of 4$10 \mathrm{~m}^{*} \mathrm{hr}^{-1}$ to be returned to either the mainstream, or to the sidestream reactor, from the bottom of the column, and the overflow of the column was flowing into the clarifier. The settling column was implemented because of another student's work done on B-stage simultaneously. All four CSTR's and the anaerobic selector contained a variable speed mixer in order to have completely mixed conditions. Water in these reactors flows by gravity throughout the system with the effluent flowing down the drain and returned to the main CE plant influent. The inlet to the clarifier was a vertical inlet submerged inside of the center well. This allowed for slowed influent hydraulic energy. A scraper mechanism was at the top of the cone bottom rotating at $0.25 \mathrm{rpm}$ in order to help compact the settling solids at the bottom of the clarifier. The clarifier had a SLR of $0.8 \mathrm{~kg}^{*} \mathrm{~m}^{-2} * \mathrm{hr}^{-1}$ and a SOR of $0.1 \mathrm{~m}^{3} \mathrm{~m}^{-2} \mathrm{hr}^{-1}$ operating at $100 \%$ RAS with a peristaltic pump returning a portion of the RAS to the anaerobic selector and a portion going to the sidestream biological phosphorus removal reactor (SBPR) depending on the process configuration which changed throughout the study.

Compressed air was sent through a membrane disc diffuser in the bottom of each CSTR to provide aeration to these reactors. The DO was controlled by a PID loop that received DO values from a Hach LDO optical DO sensor located in each reactor and connected to the PLC that controlled a mechanically operated valve (MOV) on each reactor. All four reactors were intermittently aerated based on an aerobic fraction for ammonia versus NOx-N (nitrate plus nitrite) (AVN) control. AVN control was utilized to obtain favorable NOB out-selection 
conditions, as well as provide effluent suitable for anaerobic ammonia oxidation (AMX) polishing. This was part of another student's study being performed on the B-stage process simultaneously.

Solids were wasted from the last aerated reactor for the first part of the study and changed to wasting from the bottom of the secondary clarifier for the second part of the study. This is because the influent to the SBPR changed throughout the study depending on whether the settling column was being utilized. Wasting was done automatically using a peristaltic pump to control the SRT of the system. The PLC controlled on/off durations for the pump based on the user input wastage rate. For the AVN process and intermittent aeration, $\mathrm{NO}_{3}$ and $\mathrm{NO}_{2}$ were monitored by a scan optical Spectro::lyser sensor, and $\mathrm{NH}_{4}$ by a WTW VARiON ISE sensor. The $\mathrm{pH}$ of the system was monitored by an Invensys Foxboro ISE pH sensor located in the third CSTR. The $\mathrm{pH}$ was controlled by a $\mathrm{pH}$ controller connected to a programmable digital peristaltic pump that pumped a solution of sodium bicarbonate into the third CSTR. The location of each sensor can be seen in Figure 3.2.

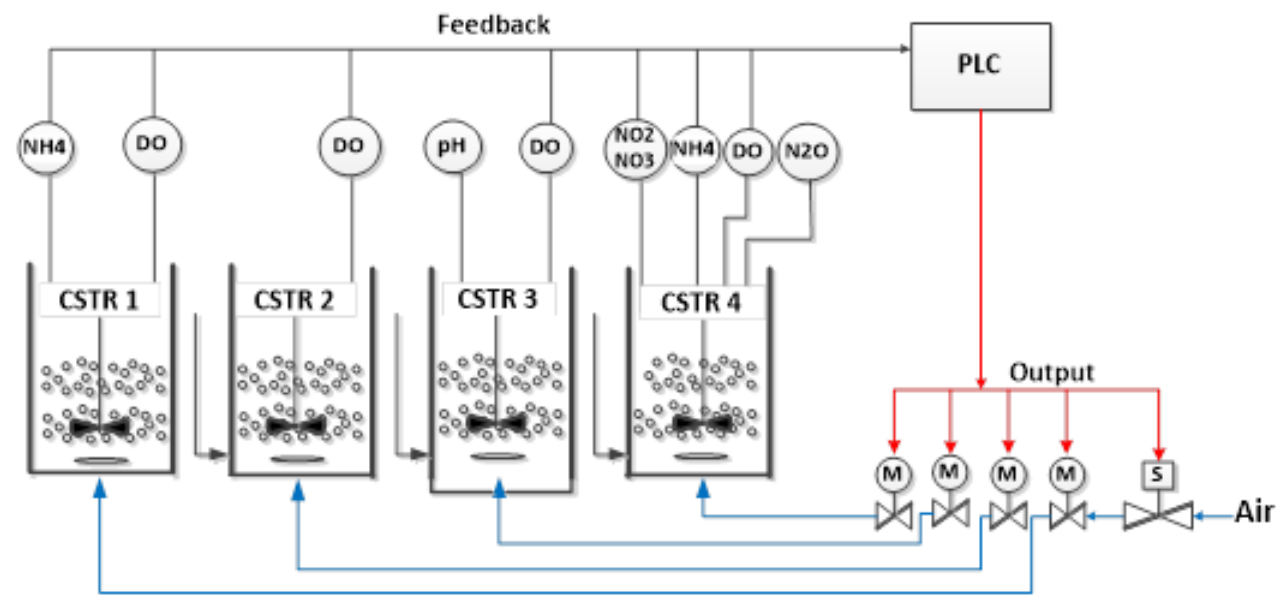

Figure 3.2. Location of Each Sensor in B-stage Process 


\subsubsection{B-stage Sidestream Biological Phosphorus Removal Reactor}

The sidestream biological phosphorus removal reactor was sized with a total volume of 174L and the HRT was determined by the percentage of RAS flow and fermentate flow that were sent to the reactor in separate proportions. The SBPR utilized a variable speed mixer to control continuous or intermittent mixing in the reactor. A portion of the RAS from the secondary clarifier (during Phases I, II, IV, and V) and the underflow from the settling column (during Phase III) were pumped to the SBPR as well as fermentate from the A-stage WAS fermenter using a programmable digital peristaltic pump. The effluent from the SBPR was then pumped to the anaerobic selector. The sidestream reactor operation changed throughout the study to achieve the lowest possible effluent OP values. The SBPR was operated with continuous mixing and intermittent mixing, as well as, the secondary clarifier feeding, and the underflow of the column feeding the SBPR. The timeline for these different mixing conditions as well as the different influent feeding conditions to the SBPR can be seen in Figure 3.3. ORP measurements were taken in the sidestream reactor weekly throughout the study. ORP measurements were conducted using an Insite IG ORP Sensor. This sensor had a measuring range of $+/-2000 \mathrm{mV}$ within a temperature range of 10-60 degrees Celsius.

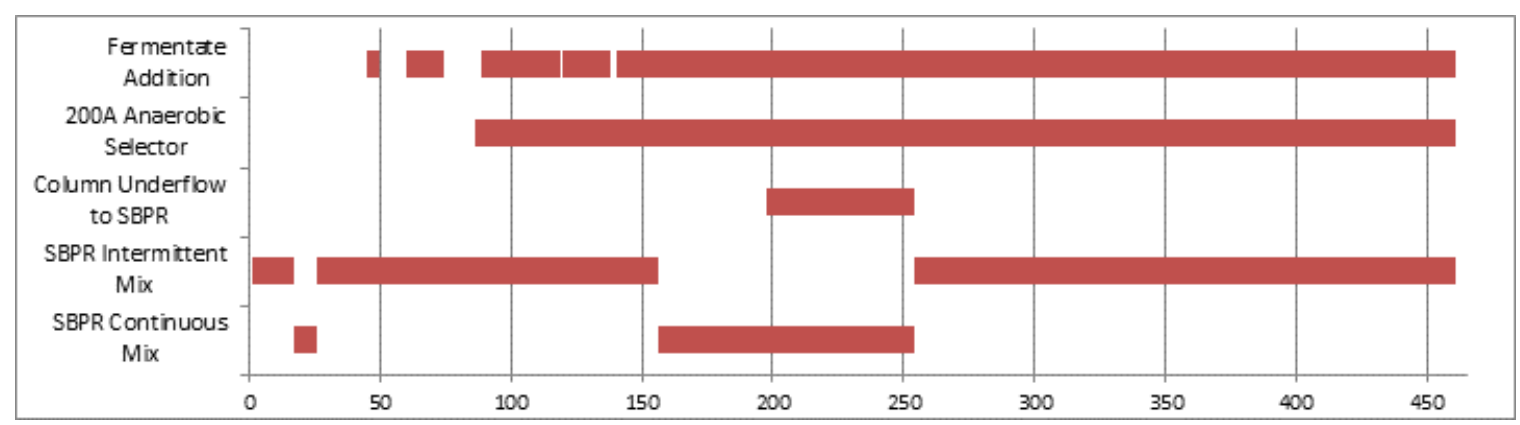

Figure 3.3. Influent Feeding and Mixing Condition in the SBPR throughout the Study 


\subsection{Activity Measurements}

\subsubsection{B-stage Polyphosphate Accumulating Organisms and Denitrifying Polyphosphate Accumulating Organisms Rate Measurements}

PAO and dPAO activity tests were performed to estimate the relative abundance of PAO, GAO, dPAO, and dGAO bacteria present in the sludge by looking at the experimentally determined stoichiometric rates. A four-liter sample was taken from the last aerated reactor of B-stage and measured for $\mathrm{NH}_{4}, \mathrm{NO}_{2}$, and $\mathrm{NO}_{3}$. It was important to have a fully denitrified sample during the PAO test so there was no competition for carbon sources. The four-liter sample was then aerated until the $\mathrm{NH}_{4}$ was reduced to zero. Once the ammonium was zero, the sample was changed to anaerobic conditions by dosing with $\mathrm{N}_{2}$ gas until the DO in the reactor dropped to zero, and then the sample was dosed with acetate. In this step the $\mathrm{NO}_{3}$ and $\mathrm{NO}_{2}$ were reduced to zero. Once there was no nitrogen present in the sample, the reactor was re-aerated to 2-6 mg/L DO, pH between 6.5-7.5, and dosed with $10 \mathrm{mg} / \mathrm{L}$ of $\mathrm{PO}_{4}{ }^{3-}$. This step ensured the PAOs were fully loaded and would be able to give a visible release rate in the anaerobic phase. By measuring OP every 10 minutes during the re-aeration period, an aerobic uptake rate was measured. After 120 minutes, the sample was measuring a lot less OP than at the beginning of the aerobic period, and the reactor was switched to the anaerobic phase. The reactor DO was brought down to zero by purging the sample with nitrogen gas. Once the DO read zero, 190mg $\mathrm{NaAc} / \mathrm{L}$ was spiked so that the OP uptake would not be kinetically limited. The reactor was then sampled after 5, 10, 15, 30, 60, 90 and 120 minutes. Each sample was analyzed for OP and sCOD. Once the values for the aerobic uptake and anaerobic release part of the test were obtained, a linear regression analysis was performed on the linear part of the curve. The slope of the line was considered the uptake or release rate.

The four-liter reactor was then split into three smaller one-liter reactors. There was no carbon left over from the anaerobic phase. During the dPAO part of the test the PAOs would utilize their internally stored PHA instead of external carbon. Each of the three reactors was dosed with $20 \mathrm{mg} \mathrm{NO}_{3} / \mathrm{L}, 5 \mathrm{mg} \mathrm{NO} / \mathrm{L}$, and air with the DO between 2-6mg/L, respectively. Each reactor was measured after 5, 10, 15, 30, 60, and 120 minutes and analyzed for $\mathrm{OP}$ and $\mathrm{NO}_{3}$. Once these samples were analyzed, a linear regression analysis was performed on the linear part of the curve. The slope of the line was considered the uptake rate. 
For the PAO part of the test, the total OP release and acetate uptake that were experimentally measured were used to determine the relative fraction of PAO within the sample with respect to the total amount of PAO and GAO present as shown in Eq. 3.1 (Lopez-Vazquez et al., 2007; Smolders et al., 1994).

$$
f_{\text {pao }}=\frac{\left[\frac{P O_{4}}{H A C}\right]_{\text {Exp }}^{A n a}}{0.51}
$$

Where,

$$
\begin{array}{r}
f_{\text {pao }}=\text { Relative } P A O \text { fraction, in terms of total } P A O+\mathrm{GAO} \\
{\left[\frac{P O_{4}}{H A c}\right]_{E x p}^{A n a}=\text { experimental anaerobic } P / H A c \text { ratio from batch test }}
\end{array}
$$

\subsection{B-stage Profiles}

Profile grabs of B-stage were taken multiple times every week to obtain a snapshot of what was happening in the system. Grab samples were collected from the influent, SBPR, anaerobic selector, all four aerated reactors, the overflow and underflow of the column, RAS, and effluent. These samples were analyzed for $\mathrm{NH}_{4}, \mathrm{NO}_{2}, \mathrm{NO}_{3}, \mathrm{OP}$, and sCOD. When examined over time, these profiles showed how the system was operating in terms of phosphorus removal and how temporal variations relate to operational conditions.

\subsection{PHA Analysis}

PHA analysis was performed on the B-stage sludge to help determine the PAO content. As discussed in chapter two, PAO have the ability to store PHA as part of their anaerobic metabolisms.

Samples from the SBPR before and after a mix when operated with intermittent mixing, the anaerobic selector, the last aerobic reactor in the mainstream, the RAS for the system, and the WAS were collected. Fourteen $\mathrm{mL}$ of each sample were placed in a centrifuge tube along with 5 drops of $37 \%$ formaldehyde. A cap was placed on each tube and they were refrigerated overnight to stop any biological activity occurring in the mixed liquor. The next morning, the 
samples were removed from the refrigerator and centrifuged for 3 minutes at 10,000 G. The samples were then decanted and 10mL of phosphate buffer saline (PBS) were added to each centrifuge tube. The samples were then re-suspended, centrifuged for 3 minutes at 10,000 G, and decanted. All samples were then placed in a deep freezer at -80 degrees Celsius. These frozen samples were then shipped on dry ice to Northeastern University for PHA extraction and analysis.

\subsection{Analytical Procedures}

All the data reported were analyzed at the HRSD CE Pilot plant, with additional volatile fatty acid analysis performed at HRSD's Central Environmental Laboratory (CEL). Samples for nutrient analysis were filtered using a $0.45 \mu \mathrm{m}$ Metricel Membrane Filter excluding COD samples which were filtered through $1.5 \mu \mathrm{m}$ glass fiber filters. Nutrient and COD values were measured using Hach colorimetric test kits and a Hach DR2800 spectrophotometer.

\subsubsection{Ammonia Hach Test Kits}

Ammonia analysis was performed using three different Ammonia test kits:

1. Hach Test ' $\mathrm{N}$ Tube Plus 830 - Ultra Low Range - 0.015 - 2 mg/L NH4 $-\mathrm{N}$

2. Hach Test 'N Tube Plus 831 - Low Range - 1 - 12 mg/L NH $4-\mathrm{N}$

3. Hach Test ' $\mathrm{N}$ Tube Plus 832 - High Range - 2 - 47 mg/L NH $4-\mathrm{N}$

\subsubsection{Nitrite Hach Test Kits}

Nitrite analysis was performed using two different Nitrite test kits:

1. Hach Test ' $\mathrm{N}$ Tube Plus 839 - Low Range - $0.015-0.6$ mg/L NO${ }_{2}-\mathrm{N}$

2. Hach Test ' $\mathrm{N}$ Tube Plus 840 - High Range $-0.6-6 \mathrm{mg} / \mathrm{L} \mathrm{NO}_{2}-\mathrm{N}$

\subsubsection{Nitrate Hach Test Kits}

Nitrate analysis was performed using two different Nitrate test kits:

1. Hach Test ' $\mathrm{N}$ Tube Plus 835 - Low Range - 0.23 - 13.5 mg/L NO${ }_{3}^{--N}$

2. Hach Test ' $\mathrm{N}$ Tube Plus 836 - High Range - 5 - $35 \mathrm{mg} / \mathrm{L} \mathrm{NO}_{3}-\mathrm{N}$ 


\subsubsection{Ortho-Phosphate Hach Test Kits}

Orthophosphate analysis was performed using two different OP test kits:

1. Hach Test ' $\mathrm{N}$ Tube Plus Reactive Phosphate - Low Range $-0-1.6 \mathrm{mg} / \mathrm{L} \mathrm{PO}_{4}{ }^{3-}-\mathrm{P}$

2. Hach Test ' $\mathrm{N}$ Tube Plus Reactive (Ortho) Phosphate - High Range $-1.6-30 \mathrm{mg} / \mathrm{L} \mathrm{PO}_{4}{ }^{3-}$ -P

\subsubsection{Chemical Oxygen Demand Hach Test Kits}

Chemical Oxygen Demand analysis was performed using three different COD test kits:

1. Hach Test ' $\mathrm{N}$ Tube Plus 820 - Ultra Low Range - 1 - 60 mg/L COD

2. Hach Test 'N Tube Plus 821 - Low Range - 3 - 150 mg/L COD

3. Hach Test ' $N$ Tube Plus 822 - High Range - 20 - 1500 mg/L COD

\subsubsection{Volatile Fatty Acid Hach Test Kits}

Volatile Fatty Acid analysis was performed using one test kit:

1. Hach Test 'N Tube Plus 872 - 50- 2500 mg/L CH3COOH

Additional VFA analysis was performed by CEL following the (APHA, 2012) standard and results were reported to the pilot. Additional information on how VFA analysis was performed at CEL can be found in the Appendix section.

\subsection{Statistical Experimental Design}

Statistical experimental design methodology was used to evaluate and identify dominant control variables directly influencing the maximum OP removal efficiency based on unit process configurations. Rationale lies that such identification is made at the system level instead of per experimental sample level so that findings can be reproducible at the system level in future research and implementation. A set of Factorial General Linear Models (GLM) (Nelder and Wedderburn, 1972) were proposed to first evaluate the strength of collinearity between source/independent variables (=influent and operating conditions) and sink/dependent variable (=effluent). Validity of proposed GLMs was first tested with analysis of variance (ANOVA), then subsequently by Stepwise selection method to determine which independent variables in the 
system worked to reduce the overall OP in the mainstream effluent through unit process configurations. Once valid collinear independent variables were identified, Duncan's Multiple Range Test (MRT) was used to determine which operation range of the valid collinear independent variables worked best and were reproducible in achieving the maximum OP removal efficiency. Objectives of this experimental design approach are as follows:

1. To conceptualize and formulate treatment and block subgroupings of variables by reflecting kinetic mass balance in each unit process.

2. To derive the optimal operation criteria in the SBPR for maximizing OP removal efficiency in the mainstream by using Factorial General Linear Models with Duncan's Multiple Range Test.

\subsubsection{Test of Hypotheses}

A standard normality test was conducted as the first step in experimental design analysis. Reflecting sample size less than 2000, Shapiro-Wilk W-statistics test (Ghasemi and Zahediasl, 2012) was conducted in Statistical Analysis System (SAS) (Statistical Analysis System User's Guide: Statistics, Version 8.2, 2001) at 95\% level of confidence with a significance, $\alpha=0.05$ with following normality test of hypothesis. Test results in the form of $\mathrm{p}$-values indicate insignificance and conclude that experimental sample data are normally distributed so that Factorial General Linear Models can be used for analysis. If the p-value is larger than the significance, $\alpha=0.05$ ( $=95 \%$ ), then it is concluded as insignificant, and the null hypothesis will not be rejected. For Shapiro-Wilk W-statistics test, insignificance means the sample came from a normally distributed system.

\section{Hypothesis \#1}

Ho: The random sample came from a normal system

Ha: The random sample did not come from a normal system

With normality of the system where experimental sample data were measured and collected from verified, a set of Factorial General Linear Models were formulated by translating kinetic mass balance in SBPR and Mainstream unit process, respectively. Source/Independent variables (=influent and operating conditions) were then further conceptualized into treatment 
and block subgroupings reflecting experimental setups where the treatment level variables represent primary contributing factors toward the sink/dependent variable (=effluent) whereas the block level variables are augmentary variables to the treatment level variables.

By using a method of deduction, each Factorial General Linear Model was then tested for collinearity between independent and dependent variables, i.e., whether any contributional relationship exists, at model level Analysis of Variance (ANOVA) result at $\alpha=0.05$.

\section{Hypothesis \#2}

Ho: All the independent variables $\left(\mathrm{OP}, \mathrm{NH}_{4}, \mathrm{NO}_{3}, \mathrm{TSS}\right)$ are equal to zero.

Ha: At least one or more of the independent variables (OP, $\left.\mathrm{NH}_{4}, \mathrm{NO}_{3}, \mathrm{TSS}\right)$ are not equal to zero.

If the p-value from the ANOVA is significant, then the null hypothesis will be rejected, and it is concluded that at least one of the independent variables is not equal to zero and are contributing to the dependent variable, the effluent from the unit process.

\subsubsection{Validation of Data Distribution}

The dependent variable, OP removal efficiency, was analyzed using the univariate Shapiro-Wilk test for normality. Because the sample size was less than 2000, the Shapiro-Wilk test could be used. The results of the normality test show that with a p-value of 0.06 the sample data set is normally distributed. If the $p$-value is larger than the significance, $\alpha=0.05(=95 \%)$, then it is concluded as insignificant, and the null hypothesis will not be rejected. For ShapiroWilk W-statistics test, insignificance means the sample came from a normally distributed system. The normal probability plot also concurs the normality with a strong linear trend with no major dispersion. The results of this test are shown in Figure 3.4.

\subsubsection{Data Filtering}

Based on the Shapiro-Wilk test and normal probability plot, there were no extreme outliers. Because there were no extreme outliers, there was not a reason to perform pre-filtering. In this case, the mild outliers shown in the normality plot were not removed as they still represented the valid system from which the data were taken. 


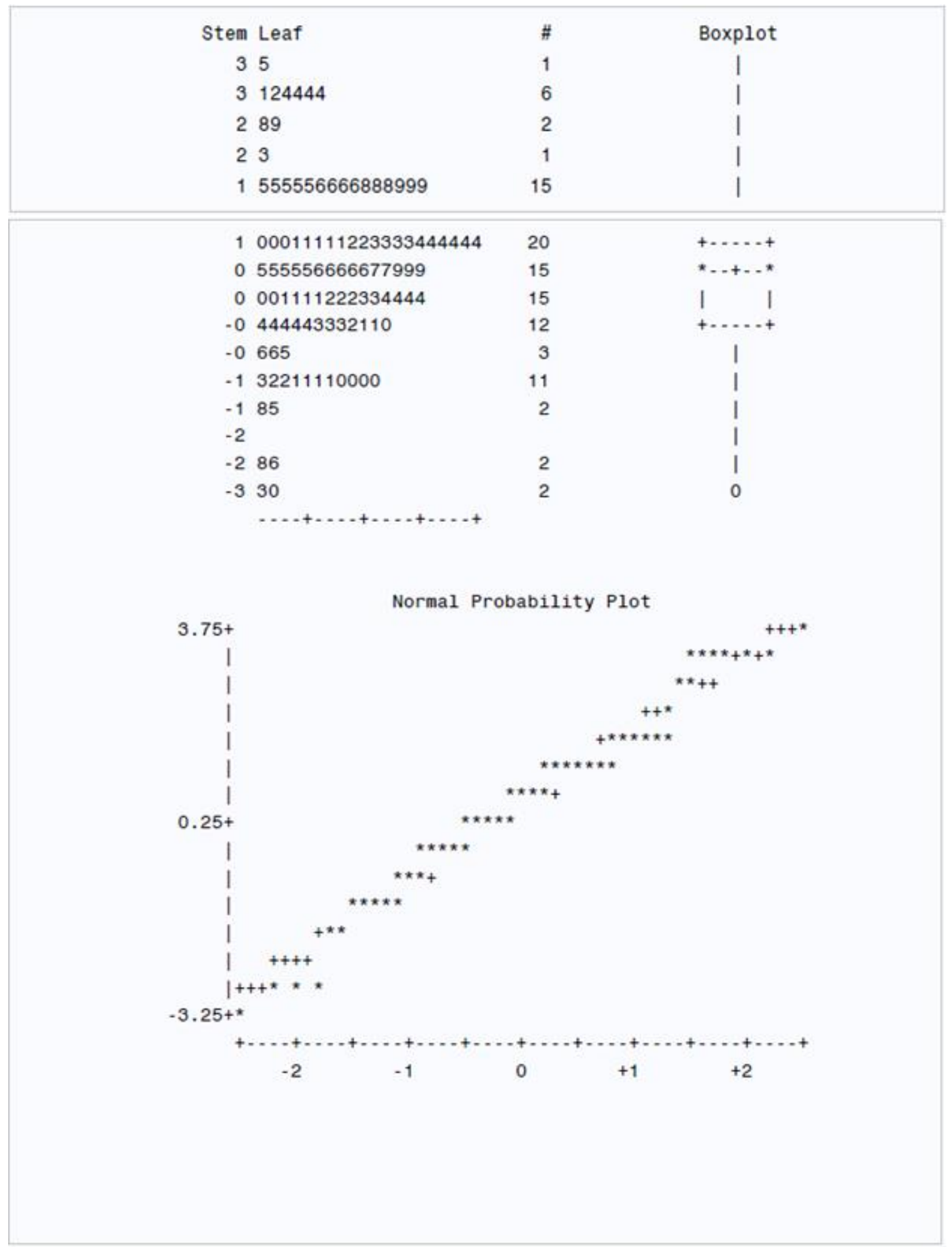

Figure 3.4. Stem and Leaf, Boxplot, and Normal Probability Plot 


\subsubsection{Assumption and Limitation}

The overall OP removal efficiency was assumed to be equivalent to the influent OP minus the effluent OP at the final Mainstream UP. This could be a limitation to the overall accuracy of the data because the OP removal efficiency might not be taking into consideration other factors affecting the removal.

\subsubsection{Experimental Design Methods}

The purpose for experimental design analysis is to determine whether the operating condition and control factors (=independent variables) play a valid role in the outcome of the OP removal efficiency (=dependent variable). By choosing the factorial general linear model, all the independent variables, by themselves and by factorialized forms, will be considered.

Procedural SAS analyses consisted of three parts. The first part defines each independent variable into treatment (=primary) and block (=augmentary) classes that the independent variables were evaluated under proportional quartile ranges defined based on collected experimental data for this study.

$$
y_{i j}=\mu+\tau_{i}+\beta_{j}+\tau \beta_{i j}+\varepsilon_{i j} \quad(\text { treatments; } \mathrm{i}=1, \ldots \mathrm{n} ; \text { block } ; \mathrm{j}=1, \ldots \mathrm{m} ;)
$$

where

$y_{i j}=$ Response on (i,j)th Obs. at the ith level of treatment A and jth level of block B

$\mu=$ Overall mean

$\tau_{i}=$ Effect of ith level of treatment $\mathrm{A}$

$\beta_{j}=$ Effect of jth level of block B

$\tau \beta_{i j}=$ Effect of interaction/factorial between treatment $\mathrm{A}$ and block B

$\varepsilon_{i j}=$ Random error due to $(\mathrm{i}, \mathrm{j})$ th Obs. $\varepsilon \sim N I D\left(0, \sigma^{2}\right)$

The second part determined which treatment and block control variables worked to influence the dependent variable. The third and last part determined which treatment and block variables worked best (among working variable identified in the second part) to influence the dependent variable, and in which combination they work best. Thus, the final results will be in the form of corresponding operational condition expressed in their quartile ranges that maximize the OP removal efficiency in this study. Following factorial general linear model (GLM) 
expressions were created to define each unit process. These expressions were built based on the system mass balance expressions for the mainstream and SBPR components. All these expressions can be seen in Table 3.1 where $\mathrm{Q}=$ flowrate $(\mathrm{L} / \mathrm{min}) ; \mathrm{C}=$ concentration $(\mathrm{mg} / \mathrm{L})$; $\mathrm{k}=$ kinetic rate constant $(\mathrm{d}-1)$.

Table 3.1. Sidestream and Mainstream Mass Balance Expressions

\begin{tabular}{|c|c|}
\hline \multicolumn{2}{|r|}{ SBPR Mass Balance Expressions } \\
\hline OP Concentration & $\begin{array}{l}\left(Q_{S B P R}+Q_{\text {Fermentate }}\right) *\left(C_{S B P R O P}\right)=\left(Q_{R A S}\right) *\left(C_{R A S O P}\right)+ \\
\left(Q_{\text {fermentate }}\right) *\left(C_{\text {Fermentate OP }}\right)-k\left(V_{S B P R} * C_{S B P R \text { OP }}\right)\end{array}$ \\
\hline $\begin{array}{l}\text { NO3 } \\
\text { Concentration }\end{array}$ & $\begin{array}{l}\left(Q_{S B P R}+Q_{\text {Fermentate }}\right) *\left(C_{S B P R N O 3}\right)=\left(Q_{R A S}\right) *\left(C_{R A S N O 3}\right)+ \\
\left(Q_{\text {fermentate }}\right) *\left(C_{\text {Fermentate NO3 }}\right)-k\left(V_{S B P R} * C_{S B P R \text { NO3 }}\right)\end{array}$ \\
\hline TSS Concentration & $\begin{array}{l}\left(Q_{S B P R}+Q_{\text {Fermentate }}\right) *\left(C_{S B P R T S S}\right)=\left(Q_{R A S}\right) *\left(C_{R A S T S S}\right)+ \\
\left(Q_{\text {fermentate }}\right) *\left(C_{\text {Fermentate TSS }}\right)-k\left(V_{S B P R} * C_{S B P R T S S}\right)\end{array}$ \\
\hline \multicolumn{2}{|r|}{ Mainstream Mass Balance Expressions } \\
\hline OP Concentration & $\begin{array}{l}\left(Q_{E f f}\right) *\left(C_{E f f O P}\right)=\left[\left(Q_{I n}\right) *\left(C_{I n O P}\right)+\left(Q_{S B P R}\right) *\left(C_{S B P R O P}\right)+\right. \\
\left.\left(Q_{R A S} * C_{R A S O P}\right)\right]-\left(Q_{W A S} * C_{W A S O P}\right)-k\left(V_{B-s t a g e} * C_{E f f O P}\right)\end{array}$ \\
\hline $\begin{array}{l}\mathrm{NH} 4 \\
\text { Concentration }\end{array}$ & $\begin{array}{l}\left(Q_{E f f}\right) *\left(C_{E f f N H 4}\right)=\left[\left(Q_{I n}\right) *\left(C_{I n N H 4}\right)+\left(Q_{S B P R}\right) *\left(C_{S B P R N H 4}\right)+\right. \\
\left.\left(Q_{R A S} * C_{R A S N H 4}\right)\right]-\left(Q_{W A S} * C_{W A S N H 4}\right)-k\left(V_{B-\text { stage }} * C_{E F F N H 4}\right)\end{array}$ \\
\hline $\begin{array}{l}\text { NO3 } \\
\text { Concentration }\end{array}$ & 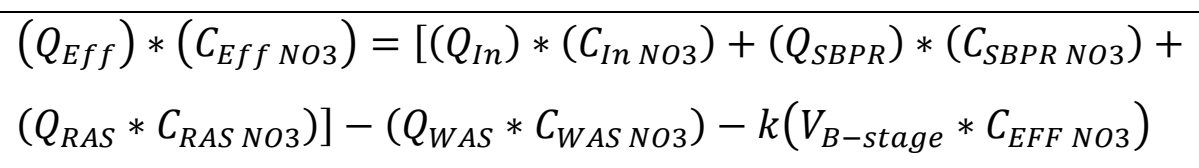 \\
\hline TSS Concentration & $\begin{array}{l}\left(Q_{E f f}\right) *\left(C_{E f f T S S}\right)=\left[\left(Q_{I n}\right) *\left(C_{I n T S S}\right)+\left(Q_{S B P R}\right) *\left(C_{S B P R T S S}\right)+\right. \\
\left.\left(Q_{R A S} * C_{R A S T S S}\right)\right]-\left(Q_{W A S} * C_{W A S T S S}\right)-k\left(V_{B-s t a g e} * C_{E F F T S S}\right)\end{array}$ \\
\hline
\end{tabular}

The factorial GLM expressions used in SAS analysis are shown below, where the individual independent variables are broken into treatments (Tau) and blocks (Beta) depending on their function in the system. In this analysis, the independent variables were broken into ranges based on proportional quartiles within the collected experimental data set. The $y$ is the 
dependent variable, the OP removal efficiency in form of diff (influent OP, effluent OP), $\mu$ is the expected mean at the reproducible system level, and $\varepsilon$ is the random error under MarkovGaussian theorem.

$$
\begin{aligned}
& y_{i j}=\mu+\tau_{i}+\beta_{j}+\tau \beta_{i j}+\varepsilon_{i j} \quad(\text { treatments; } \mathrm{i}=1, \ldots . \mathrm{n} ; \text { block } ; \mathrm{j}=1, \ldots . \mathrm{m} ;) \\
& \text { where } \\
& y_{i j}=\text { Response on (i,j)th Obs. at the ith level of treatment A and jth level of } \\
& \text { block B } \\
& \mu=\text { Overall mean } \\
& \tau_{i}=\text { Effect of ith level of treatment } \mathrm{A} \\
& \beta_{j}=\text { Effect of } \mathrm{jth} \text { level of block B } \\
& \tau \beta_{i j}=\text { Effect of interaction/factorial between treatment A and block B } \\
& \varepsilon_{i j}=\text { Random error due to }(\mathrm{i}, \mathrm{j}) \text { th Obs. } \varepsilon \sim \operatorname{NID}\left(0, \sigma^{2}\right)
\end{aligned}
$$

Table 3.2 shows each GLM expression for the sidestream and mainstream. 
Table 3.2 Sidestream and Mainstream Generalized Linear Model Expressions

\begin{tabular}{|c|c|}
\hline \multicolumn{2}{|r|}{ SBPR GLM Expressions } \\
\hline OP Concentration & $\begin{array}{c}\text { Model OP } P_{S B P R}=Q_{R A S} O P_{R A S}+Q_{F E R M} O P_{F E R M}+Q_{S B P R} \\
O P_{S B P R \text { Class }}+O P_{R A S \text { Class }} O P_{\text {Fermclass }}+Q_{S B P R \text { Class }}\end{array}$ \\
\hline $\begin{array}{l}\text { NO3 } \\
\text { Concentration }\end{array}$ & $\begin{array}{c}\text { Model OP } P_{S B P R}=N O 3_{R A S} N H 4_{F E R M}+Q_{S B P R} Q_{F E R M}+ \\
N O 3_{\text {RAS Class }} N H 4_{F E R M \text { Class }}+Q_{S B P R \text { Class }}\end{array}$ \\
\hline $\begin{array}{l}\text { TSS } \\
\text { Concentration as } \\
\text { a Function of } \\
\text { SBPR OP }\end{array}$ & $\begin{array}{c}\text { Model OP } P_{S B P R}=T S S_{R A S} T S S_{F E R M}+Q_{S B P R} Q_{F E R M}+ \\
T_{S S} S_{R A S \text { Class }} T S S_{F E R M \text { Class }}+Q_{S B P R \text { Class }}\end{array}$ \\
\hline $\begin{array}{l}\text { TSS } \\
\text { Concentration as } \\
\text { a Function of } \\
\text { SBPR TSS }\end{array}$ & $\begin{array}{c}\text { Model } T S S_{S B P R}=T S S_{R A S} T S S_{F E R M}+Q_{S B P R} Q_{F E R M}+ \\
T S S_{R A S \text { Class }} T S S_{F E R M ~ C l a s s}+Q_{S B P R \text { Class }}\end{array}$ \\
\hline \multicolumn{2}{|r|}{ Mainstream GLM Expressions } \\
\hline $\begin{array}{l}\text { OP } \\
\text { Concentration }\end{array}$ & $\begin{array}{l}\text { Model } O P_{E F F}=O P_{I N} Q_{R A S}+O P_{R A S} Q_{E F F}+ \\
O P_{I N} \text { class } O P_{R A S \text { Class }}+Q_{W A S \text { Class }} Q_{E F F \text { Class }}\end{array}$ \\
\hline $\begin{array}{l}\mathrm{NH} 4 \\
\text { Concentration }\end{array}$ & $\begin{array}{c}\text { Model } O P_{E F F}=N H 4_{I N} \\
O P_{R A S \text { Class }}+Q_{W A S \text { Class }} Q_{E F F \text { Class }}\end{array}$ \\
\hline $\begin{array}{l}\text { NO3 } \\
\text { Concentration }\end{array}$ & 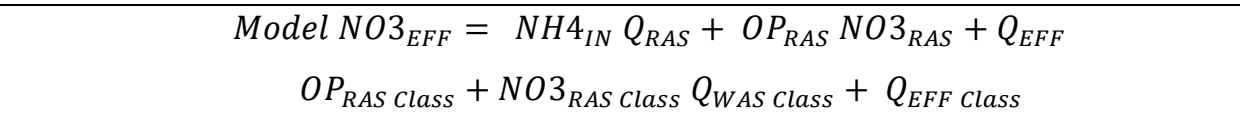 \\
\hline $\begin{array}{l}\text { TSS } \\
\text { Concentration }\end{array}$ & $\begin{array}{l}\quad \text { Model TSS } S_{E F F}=T S S_{\text {Mainstream }} Q_{S B P R}+T S S_{S B P R} T S S_{R A S}+T S S_{W A S} Q_{E F F}+ \\
T S S_{\text {MainstreamClass }} Q_{S B P R \text { Class }}+T S S_{S B P R \text { Class }} T S S_{R A S C l a s s}+Q_{W A S C l a s s} T S S_{W A S C l a s s}+ \\
Q_{E F F C l a s s}\end{array}$ \\
\hline
\end{tabular}




\section{CHAPTER 4}

\section{RESULTS AND DISCUSSION}

\subsection{Evaluation of Study Phases}

A total of four experimental phases were employed in this study to evaluate a condition that optimizes OP removal. An overview of these phases can be seen in Table 4.1. Each phase of the study was chosen based on the operational strategy of the SBPR, as well as the goal of that phase of the experiment. Throughout this entire experiment, B-stage was operated in intermittent AVN control, temperature controlled to 20 degrees Celsius, and $\mathrm{pH}$ controlled to 7.0 with fluctuations between 6.8 and 7.78 by feeding sodium bicarbonate feed stock whenever the $\mathrm{pH}$ hit a low level of 6.8 and continually feeding until the $\mathrm{pH}$ increased to 7.78. An overview of the operating conditions throughout each phase of the project is shown in Figures 4.1 and 4.2.

Table 4.1: Overview of Each Phase throughout the Study

\begin{tabular}{|l|c|l|}
\hline Phase & Days & Overview \\
\hline I & $0-48$ & $\bullet \quad$ Startup of the SBPR \\
\hline II & $49-197$ & SBPR HRT less than four \\
& $198-254$ & hours \\
\hline III & $\begin{array}{l}\text { SBPR HRT between five and } \\
\end{array}$ & eleven hours \\
& & Column underflow feeding \\
& & SBPR \\
\hline IV & $255-443$ & SBPR HRT less than four \\
& & hours \\
\hline V & $444-461$ & SBPR HRT around twenty \\
& & hours \\
\hline
\end{tabular}




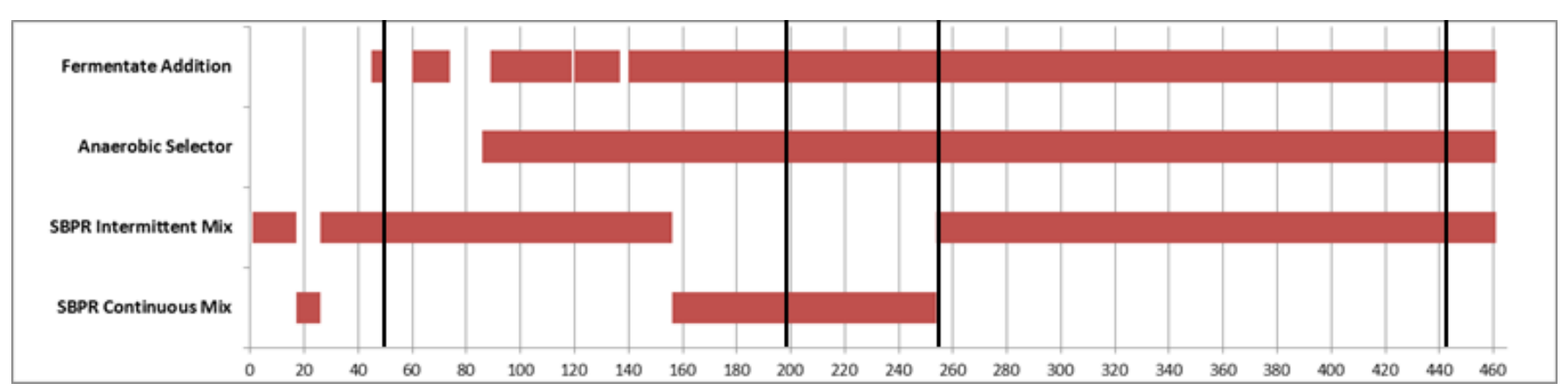

Figure 4.1. Operating Conditions throughout the Study

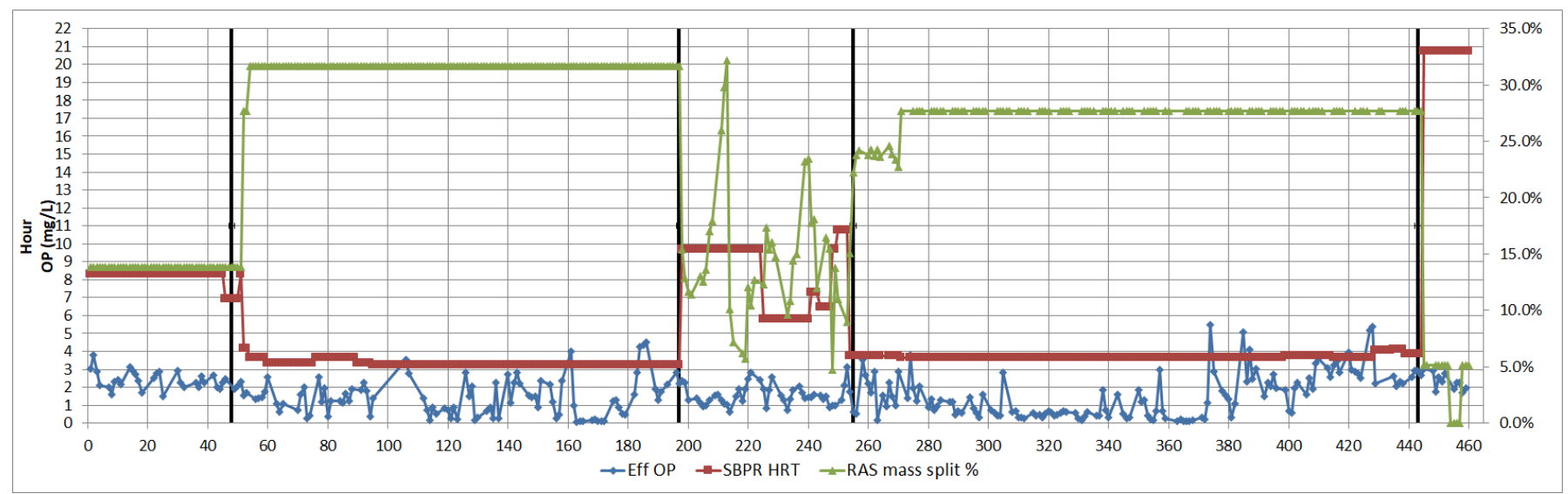

Figure 4.2. Sidestream Operation with Mainstream Effluent OP Values throughout the Study

\subsubsection{Phase I}

Phase I began after the design, build, and implementation of the sidestream bio-P reactor. During this phase, the SBPR was intermittently and continuously mixed, the secondary clarifier RAS was feeding the SBPR, and there was no fermentate addition yet, as the A-stage WAS fermenter was still being designed. Table 4.2 shows the operational parameters during Phase I. 
Table 4.2. Phase I Operational Parameter Values

\begin{tabular}{|c|c|}
\hline Length of Phase I & $\begin{array}{c}\text { 0-48 Days } \\
\text { (461 days for entire study) }\end{array}$ \\
\hline RAS Mass Split to SBPR (\%) & 14 \\
\hline HRT (hrs) & 8.3 \\
\hline Fermentate Addition (mL/min) & 0 \\
\hline
\end{tabular}

\subsubsection{Phase II}

The goal of phase II was to run the SBPR with a larger percent of solids passing through the sidestream tank in a shorter residence time and contacting with a large amount of VFA from the fermentate addition. Phase II was operated from day 49-197 and was operated with a shorter side stream HRT of less than four hours. Phase II was operated with a higher RAS percentage feeding the side stream reactor at $32 \%$. Fermentate addition ranged from $10 \mathrm{~mL} / \mathrm{min}$ to 100 $\mathrm{mL} / \mathrm{min}$ feed rate with an average VFA concentration of $557 \mathrm{mg} / \mathrm{L} \pm 209 \mathrm{mg} / \mathrm{L}$. Intermittent mixing as well as continuous mixing was utilized in phase II. In Phase II, the optimal operating conditions of the side stream reactor were still being determined, so the change from intermittent mixing to continuous mixing was made. 
Table 4.3. Phases II Operational Parameter Values

\begin{tabular}{|c|c|}
\hline Length of Phase II & 49-197 Days \\
\hline RAS Mass Split to SBPR (\%) & 32 \\
\hline HRT (hrs) & 3.6 \\
\hline $\begin{array}{c}\text { Fermentate Addition } \\
(\mathrm{mL} / \mathrm{min})\end{array}$ & $10-100$ \\
\hline
\end{tabular}

\subsubsection{Phase III}

Phase III was operated with an HRT between five and eleven hours. Experimental operating conditions employed in Phase III are summarized in Table 4.4. The solids feeding the side stream reactor came from the bottom of the settling column and provided unstable solids concentration. This led to an inconsistent RAS mass percent being fed to the SBPR. The mixing regime during this time was continuous mixing. The goal of Phase III was to allow a portion of much higher solids concentration in the RAS coming from the bottom of the settling column to be continuously mixed in the sidestream reactor and contacted with VFA from the fermenter before entering the mainstream process. The rationale behind using the higher solids concentration contacted with VFA was that a longer retention time is not needed to try to ferment the RAS itself, so the reactor could be continuously mixed, and a larger concentration of the PAO's would rely on the external carbon addition from the fermenter. 
Table 4.4. Phase III Operational Parameter Values

\begin{tabular}{|c|c|}
\hline Length of Phase III & 198-254 Days \\
\hline RAS Mass Split to SBPR (\%) & $5-32$ \\
\hline HRT (hrs) & $5-11$ \\
\hline Fermentate Addition (mL/min) & 100 \\
\hline
\end{tabular}

\subsubsection{Phase IV}

The goal of Phase IV was to run the sidestream reactor with a larger percent of solids passing through a sidestream tank in a shorter residence time and contacting with a large amount of VFA from the fermentate addition. Phase IV was operated from day 255-443. Phase IV was operated with a shorter side stream HRT of less than four hours and a higher RAS percentage feeding the side stream reactor at $27 \%$. Fermentate addition ranged from $10 \mathrm{~mL} / \mathrm{min}$ to 100 $\mathrm{mL} / \mathrm{min}$ feed rate with an average VFA concentration of $646 \mathrm{mg} / \mathrm{L} \pm 181 \mathrm{mg} / \mathrm{L}$. In Phase IV, the optimal operation of the SBPR was already determined and kept with intermittent mixing. Figure 4.5 indicates that the effluent OP values were consistently below $0.5 \mathrm{mg} / \mathrm{L}$ in Phase IV showing optimal operation over all other phases including Phase II, which was very similar operation to Phase IV. 
Table 4.5. Phase IV Operational Parameter Values

\begin{tabular}{|c|c|}
\hline Length of Phase IV & 255-443 Days \\
\hline RAS Mass Split to SBPR (\%) & 27 \\
\hline HRT (hrs) & 3.8 \\
\hline $\begin{array}{c}\text { Fermentate Addition } \\
\text { (mL/min) }\end{array}$ & $10-100$ \\
\hline
\end{tabular}

From preliminary data, the amount of nitrate present in the SBPR was a concern throughout the study. In a full-scale facility, a large amount of nitrate returned to the anaerobic zone would never be ideal, as this would cause competition between PAOs and denitrifiers attempting to take up the VFA source. Because of this, a pre-denite reactor was installed on day 373. The pre-denite reactor was designed so that the RAS entered a smaller reactor that was completely mixed and combined with the VFA rich fermentate feed before entering the SBPR. The goal of adding this pre-denite reactor was to have denitrification occur in this reactor so there would be no nitrate present in the SBPR. The pre-denite reactor remained in the process until Phase V, when the reactor was removed.

\subsubsection{Phase V}

Phase V operated with a much higher SBPR HRT of twenty hours with a much smaller amount of RAS being sent to the side stream reactor of 5\%. Experimental operating conditions employed in Phase V are summarized in Table 4.6. The goal of Phase V was to send a much smaller amount of the RAS to the sidestream reactor, as well as, a smaller concentration of fermentate to allow the SBPR to ferment the RAS and rely more heavily on producing VFA's internally, as well as, PAOs outcompeting GAOs because of their ability to survive extended anaerobic conditions with a slower decay rate. In order to achieve this, the reactor was intermittently mixed allowing deep anaerobic conditions in the reactor and a longer contact time 
for the RAS and small amount of fermentate. Research done by Li et al. (2018) showed that around 18 hours of retention allows for PAOs to operate under an EBPR-oriented metabolism with active $P$ release and VFA uptake, and after this point they transition to a maintenanceoriented metabolism where OP being released is from biomass decay without substrate uptake. During these longer anaerobic retention times, glycogen is depleted from both PAOs and GAOs, however, intracellular polyP found only in PAOs is used at slower rates for cell maintenance. This indicates that PAOs can survive these longer anaerobic retention times better than their counterpart, GAOs. The fermentate flow rate was $10 \mathrm{~mL} / \mathrm{min}$ with an average VFA (as COD) concentration of $729 \mathrm{mg} / \mathrm{L} \pm 130 \mathrm{mg} / \mathrm{L}$.

Table 4.6. Phase V Operational Parameter Values

\begin{tabular}{|c|c|}
\hline Length of Phase V & 444-461 Days \\
\hline RAS Mass Split to SBPR (\%) & 5 \\
\hline HRT (hrs) & 20 \\
\hline Fermentate Addition (mL/min) & $0-10$ \\
\hline
\end{tabular}

\subsection{Maximum Activity Measurements}

\subsubsection{PAO and dPAO Maximum Rate Measurements}

Maximum PAO and dPAO rate tests were performed weekly and bimonthly, respectively. These tests were done to determine the amount of PAO versus GAO activity, and the amount of dPAO versus dGAO activity. Phase I maximum activity tests did not reveal much PAO or dPAO activity as shown in Figure 4.3. This is because there was not a sufficient carbon source for the PAO to proliferate. The activity values for anaerobic release rate and aerobic 
uptake rate on average were $1.6 \mathrm{mgOP} / \mathrm{gMLVSS} / \mathrm{hr}$ and $0.6 \mathrm{mgOP} / \mathrm{gMLVSS} / \mathrm{hr}$, respectively. Throughout the entire study, dPAO activity was extremely low to non-detectable in every maximum activity test performed. During Phase II and Phase III, the anaerobic release and aerobic uptake rates were increasing with values on average of $8 \mathrm{mgOP} / \mathrm{gMLVSS} / \mathrm{hr}$ and 2 $\mathrm{mgOP} / \mathrm{gMLVSS} / \mathrm{hr}$, respectively. It was not until Phase IV that the anaerobic release and aerobic uptake rates really increased to values we would expect to see in the literature. These values on average for anaerobic release and aerobic uptake rates were $13.9 \mathrm{mgOP} / \mathrm{gMLVSS} / \mathrm{hr}$ and $5.8 \mathrm{mgOP} / \mathrm{gMLVSS} / \mathrm{hr}$, respectively. It is important to note as well that the optimum mainstream process OP removal achieved throughout the entire study was at the end of Phase IV, coinciding with the higher maximum bench activity rates. Phase V anaerobic release and aerobic uptake rates drastically declined. These rates were on average $2.6 \mathrm{mgOP} / \mathrm{gMLVSS} / \mathrm{hr}$ and 0.0 $\mathrm{mgOP} / \mathrm{gMLVSS} / \mathrm{hr}$, respectively. This is because at the end of Phase IV, the population dynamics in the sidestream reactor changed to be dominated by GAOs. This population change occurred because of the installation of the pre-denite reactor. This change in population drastically reduced the mainstream OP reduction as determined with the bench activity measurements. The change in dominant population during Phase V can be seen by looking at the phosphorus release rate/ COD uptake rate $(\mathrm{P} / \mathrm{C})$ ratios during the maximum bench activity tests. The $\mathrm{P} / \mathrm{C}$ ratio indicates that at 0.51 or higher there is a $\mathrm{PAO}$ dominated population rather than a GAO dominated population (Smolders et al., 1994). By comparing the $\mathrm{P} / \mathrm{C}$ ratio in each phase it is easy to see that a PAO dominated population existed throughout the majority of Phases III and IV, and changed to a GAO dominated population in Phase V. The shift in population occurred because the pre-denite reactor had a very short retention time, and a much higher concentration of VFA, which allowed for GAOs to outcompete PAOs. The P/C values along with the anaerobic release and aerobic uptake rates are summarized in Table 4.6. 
Table 4.7. Maximum Average Anaerobic Release Rate, Aerobic Uptake Rate, and P/C Ratio for Each Phase.

\begin{tabular}{|l|c|c|c|}
\hline & $\begin{array}{c}\text { Average Anaerobic } \\
\text { Release Rate } \\
\text { (mg OP/g MLVsS/ hr) }\end{array}$ & $\begin{array}{c}\text { Average Aerobic } \\
\text { Release Rate } \\
\text { (mg OP/g MLvs/ hr) }\end{array}$ & $\begin{array}{c}\text { Average P/C ratio } \\
\text { (g P released/g COD } \\
\text { taken up) }\end{array}$ \\
\hline Phase I & $1.6 \pm 0.10$ & $0.6 \pm 0.32$ & $0.0 \pm 0.0$ \\
\hline Phase II & $7.3 \pm 2.9$ & $2.6 \pm 2.1$ & $0.33 \pm 0.11$ \\
\hline Phase III & $9.1 \pm 2.8$ & $5.2 \pm 1.7$ & $0.40 \pm 0.15$ \\
\hline Phase IV & $13.9 \pm 6.2$ & $5.8 \pm 2.7$ & $0.60 \pm 0.34$ \\
\hline Phase V & $2.6 \pm 0.0$ & $0.0 \pm 0.0$ & $0.20 \pm 0.0$ \\
\hline
\end{tabular}

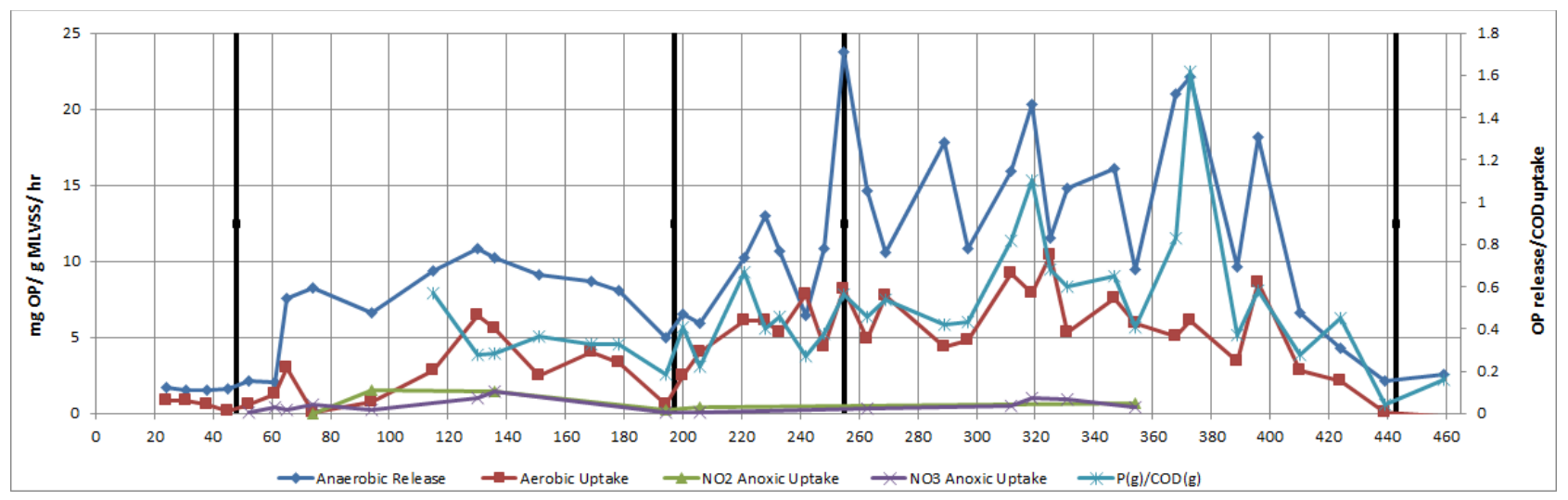

Figure 4.3. Overview of Maximum PAO and dPAO Bench Scale Activity Rates

Maximum PAO rate tests were also performed using different carbon substrates to determine their effect on the anaerobic release and aerobic uptake rates. Consistently the PAO bench scale tests were operated with acetate addition as the carbon source because it is the most common carbon source used for these tests as reported in the literature and allowed comparison 
with other studies. However, because VFA sources found more commonly in wastewater treatment plants do not consist of one single type of VFA, these bench scale tests were operated with acetate, fermentate, propionate, a propionate and acetate blend, glucose, and peptone. For different carbon sources as shown in Figure 4.4, the acetate, propionate, and propionate and acetate blend fed reactors performed with the highest anaerobic release rates, while the propionate and acetate blend and glucose fed reactors performed with the highest aerobic uptake rates. These maximum rate tests with different carbon sources were all conducted during Phase II of the project. Overall, the propionate and acetate blend fed bench scale reactor showed the highest potential for OP removal because of the high anaerobic release and aerobic uptake rates measured. This is not surprising considering PAOs perform better under conditions with a mixed VFA feed rather than a sole carbon source (Chen et al., 2005; Chen et al., 2004).

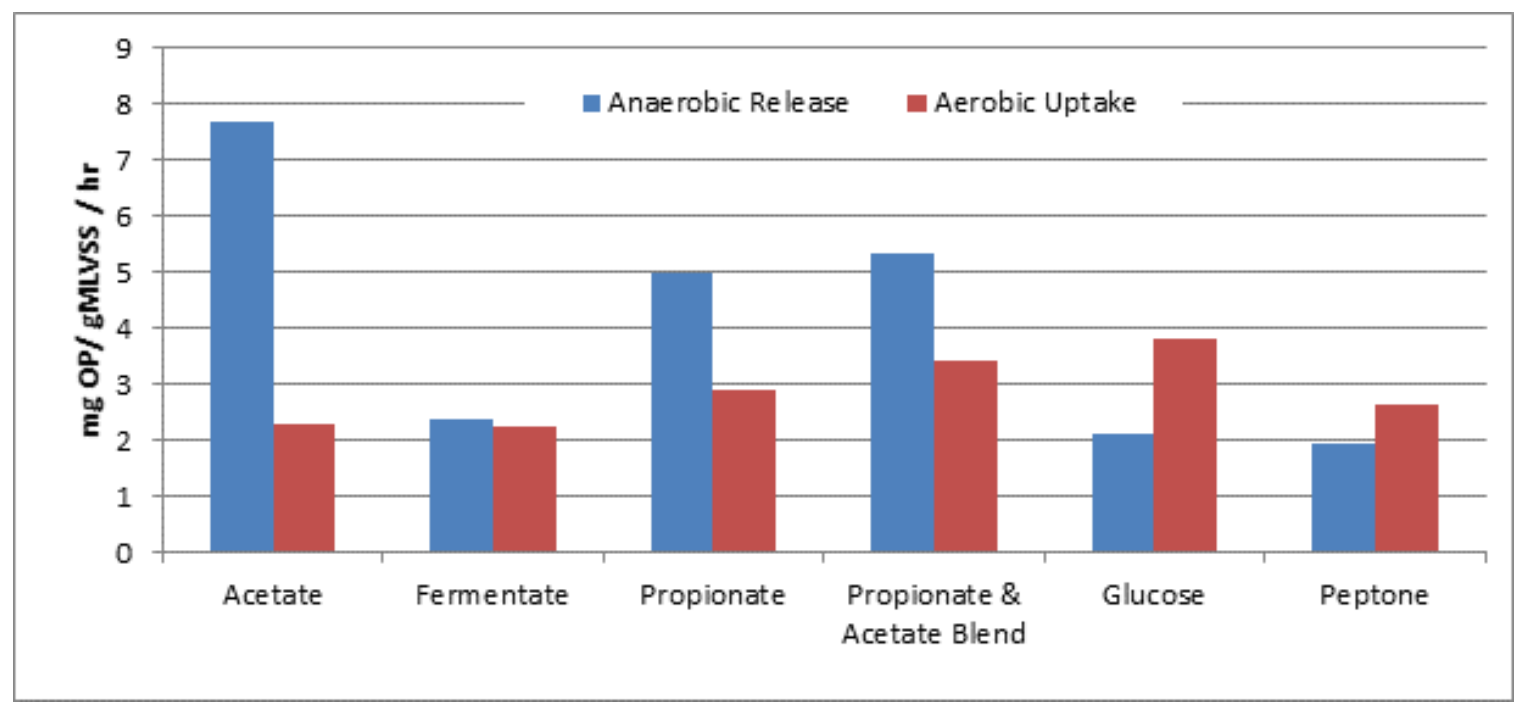

Figure 4.4. Maximum PAO Rates Using Different Carbon Sources

\subsection{PHA Results}

Four intensive sampling campaigns were run on day 332, 368, 372, and 400 with PHA analysis performed. These sampling campaigns are all within Phase IV of the project, Days 255- 
443. Because Phase IV of the project contains the optimal operating condition with effluent OP at its lowest concentration as well as at the end of this phase a transition to a GAO dominated population occurred, these sample data represent PHA storage during good operation and poor operation. Figures 4.5 through 4.8 show the profile and PHA data.

Profiles were taken on all four of the intensive sampling days along with the PHA samples. By comparing the PHA, OP, and sCOD content in all the reactors for every profile, assumptions about what was happening with PAOs and GAOs can be made.

The total PHA measurement in each of the profiles was measured as PHB and PHV. It is known that PAOs produce mainly PHB approximately 90\% when fed with acetate, and about 10\% PHV (T. Mino et al., 1998; Satoh et al., 1992; Smolders et al., 1994), whereas GAOs produce approximately $75 \%$ PHB and about $25 \%$ PHV when fed with acetate (Filipe et al., 2001b; Zeng et al., 2003). From the profile data shown in Figures 4.5 through 4.8, as the OP concentration is trending down across the four aerated reactors $(201,202,203,204)$, the total PHA is also trending down. This indicates that the PAOs are taking up excess OP as they are utilizing their PHA stores. Profiles also indicate pronounced changes in OP uptake across the reactors from day 332 to day 400. As the effluent concentration of OP in the reactors from day 332 to day 400 increases, the amount of total PHA utilized decreases. However, the amount of total PHA present in the SBPR on day 400 is greater than the amount present in the other three samples. This correlates with the pre-denite reactor installation and change in dominant population. These results indicate that GAOs were storing more PHA than PAOs at this time causing reduced OP removal across the system. 


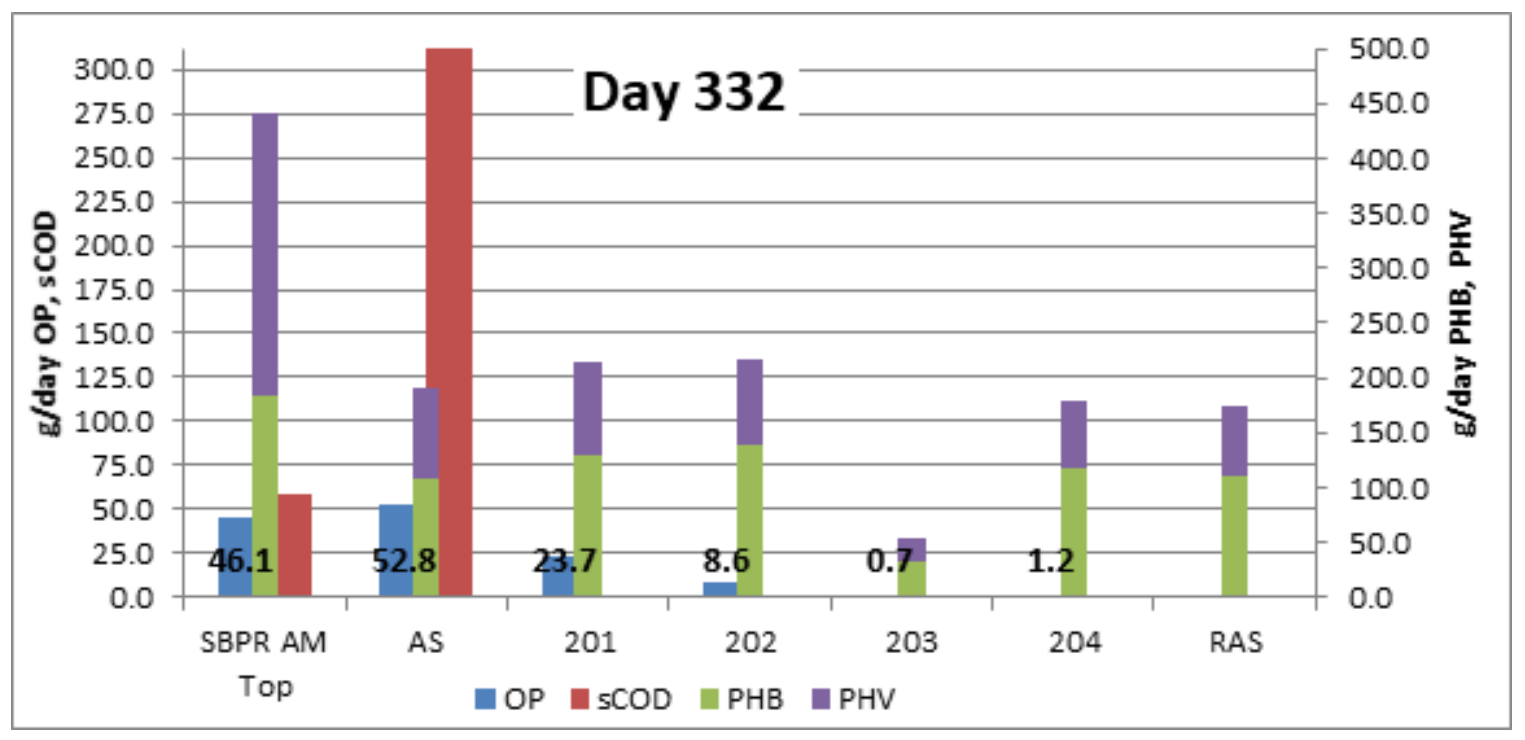

Figure 4.5. Profile data on Day 332 with PHA, OP, and sCOD

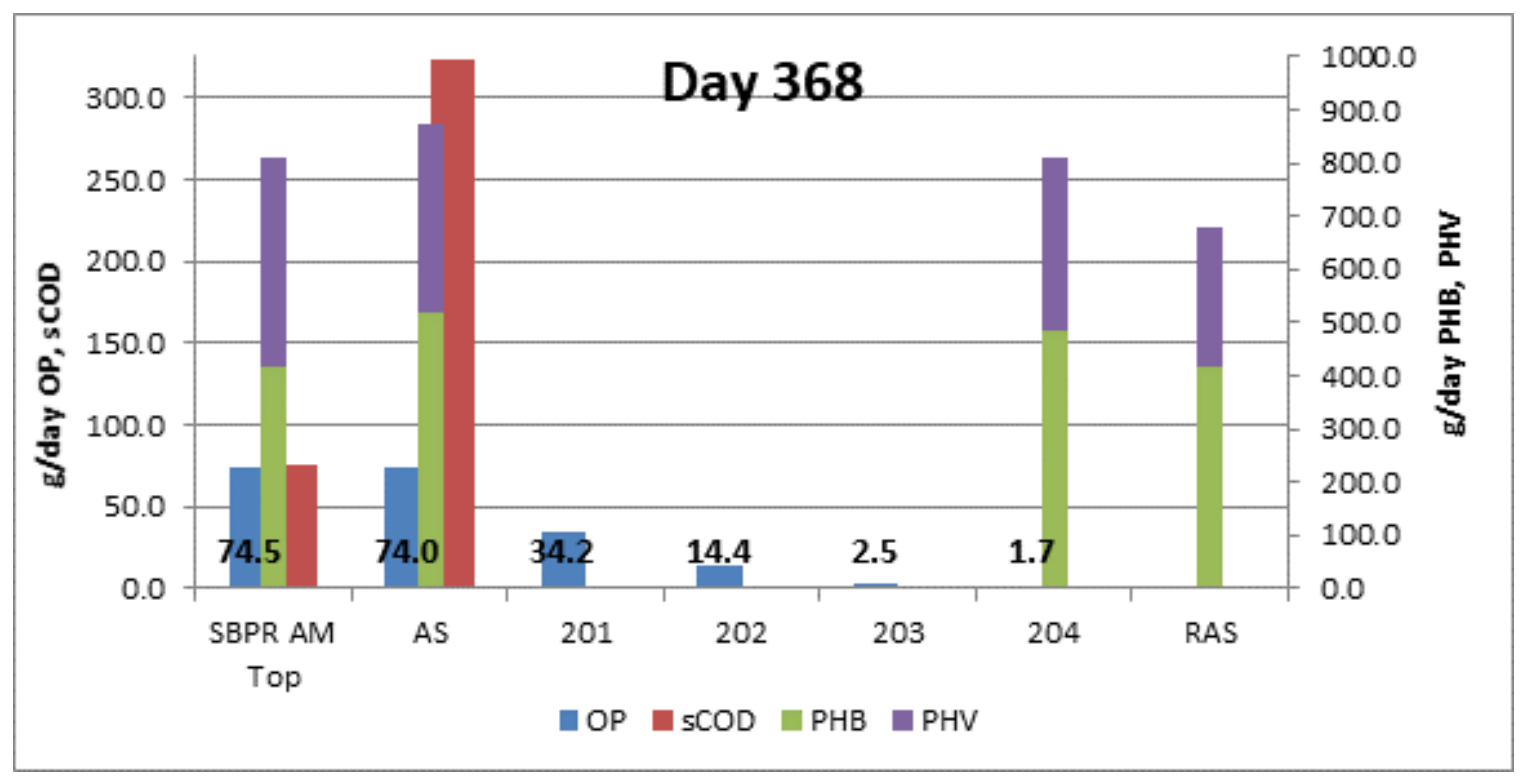

Figure 4.6. Profile Data on Day 368 with PHA, OP, and sCOD 


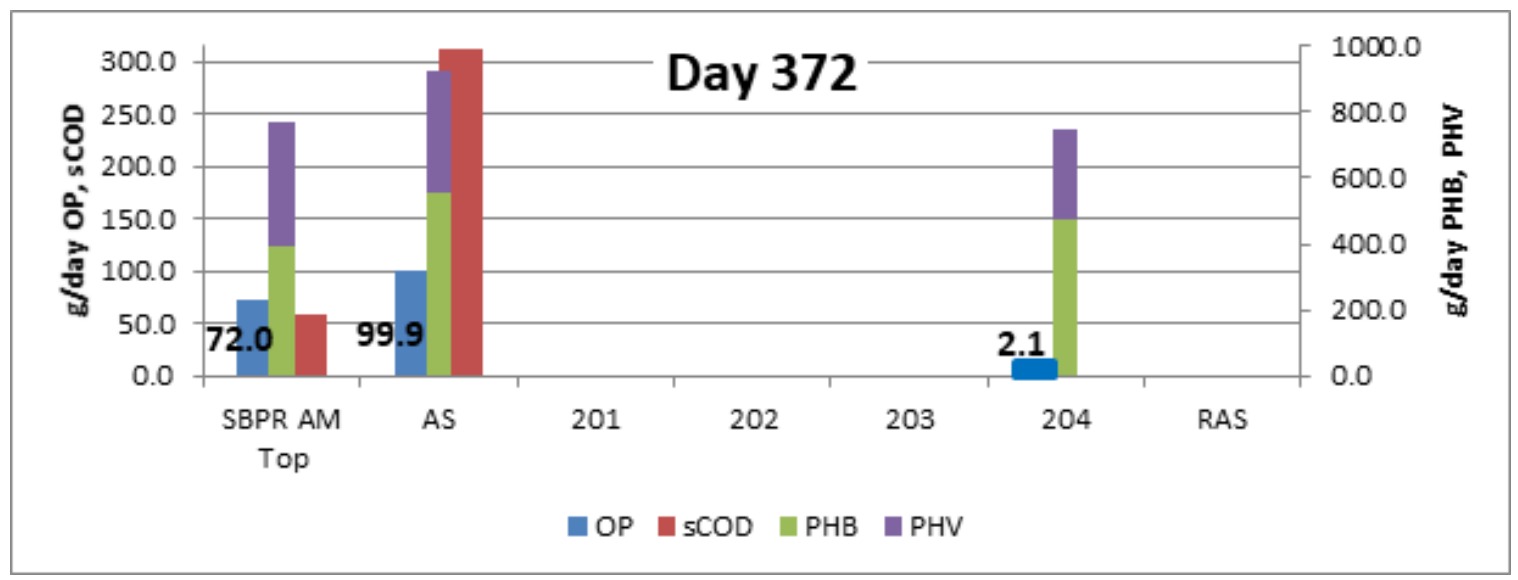

Figure 4.7. Profile Data on Day 372 with PHA, OP, and sCOD

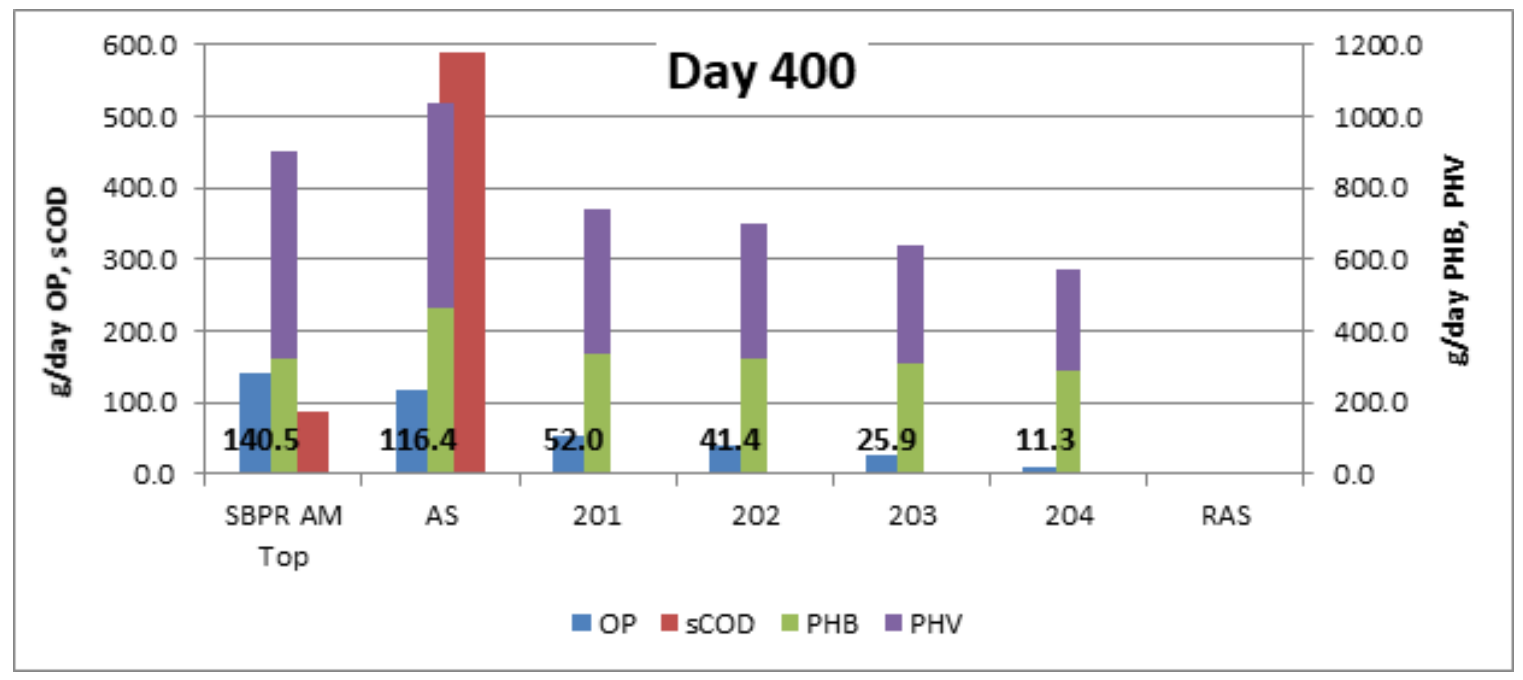

Figure 4.8. Profile Data on Day 400 with PHA, OP, and sCOD

Four sampling days are shown in Figure 4.9 with the amount of PHB and PHV in the anaerobic selector compared to the anaerobic release and aerobic uptake rates from the bench test maximum PAO rate tests for samples collected from reactor 204. The results of the graph show that the anaerobic release rates increase from day 332 to day 372, and on day 400 the release rates show a decline. This could correspond with a higher percent of PHV produced compared 
to PHB produced with a majority of acetate being fed from the fermenter. As shown in the literature, PAOs would produce a majority of PHB or PHV when acetate is being fed, leading to the conclusion that the GAO population was beginning to dominate the system.

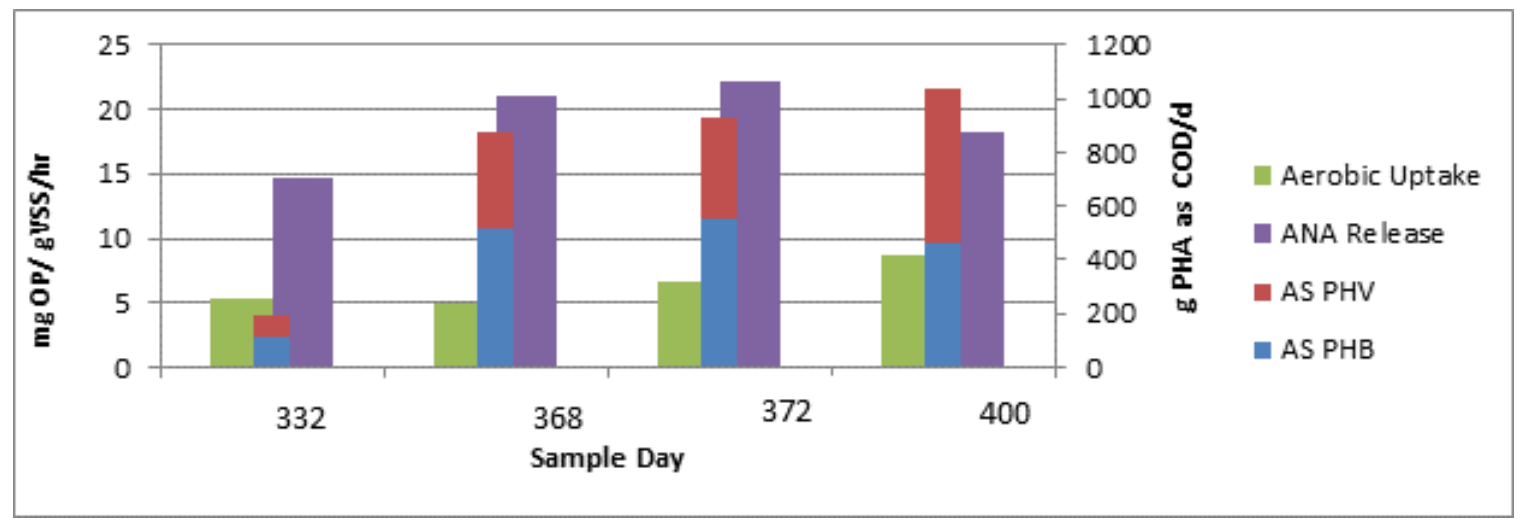

Figure 4.9. Sample Days Comparing Maximum Anaerobic Release and Aerobic Uptake Rates from Reactor 204 with PHA Concentration in the Anaerobic Selector

Figure 4.10 shows the average VFA feed to the SBPR in g/day with the effluent OP concentration in $\mathrm{mg} / \mathrm{L}$. From the graph it is clear that the magnitude of VFA was much higher between days 286 - 380 when the effluent OP was the lowest. The increased magnitude of VFA may correlate with an increased amount of PHA during Phase IV of the study, considering PHA is the carbon storage compound. The amount of VFA addition to the sidestream reactor could also have played a role in the optimal removal of OP during Phase IV of the project. Location and schematic configuration of the sidestream reactor is summarized in Figure 3. 1. 


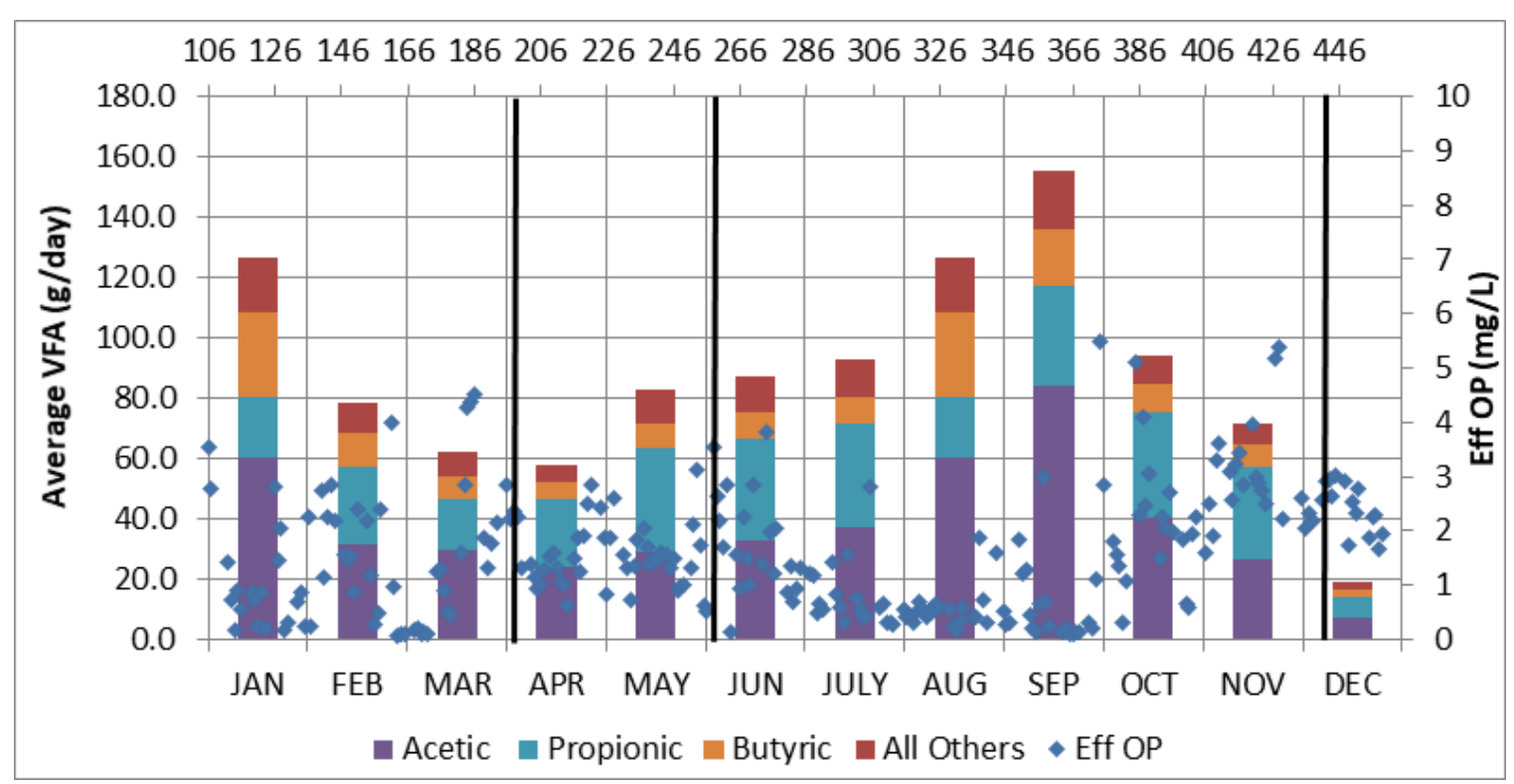

Figure 4.10. Average VFA Fractionation Added to SBPR and Effluent OP Concentration

\subsection{Fermenter and Thickener Performance}

Evaluation of the fermenter and thickener performance was based on the amount of sCOD, tCOD, VFA, $\mathrm{NH}_{4}$, and OP produced. The fermenter should be operated in such a way that a maximum yield of sCOD and VFA are produced with the smallest amount of tCOD, $\mathrm{NH}_{4}$, and OP being produced. The fermenter was operating at its optimum at a 5-day SRT, pH of 5.56, and temperature between 21-22 degrees Celsius. This optimal operating condition occurred during Phase IV and was producing the maximum amount of VFA from influent A-stage WAS without dosing caustic to achieve higher VFA yields. During this period, the fermenter effluent concentrations were on average 3280mg/L tCOD, 1738mg/L sCOD, and 618mg/L VFA as COD. These values can be seen in Figure 4.12. Even though the A-stage WAS fermenter produces a large amount of VFA and sCOD to be utilized in the SBPR, it also produces more $\mathrm{NH}_{4}$ and OP. It can also be seen from the graphs that during Phase IV when a larger portion of VFA and sCOD were being produced, a larger amount of $\mathrm{NH}_{4}$ and $\mathrm{OP}$ were also being produced. This additional nutrient load to the mainstream system also must be treated and can be seen in Figure 4.13. 


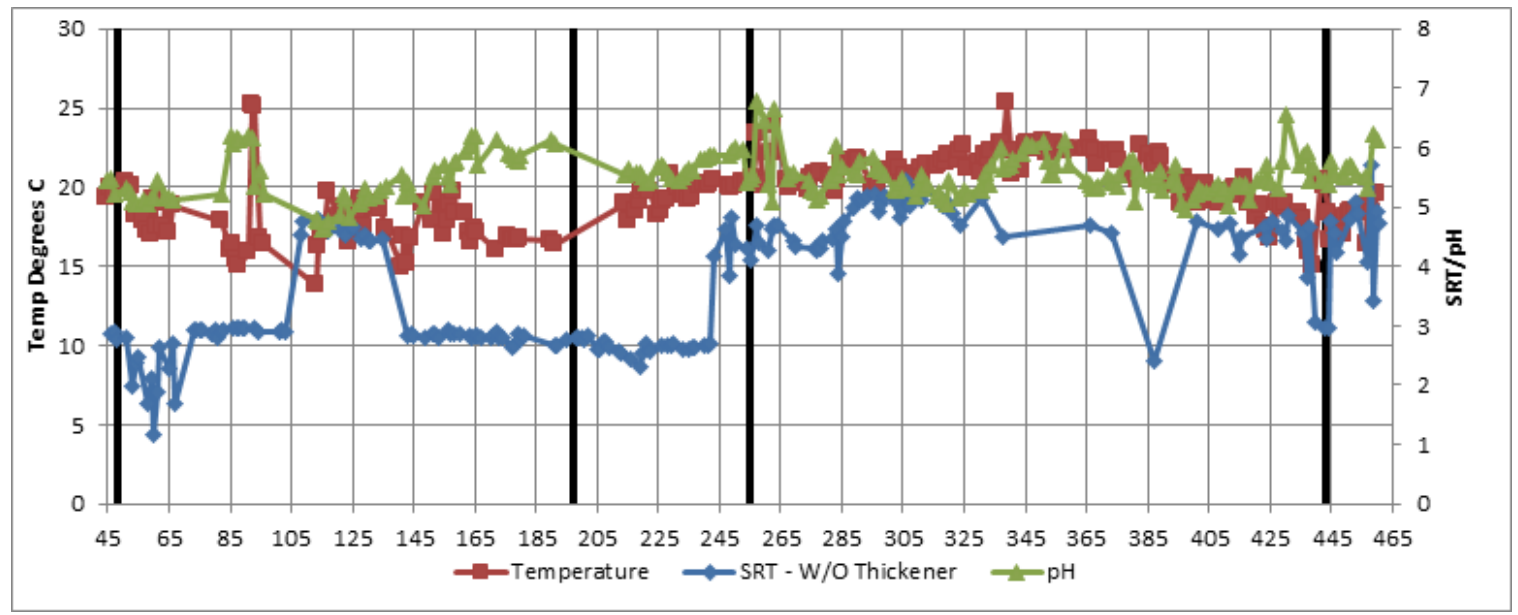

Figure 4.11. Temperature, SRT, and $\mathrm{pH}$ of the A-stage WAS fermenter

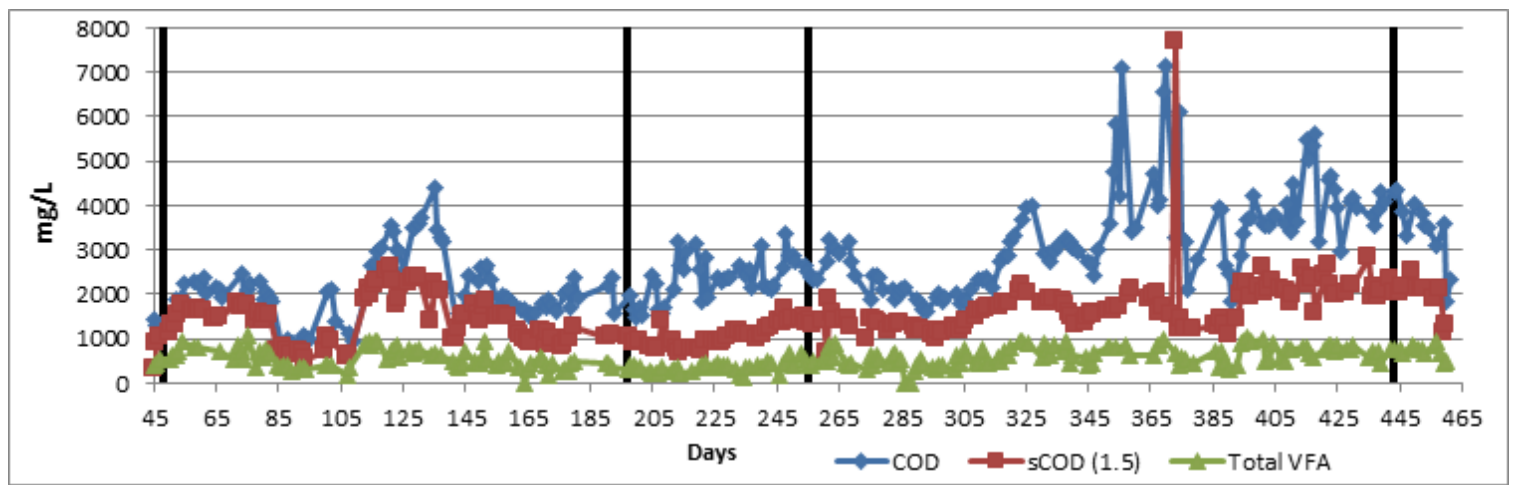

Figure 4.12. tCOD, sCOD, and VFA Produced in the Fermenter 


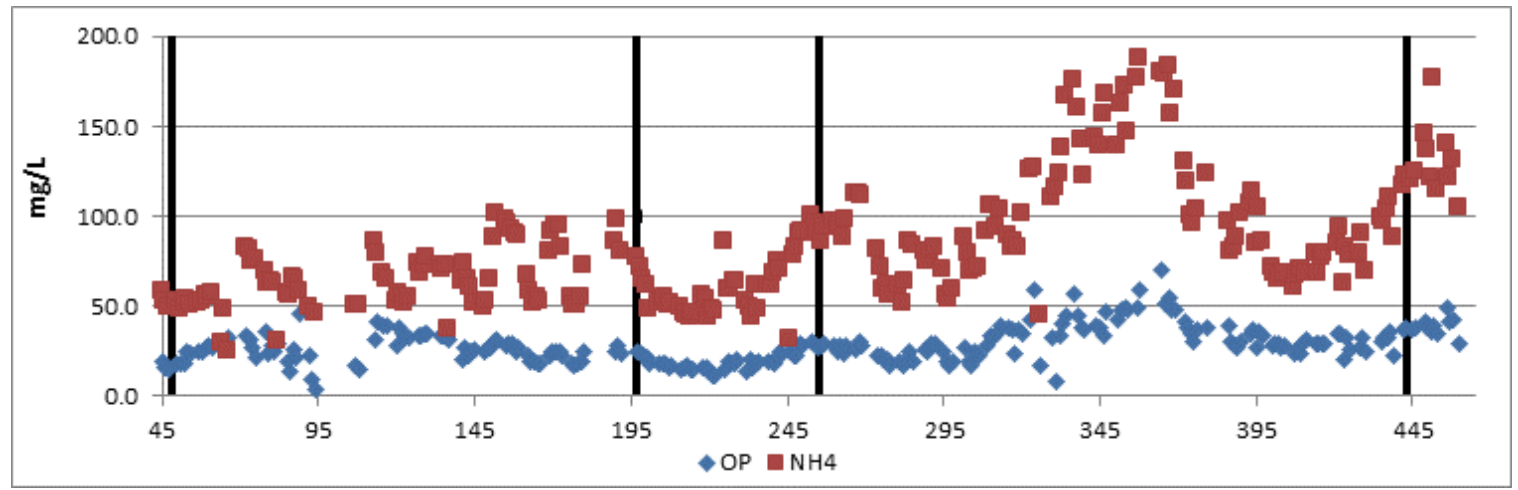

Figure 4.13. $\mathrm{NH}_{4}$ and OP Produced in the Fermenter

The VFA yield of the fermenter is a function of the mg VFA as COD produced by the fermenter divided by the mg influent COD. Figure 4.14 shows an increase in VFA yield that correlates with the increased SRT of 5 days. In Phase IV the SRT was optimized to 5 days and remained there with small fluctuations throughout the rest of the experiment. The VFA yield increased from an average of $4.7 \%$ to $6.7 \%$ from the beginning of the experiment to Phase IV. The average VFA yield is lower than VFA yields that could be produced by a primary sludge fermenter because of the longer retention time needed to perform cell lysis before sludge hydrolysis and fermentation can occur fully (Cagnetta et al., 2016). 


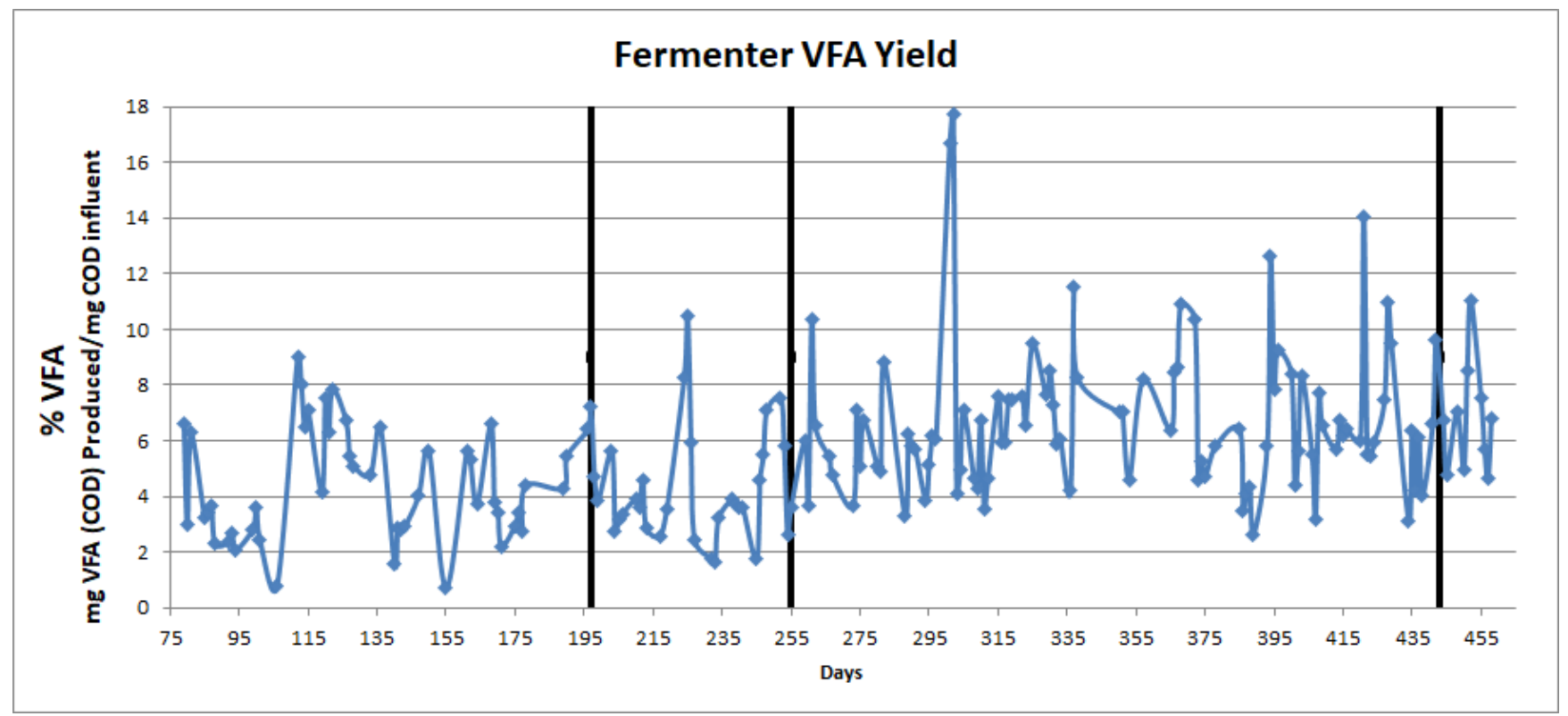

Figure 4.14. A-stage WAS Fermenter VFA Yield in Percent

Fractionation of the A-stage WAS fermenter VFA was examined and is shown in Figure 4.15. The 2018 average VFA fractions in percent show that acetic acid makes up the majority of the VFA produced by the A-stage WAS fermenter at $43 \%$, with propionic not far behind at $31 \%$. This is good operation for the fermenter and the type of VFA needed for the operation of the SBPR to target a PAO dominated population rather than a GAO dominated population. As stated in the literature by Oehmen, Yuan, et al. (2005), Oehmen et al. (2006), and LopezVazquez et al. (2008), PAOs perform better with a mixed fractionation of carbon source and perform in the optimum condition with roughly equivalent acetic and propionic acids. This is in comparison to GAOs that perform better under a single carbon source. 


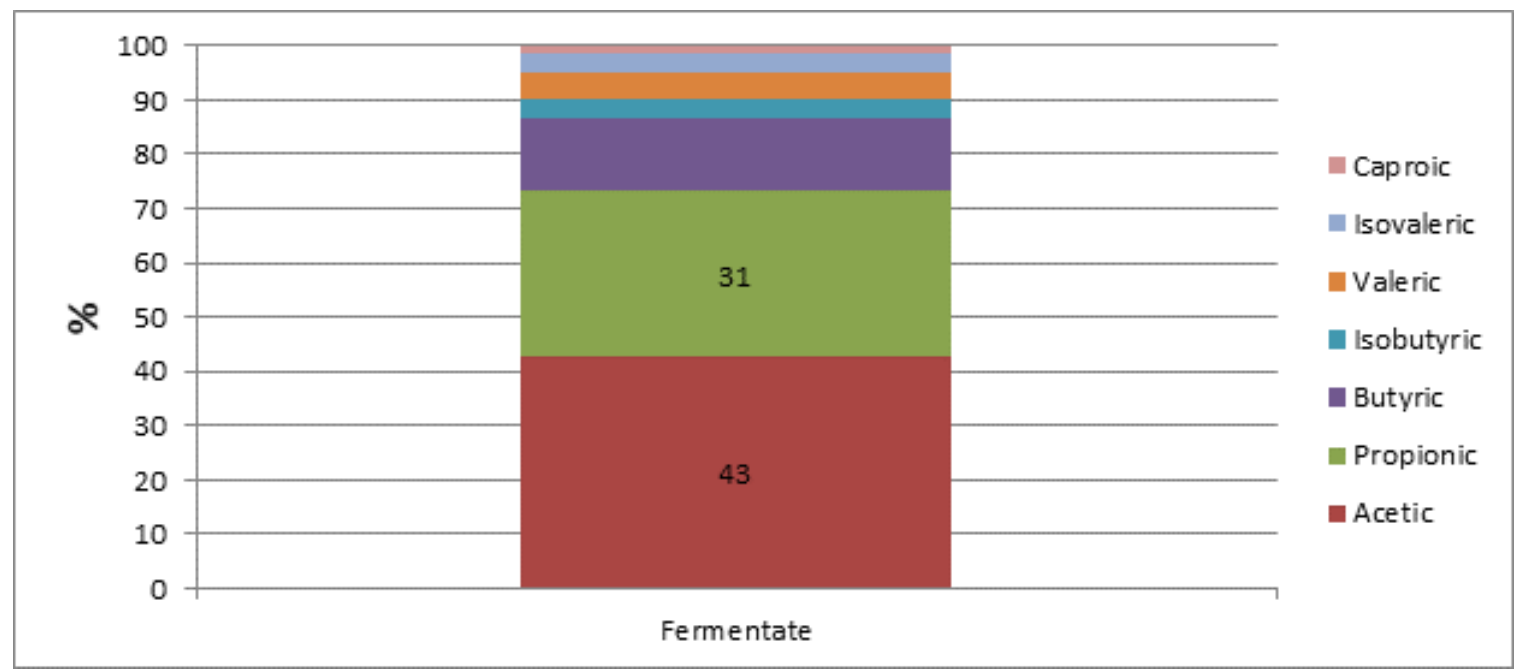

Figure 4.15. 2018 Average VFA Fractionation of the A-stage WAS Fermenter

Additional graphs, Figures 4.16 and 4.17, respectively show the three largest percentage VFAs produced in the fermenter, along with the effluent OP values in the mainstream, and temperature of the fermenter. Even though the pilot was operated in a temperature-controlled lab to 20 degrees Celsius, as well as, temperature-controlled tanks to 20 degrees Celsius within the system, the A-stage WAS fermenter temperature fluctuated slightly throughout the year. 


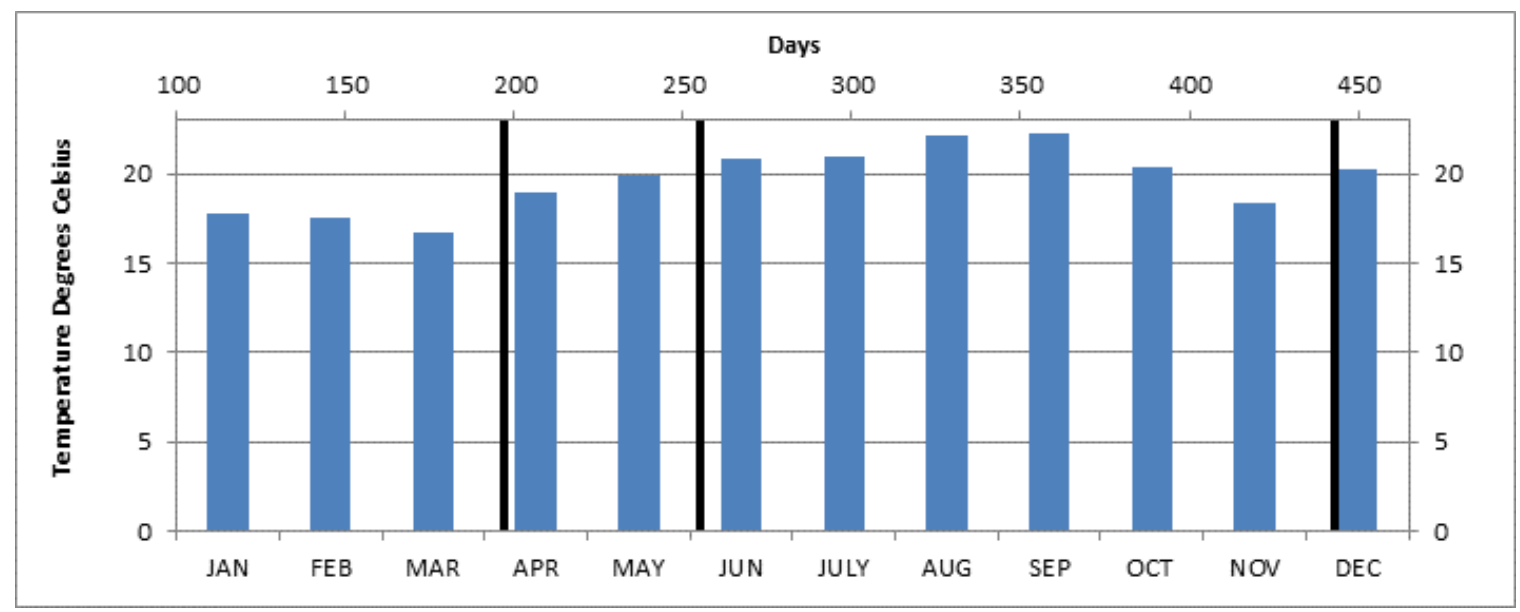

Figure 4.16. Average Monthly Fermenter Temperature throughout the Study

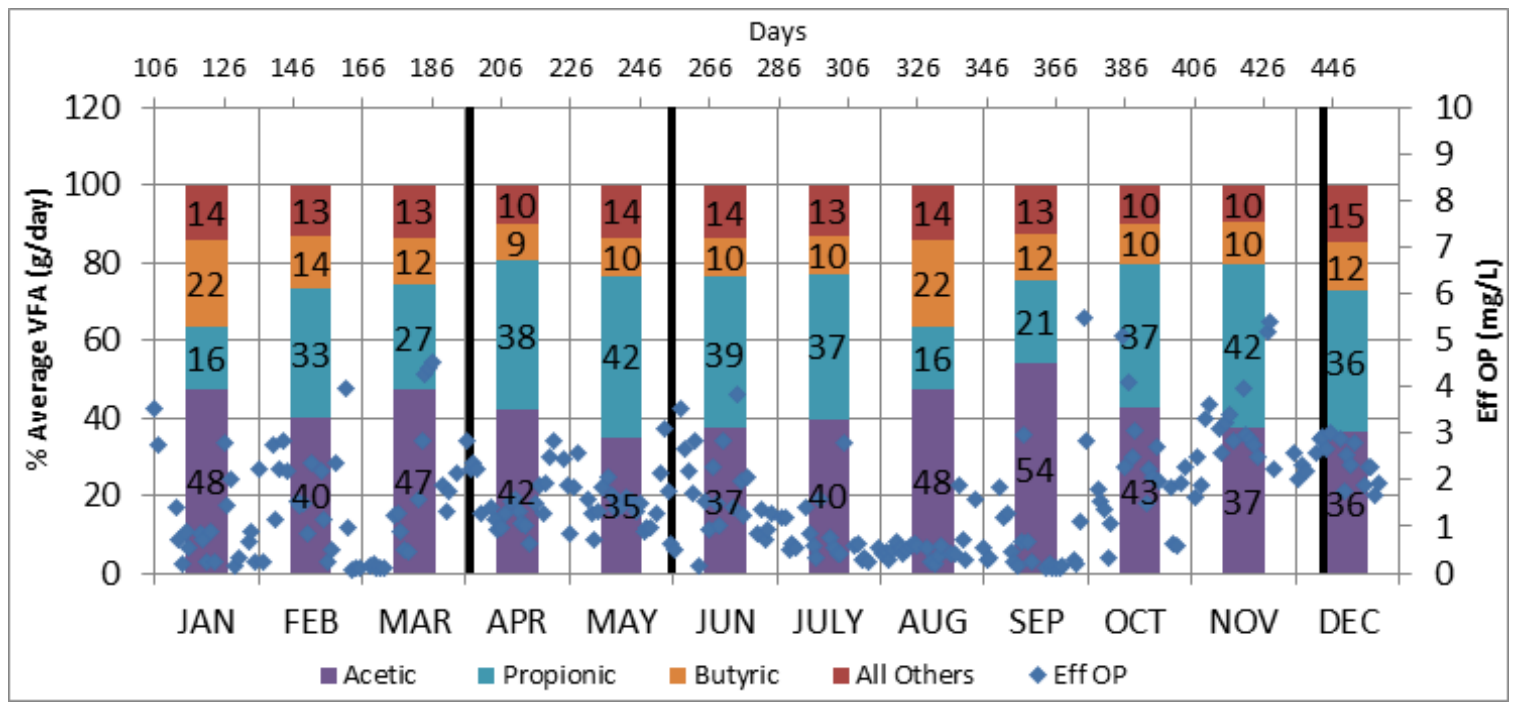

Figure 4.17. Average Percent VFA Production from the Fermenter and B-stage Effluent OP

During Phase IV of this experiment, the temperature in the fermenter reached its highest average value at 22.3 degrees Celsius. During Phase IV, the fermenter was producing a higher percent of acetic acid 54\% and propionic acid 21\%. Most importantly, during this period with higher acetic and propionic acid, and higher temperatures, the fermenter was operating at its 
optimum performance contributing to the effluent $\mathrm{OP}$ values in the mainstream being consistently low, below $1 \mathrm{mg} / \mathrm{L}$. This operating period was the best performance to date throughout this experiment.

\subsection{Residual Phosphorus Uptake Test}

Residual phosphorus uptake tests determine the amount of excess phosphorus uptake storage capacity the PAOs have in the system. From tests performed at the ChesapeakeElizabeth Pilot Plant, this measurement seems to be a good indicator of process performance. When the PAOs in the system have a large amount of excess storage capability, the effluent OP values are lower because the phosphorus is being taken up. However, when the storage capability drops lower, this indicates that the PAOs capability to take up excess phosphorus is inhibited, or that the number of PAOs relative to GAOs is lower. This could be for a number of different reasons including: not enough VFA source in the anaerobic zone, not a long enough retention time in the anaerobic zone, not long enough retention time in the aerobic zone, or a decrease in PAO population, leading to a smaller percentage of the biomass organisms capable of taking up excess phosphorus.

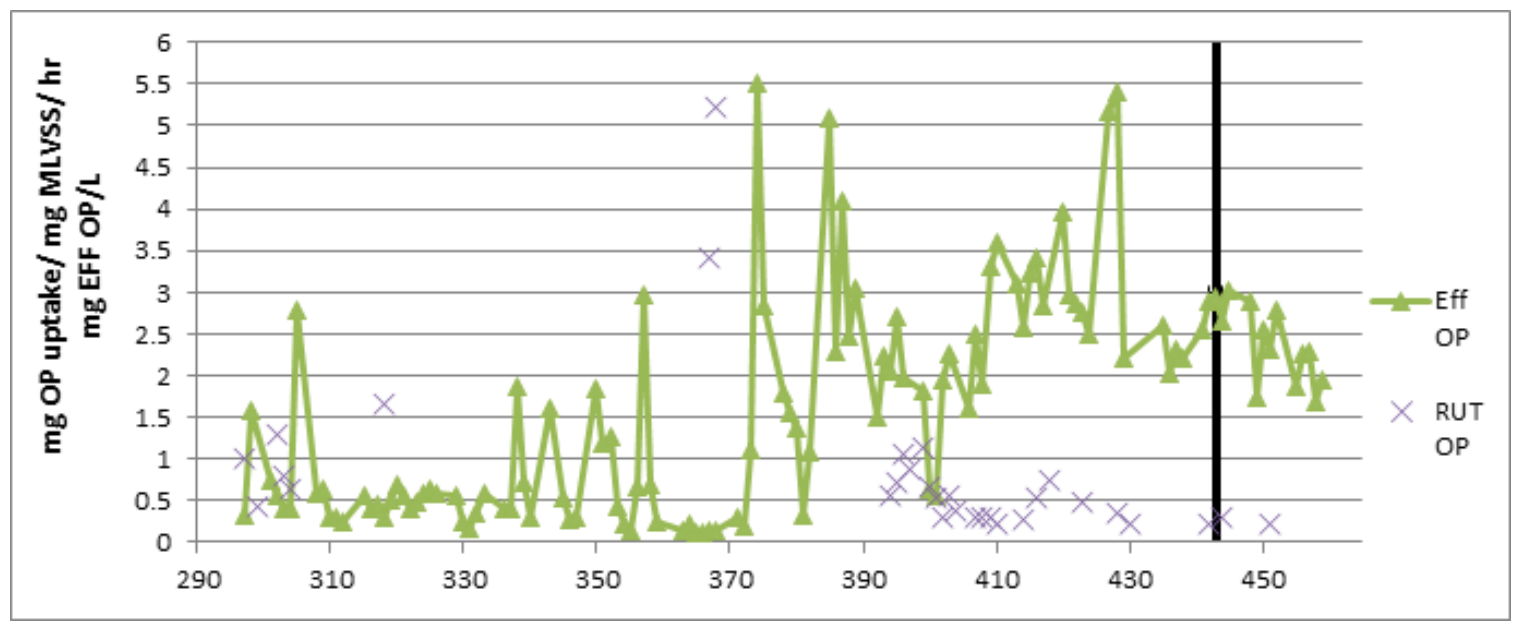

Figure 4.18. Residual Phosphorus Uptake Rate Test and Effluent OP Concentration 
Figure 4.18 depicts the results of the residual phosphorus uptake tests (RUT) performed throughout Phases IV and V of the study. RUT was implemented during Phase IV of the experiment so that results shown in Figure 4.18 only include Phase IV and Phase V of the experiment.

The residual uptake test shows the portion of Phase IV when effluent OP values were consistently low below $0.5 \mathrm{mg} / \mathrm{L}$; the RUT values were high above $3 \mathrm{mg} \mathrm{OP} / \mathrm{mg}$ MLVSS/ hr. However, after day 373 when the pre-denite reactor was installed, the effluent OP values start to trend higher, losing the good OP removal performance. Following the drop in OP removal, the RUT values drop to below $1 \mathrm{mg} \mathrm{OP/mg} \mathrm{MLVSS/} \mathrm{hr.} \mathrm{This} \mathrm{measurement} \mathrm{is} \mathrm{a} \mathrm{good} \mathrm{tool} \mathrm{to} \mathrm{use} \mathrm{for}$ performance evaluation of effluent OP values, but not necessarily a tool that can be used for predictive system behaviors, as the effluent OP values change faster than the results of the RUT test can be determined.

\subsection{Profile Data}

Profile data were taken every week to show a snapshot in space of the conditions of phosphorus removal throughout the system. The profile data was used to determine the amount of phosphorus being released in the anaerobic zone, the amount of phosphorus being taken up in the aerobic zone, as well as, the amount of soluble COD addition from the sidestream reactor to the mainstream reactors. Figures 4.19, 4.20, and 4.21 show the profile concentrations.

Figures 4.19 and 4.20 illustrates the amount of phosphorus in the influent and effluent of the mainstream through profile grabs. These values are relatively the same in Phase I, indicating no phosphorus has been removed. This is attributed to the fact that there was no external VFA available from the A-stage WAS fermenter yet, and there was not a long enough retention time to have RAS fermentation and production of VFA in the sidestream reactor. In this phase, VFA and carbon sources were the limiting factor for biological phosphorus removal to occur. 


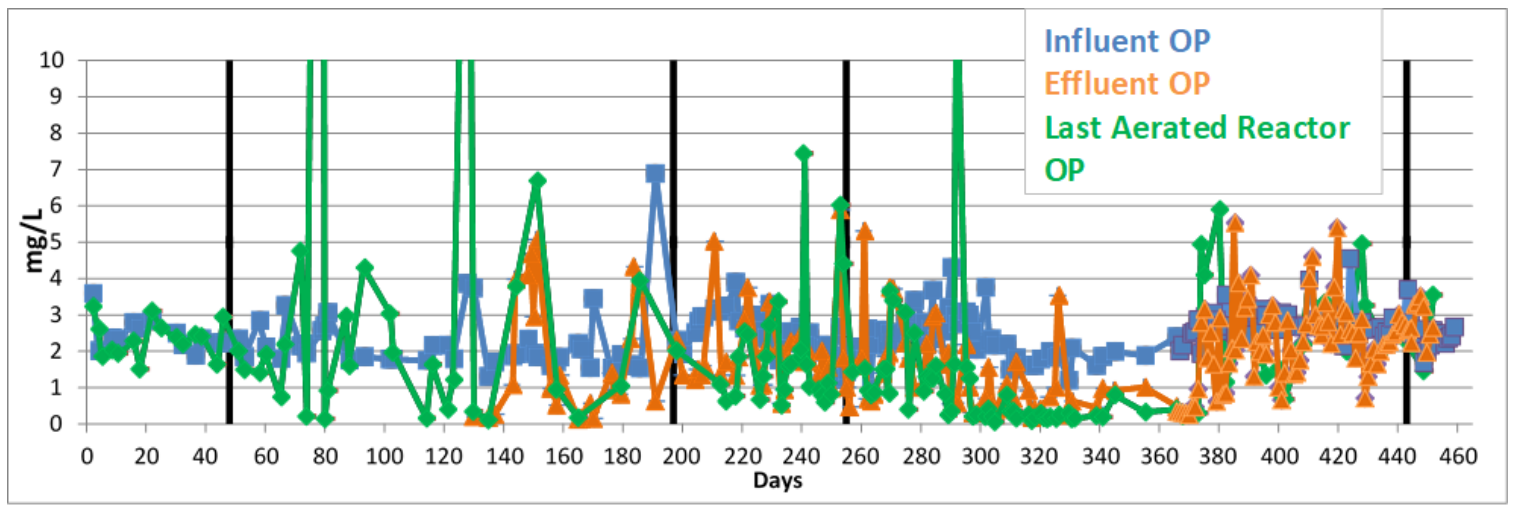

Figure 4.19. Profile Graphs Depicting Influent, Effluent, and Last Aerated Reactor OP Concentration

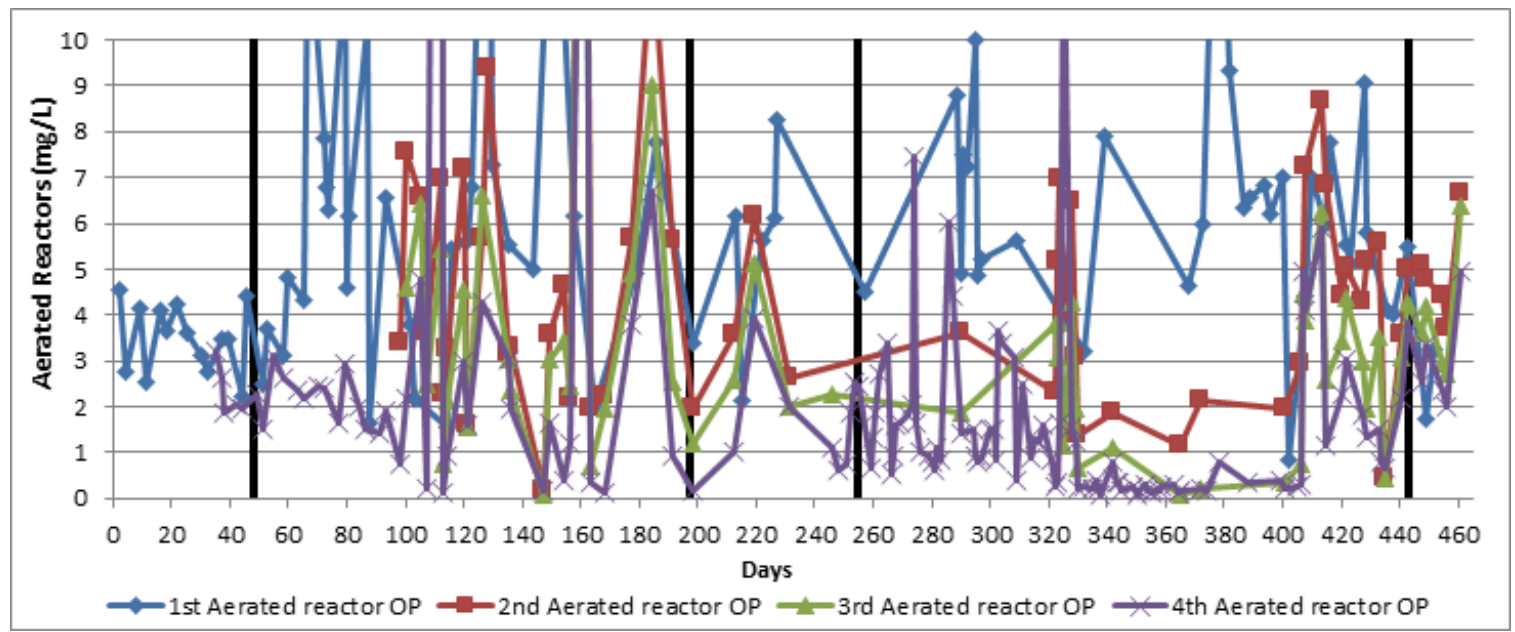

Figure 4.20. Profile Graphs Depicting the Four Aerated Reactor OP Concentrations

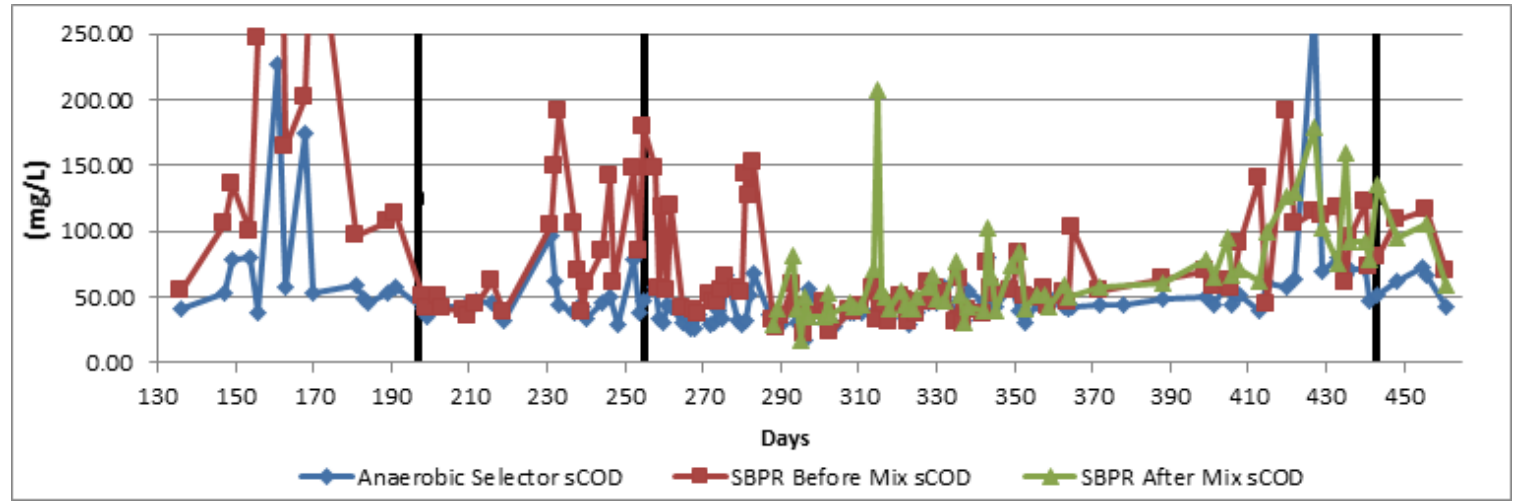

Figure 4.21. B-stage Anaerobic Selector and SBPR sCOD Profile Grab Values 
Overall profile graphs illustrate clearly that the lowest effluent OP values were during Phase IV of the experiment. These effluent values were consistently below $0.5 \mathrm{mg} / \mathrm{L} \mathrm{OP}$. Taking a closer look at the first profile graph, Figure 4.19, throughout the entire experiment, the last aerated reactor had lower OP values than the effluent grabs. This occurred because of secondary phosphorus release in the clarifier. This pilot was operated with roughly $50 \%$ of the solids in anaerobic conditions and outside of the mainstream system at any given time. The inventory split can be seen in Figure, 4.22, the pie chart. The secondary release of phosphorus should be monitored closely as this would cause higher effluent OP values than could be achieved in this process design. Looking at the aerated reactor profile graph in Figure 4.20, during optimal operation, Phase IV, the majority of OP is taken up between the first and second reactors. Also, by examining the soluble COD graph, it is apparent that during Phase IV, there is little sCOD breakthrough coming from the sidestream reactor, as well as, from the anaerobic selector (see Figure 3.1 for the unit processes schematic), meaning the amount of VFA and sCOD being sent to the sidestream reactor is being taken up and utilized by the PAOs in the SBPR. However, during poor bio-P operation, like in Phase V, the amount of sCOD being sent to the sidestream reactor is not being utilized, causing more breakthrough to the anaerobic selector and the mainstream process. This breakthrough of SCOD to the mainstream exerts additional oxygen demand as it is oxidized immediately when it reaches the aerated reactors. One of the main goals of this project was to optimize bio-P performance in conjunction with the amount of COD and VFA sent to the SBPR. 


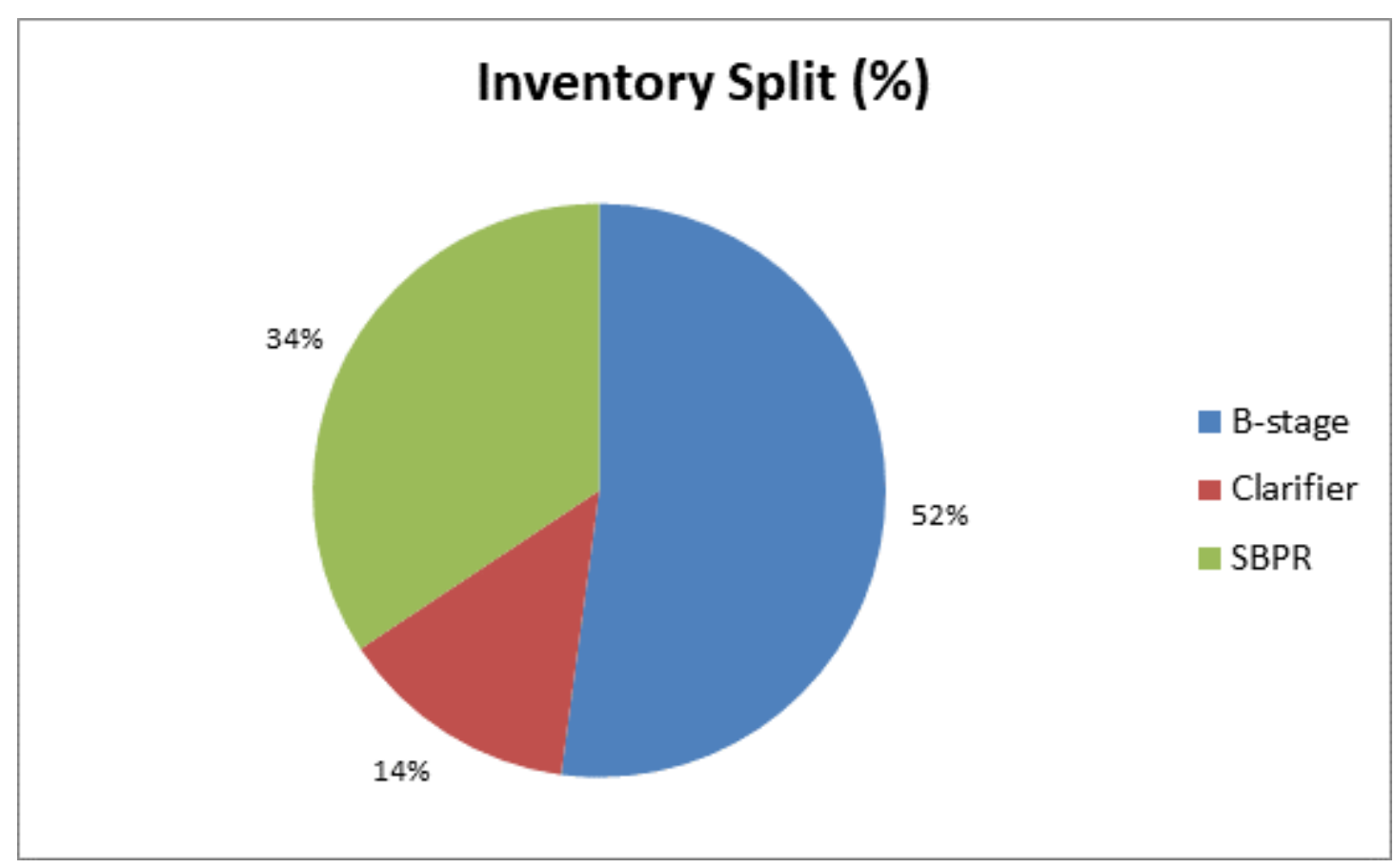

Figure 4.22. Mainstream and Sidestream Solids Inventory Split

\subsection{Solids Inventory}

The solids were split between the mainstream and sidestream system. Throughout the entire experiment, making sure the solids were not accumulating and being trapped in the sidestream was a huge challenge. Throughout Phase I, Phase II, and Phase III, the solids would get trapped in the SBPR, and continuous mixing would be used to redistribute the solids inventory (see Figure 3.1 for the unit processes schematic). The mixing strategy was also hard to determine. With little mixing occurring in the SBPR, and long retention times, as well as denitrification occurring in the sidestream, gas entrainment in the reactor was a problem. The gases would release causing a thick pudding like layer to form on the surface of the reactor, making it difficult for solids to be transferred to the mainstream system. This may be a result of pilot-scale research, because large, full scale plants operate with mixing for short periods of time one time per day, and do not accumulate large inventories of solids in their anaerobic zones. After going through iterations of mixing regimes, understanding how the SBPR operated became clearer. During intermittent mixing, the reactor solids would stratify leaving a very small 
percentage of solids entering the mainstream during non-mixing periods. The mixing cycle time and duration of the sidestream needed to be often enough, and long enough to completely mix the reactor to avoid the pudding layer on the top, as well as, send a large enough concentration of solids through to the mainstream reactor. While the reactor was stratified, nutrients including released phosphorus were being sent to the mainstream system, without the PAOs present in the solids.

Therefore, a balance between the stratified supernatant, and the solids allowed for the optimal performance period in Phase IV, where enough phosphorus release was occurring in the SBPR, simultaneously with enough PAOs making it through to the mainstream aerated reactors to take up phosphorus. Figure 4.23 and 4.24 show the solids concentrations in the mainstream and sidestream throughout the entire experiment.

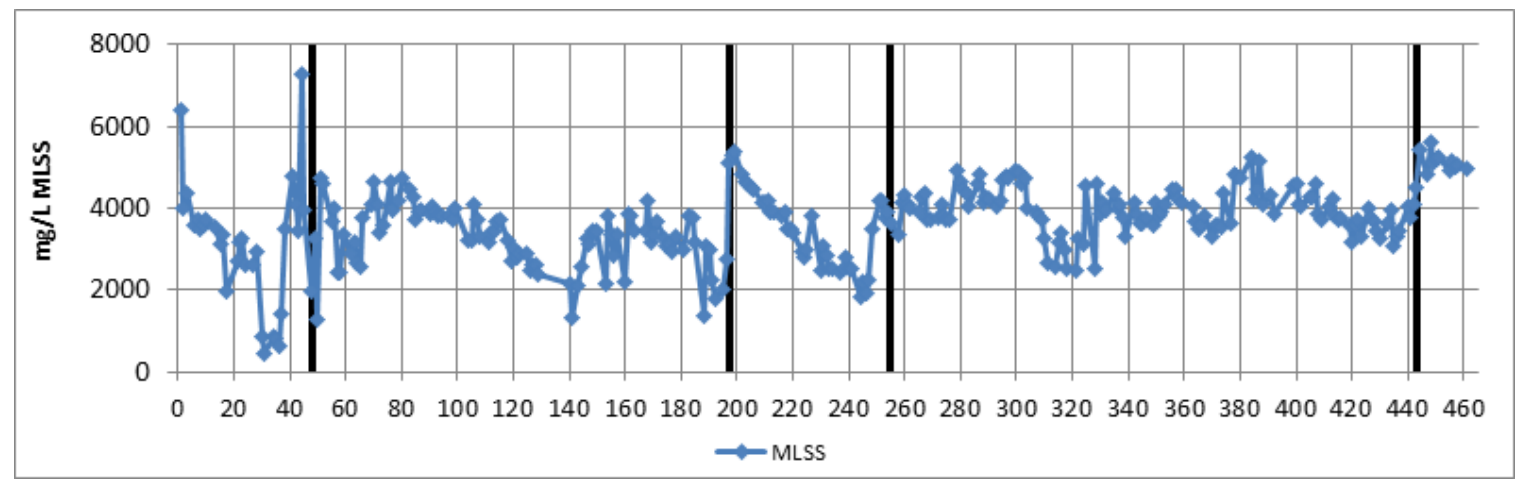

Figure 4.23. Mainstream Solids Concentration

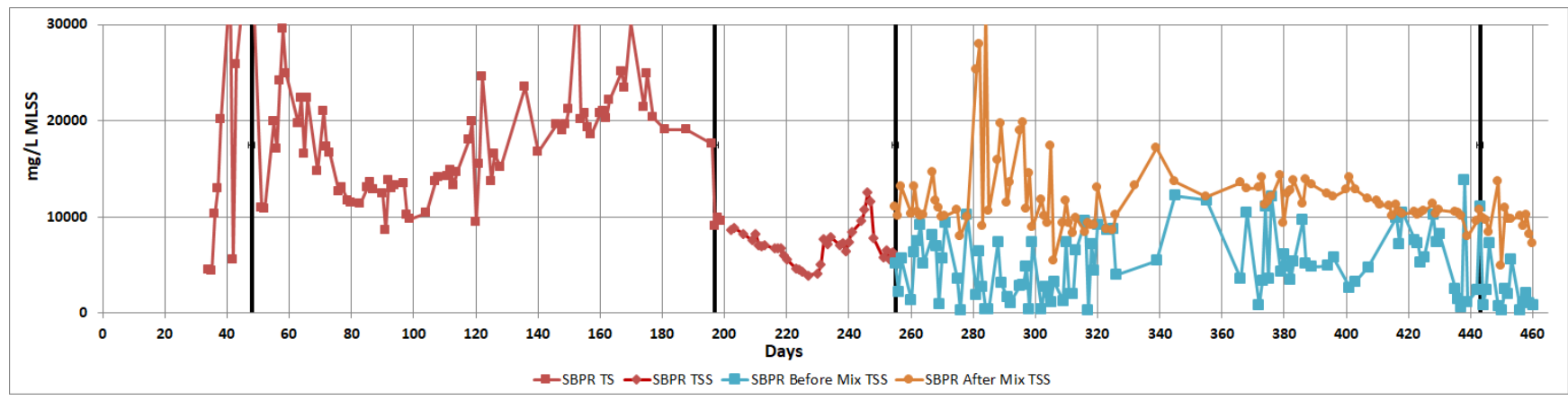


Figure 4.24. Sidestream Solids Concentration

From the beginning of this study, the solids in the SBPR were calculated as one measurement either as total solids, or total suspended solids depending on the percent solids in the sidestream. If the reactor was being continuously mixed, the time at which the solids measurement was taken did not matter. However, if the SBPR was intermittently mixed, the solids measurement was taken after the mix to capture the entire inventory of the reactor. As Phase IV began, the reactor was intermittently mixing, and the need for two different sidestream solids inventory measurements came about. Separating the before mix and after mix samples of the SBPR allowed for the entire reactor inventory to be known (after mix sample), as well as, the concentration of solids making it through to the mainstream the majority of the time when a mix was not occurring (before mix sample). The mixing regime in the SBPR changed throughout each phase in an attempt to optimize the reactor, however, in the end the optimal conditions consisted of intermittent mixing with a cycle every 3 hours, a duration of 2-10 minutes, and a speed of 200RPM.

The mainstream and sidestream solids concentration figures show that the solids remained relatively stable throughout Phase IV, once optimum sidestream mixing was achieved. However, it was necessary to watch the solids inventory closely. In Phase II, around day 106, the solids began to accumulate in the sidestream, causing a smaller amount of PAOs that had passed through an anaerobic zone with VFA present to reach the mainstream system. This can be detrimental, as it will lead to poor bio-P conditions.

\subsection{Sidestream ORP}

From the literature, it is expected that with an ORP value of $-250 \mathrm{mV}$ or less in the anaerobic zone, the system should be able to perform with good OP removal performance. This is because the deep anaerobic conditions in conjunction with enough VFA available allows PAOs to perform their anaerobic metabolisms (J. Barnard et al., 2017). In Figure 4.25, it can also be seen that the ORP in the sidestream reactor was below $-300 \mathrm{mV}$ the majority of the study indicating that good OP removal performance could be achieved. 


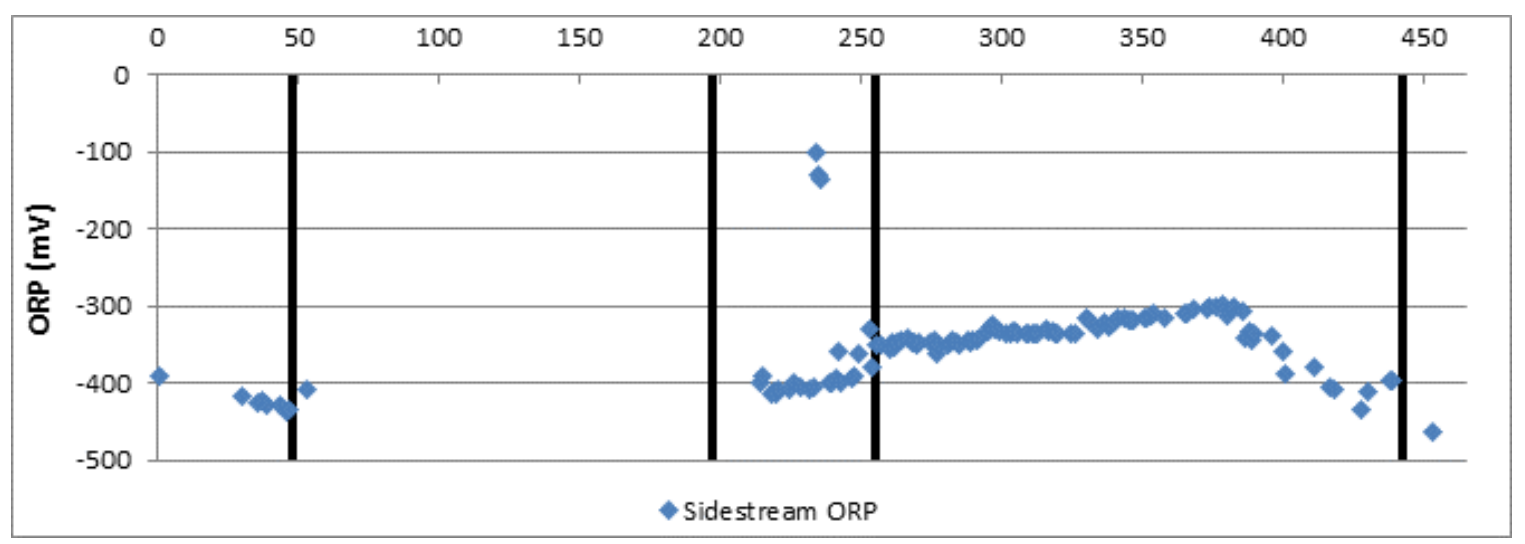

Figure 4.25. Sidestream ORP

\subsection{Experimental Design Results}

The goal of the experimental design analysis was to identify which control/independent variables in the system, used in this experimental study, played a role in reducing the overall mainstream OP, and to further identify which operating setting(s) of such control/independent variables will achieve the optimal system outcome of maximizing effluent OP removal efficiency by using statistical methodology. Once identified, then the same optimal system outcome of maximizing effluent OP removal efficiency shall be equally reproducible in future implementations/studies under similar configurations or at a system level.

Throughout this entire experiment, B-stage was operated in intermittent AVN control, temperature controlled to 20 degrees Celsius, and $\mathrm{pH}$ controlled to 7.0. During this study, solids and nutrient concentrations fluctuated in the sidestream and mainstream responding to the level of performance of the system. Reflecting such fluctuations, representative range of the sampled data from the experimental system was partitioned into quartiles to evaluate and identify corresponding system responses under different control settings of solid and nutrient concentrations. After determining which control (or independent) variables were playing a role in contributing to the overall reduction of OP in the mainstream (i.e., which had an influence), these control variables were further examined to determine which quartile range(s) of each 
control variable constituted the optimal operation condition (i.e., which influenced OP under what operating condition).

\subsubsection{Identification of Contributing Control Variables in the System}

As described in Chapter 3, Section 3.8.5, source-sink mass balances in sidestream and mainstream unit processes were used to develop a general linear model (GLM) relationship in form of the effluent as dependent variable, and influents and operating conditions as control/independent variables to be analyzed.

GLM analysis results calculated by using Statistical Analysis System (SAS) were then interpreted in a following deductive sequence to identify a combination of control factors and operating conditions that produced and will reproduce the maximum effluent OP removal efficiency in this study.

1. For each GLM model, test model validity at $\alpha=0.05$

2. If the estimate ANOVA p-value is less than $\alpha=0.05$, i.e., significant, then the proposed GLM model is valid with at least one of more of its independent/control variables contributed toward dependent variable in a reproducible manner. If ANOVA p-value was insignificant, then conclude that the proposed model was not valid or did not exhibit any collinearity.

3. If the GLM model was validated for its reproducibility, then use Covariance estimate (in form of the Squared Sum of residuals) matrix to further identify which independent/control variables in the model did contribute and which did not. (which control had an influence)

4. Once active/contributing independent/control variables were identified, further evaluate per independent/control variable to identify which operational range produced local maxima/minima in model's dependent variable. Duncan's multiple range test (MRT) was used for this purpose to determine which control variables worked best to maximize or minimize the dependent variable, and which combination of the independent variables worked best to maximize or minimize the dependent variable. This was done by reviewing the Duncan Grouping, and depending on whether the dependent variable 
should be maximized or minimized, choosing the Duncan Group and the corresponding independent variable range value that correlated with it (which control had an influence under what operating condition).

Tables 4.8 and 4.9 summarize subgrouping of variables used in the analysis of sidestream and mainstream processes, and their subsequent data were analyzed based on the mass balances and GLM expressions from Chapter 3, Section 3.6.5.

Table 4.8. Sidestream Unit Processes Broken into Ranges Based on Quartiles of the Data

\begin{tabular}{|l|l|}
\hline \multicolumn{2}{|c|}{ Sidestream Unit Processes } \\
\hline Unit Process Dependent Variables & Unit Process Independent Variables \\
\hline SBPR OP & $\begin{array}{l}\text { SBPR OP, RAS OP, Fermentate OP, SBPR } \\
\text { Flowrate }\end{array}$ \\
\hline SBPR NO3 & RAS NO3, Fermentate NH4, SBPR Flowrate \\
\hline SBPR TSS as a function of SBPR OP & RAS TSS, Fermentate TSS, SBPR Flowrate \\
\hline $\begin{array}{l}\text { SBPR Effluent TSS as a function of SBPR } \\
\text { TSS }\end{array}$ & RAS TSS, Fermentate TSS, SBPR Flowrate \\
\hline
\end{tabular}

Table 4.9. Mainstream Unit Processes Broken into Ranges Based on Quartiles of the Data

\begin{tabular}{|l|l|}
\hline \multicolumn{2}{|c|}{ Mainstream Unit Processes } \\
\hline Unit Process Dependent Variables & Unit Process Independent Variables \\
\hline Mainstream Effluent OP & $\begin{array}{l}\text { Influent OP, RAS OP, WAS Flowrate, Effluent } \\
\text { Flowrate }\end{array}$ \\
\hline Effluent OP as a function of Mainstream NH4 & RAS OP WAS Flowrate, Effluent Flowrate \\
\hline Mainstream NO3 & $\begin{array}{l}\text { Mainstream TSS, RAS TSS, WAS Flowrate, WAS } \\
\text { TSS, Effluent Flowrate }\end{array}$ \\
\hline Mainstream TSS & Effluent TSS, RAS TSS, WAS TSS, Effluent \\
\hline
\end{tabular}


flowrate

Reviewing each unit process ANOVA table explained whether the data set of independent variables contributed towards the dependent variable and could be further interpreted. A table summarizing all the unit process GLM model ANOVA table p-values (evaluated at $\alpha=0.05$ ) is shown in Table 4.10.

Table 4.10 GLM Model Validity on Contributional Collinearity by Independent Variables

\begin{tabular}{|c|c|c|c|c|c|c|c|}
\hline & \multicolumn{7}{|c|}{ Unit Processes } \\
\hline & $\begin{array}{c}\text { SBPR } \\
\text { OP }\end{array}$ & $\begin{array}{l}\text { SBPR } \\
\text { NO3 }\end{array}$ & $\begin{array}{c}\text { SBPR } \\
\text { TSS as a } \\
\text { function } \\
\text { of SBPR } \\
\text { OP }\end{array}$ & $\begin{array}{c}\text { SBPR } \\
\text { Effluent } \\
\text { TSS as a } \\
\text { function } \\
\text { of SBPR } \\
\text { TSS }\end{array}$ & $\begin{array}{l}\text { Mainstream } \\
\text { Effluent } O P\end{array}$ & $\begin{array}{c}\text { Effluent OP } \\
\text { as a } \\
\text { function of } \\
\text { Mainstream } \\
\text { NH4 }\end{array}$ & $\begin{array}{c}\text { Mainstream } \\
\text { NO3 }\end{array}$ \\
\hline $\begin{array}{l}\text { ANOVA Table } \\
\text { p-value }\end{array}$ & $\begin{array}{c}<0.000 \\
1\end{array}$ & $\begin{array}{c}0.325 \\
3\end{array}$ & 0.5540 & 0.0027 & 0.0001 & $<0.0001$ & $<0.0001$ \\
\hline Significance & Yes & No & No & Yes & Yes & Yes & Yes \\
\hline $\begin{array}{l}\text { Are } \\
\text { Independent } \\
\text { variables } \\
\text { contributing } \\
\text { to dependent } \\
\text { variable? }\end{array}$ & YES & NO & NO & YES & YES & YES & YES \\
\hline
\end{tabular}

Once a GLM model was validated, determining which independent variables worked to contribute towards the dependent variable in each unit process was analyzed based on the 
Covariance table estimates from each unit process. Table 4.11 summarizes which independent variables from each unit process/GLM model contributed to the dependent variables.

Table 4.11 Contributional Collinearity Independent Variables in Validated GLM Model

\begin{tabular}{|c|c|c|c|c|c|c|c|}
\hline \multicolumn{8}{|c|}{ Unit Processes } \\
\hline Type I SS & $\begin{array}{c}S B P R \\
O P\end{array}$ & $\begin{array}{l}\text { SBPR } \\
\text { NO3 }\end{array}$ & $\begin{array}{c}\text { SBPR } \\
\text { TSS as a } \\
\text { function } \\
\text { of SBPR } \\
\text { OP }\end{array}$ & $\begin{array}{c}\text { SBPR } \\
\text { Effluent } \\
\text { TSS as a } \\
\text { function } \\
\text { of SBPR } \\
\text { TSS }\end{array}$ & $\begin{array}{c}\text { Mainstream } \\
\text { OP }\end{array}$ & $\begin{array}{c}\text { Mainstream } \\
\text { NH4 as a } \\
\text { function of } \\
\text { Effluent OP }\end{array}$ & $\begin{array}{c}\text { Mainstream } \\
\text { NO3 }\end{array}$ \\
\hline \multirow{3}{*}{$\begin{array}{l}\text { Contributing } \\
\text { Independent } \\
\text { Variables }\end{array}$} & $\begin{array}{l}\text { RAS } \\
\text { OP }\end{array}$ & $N / A$ & $\mathrm{~N} / \mathrm{A}$ & RAS TSS & RAS OP & RAS OP & RAS NO3 \\
\hline & $\begin{array}{c}\text { Ferm } \\
\text { OP }\end{array}$ & $N / A$ & $\mathrm{~N} / \mathrm{A}$ & $\begin{array}{c}\text { Ferm } \\
\text { TSS }\end{array}$ & EFF Q & EFF Q & \\
\hline & $\begin{array}{c}\text { SBPR } \\
Q\end{array}$ & $\mathrm{~N} / \mathrm{A}$ & $\mathrm{N} / \mathrm{A}$ & SBPR Q & & & \\
\hline
\end{tabular}

Once contributional collinearity independent variables were identified, results from Duncan's MRT for each unit process were used to further decide which independent variables worked best at contributing towards the dependent variable, and at which range of the operating condition this occurred.

For the dependent variable of mainstream effluent OP, the Duncan group and corresponding independent variable range that minimizes the dependent variable should be chosen so that the mainstream effluent $\mathrm{OP}$ is minimized. Figures 4.26, 4.27, and 4.28 indicate which Duncan group and independent variable class to choose to achieve minimal effluent OP in the mainstream.

Duncan MRT results in Figure 4.26 indicate that the second quartile range (Q2) effluent flowrate condition augmented with the first quartile range (Q1) of RAS OP concentration would 
minimize the mainstream effluent $\mathrm{OP}$ concentration under current experimental configuration, reproducible at $95 \%$ level of confidence. From the Type I SS covariance table summarized in Table 4.10, we know that the influent OP variable and the WAS flowrate variable did not contribute to the resultant effluent OP concentration at a reproducible system level and need not to be examined further using Duncan's multiple range test results.

\begin{tabular}{|l|l|r|r|l|}
\hline \multicolumn{5}{|c|}{$\begin{array}{c}\text { Means with the same letter } \\
\text { are not significantly different. }\end{array}$} \\
\hline & A & 1.6131 & 16 & 1 Q \\
\hline & A & & & \\
\hline B & A & 1.3058 & 26 & 4 Q \\
\hline B & & & & \\
\hline B & & 1.0431 & 54 & 2 Q \\
\hline
\end{tabular}

\begin{tabular}{|l|r|r|l|}
\hline \multicolumn{4}{|c|}{$\begin{array}{c}\text { Means with the same letter } \\
\text { are not significantly different. }\end{array}$} \\
\hline Duncan Grouping & Mean & N & RAS_OP_class \\
\hline A & 2.1838 & 21 & 4 Q \\
\hline & & & \\
\hline B & 1.3467 & 21 & 3 Q \\
\hline B & & & \\
\hline B & 1.0155 & 29 & 2 Q \\
\hline & & & \\
\hline C & 0.5000 & 25 & 1 Q \\
\hline
\end{tabular}

Figure 4.26. Duncan's MRT Grouping of EFF_Q and RAS_OP in Mainstream OP

For the dependent variable of mainstream $\mathrm{NH}_{4}$ as a function of effluent OP, Figure 4.27 summarizes the Duncan groups and corresponding ranges of collinear independent variables, EFF_Q and RAS_OP, should be chosen so that the mainstream effluent OP is minimized. Figure 4.27. indicates which Duncan group and independent variable class to choose to achieve minimal effluent OP in the mainstream.

As shown in Figure 4.27, to minimize the mainstream $\mathrm{NH}_{4}$ as a function of effluent $\mathrm{OP}$ concentration, the effluent flowrate should be kept within the second quartile range and the RAS OP concentration should be kept within the first quartile range. From the Type I SS covariance table we know that the influent OP variable did not contribute to the resultant effluent OP concentration and should not be examined further using Duncan's multiple range test results. 


\begin{tabular}{|l|l|r|r|l|}
\hline \multicolumn{5}{|c|}{$\begin{array}{l}\text { Means with the same letter } \\
\text { are not significantly different. }\end{array}$} \\
\hline & A & 1.6131 & 16 & 1 Q \\
\hline & A & & & \\
\hline B & A & 1.3917 & 24 & 4 Q \\
\hline B & & & & \\
\hline B & & 1.0420 & 49 & 2 Q \\
\hline
\end{tabular}

\begin{tabular}{|l|r|r|l|}
\hline \multicolumn{4}{|c|}{$\begin{array}{c}\text { Means with the same letter } \\
\text { are not significantly different. }\end{array}$} \\
\hline Duncan Grouping & Mean & N & RAS_OP_class \\
\hline A & 2.1505 & 20 & 4 Q \\
\hline & & & \\
\hline B & 1.3640 & 20 & 3 Q \\
\hline B & & & \\
\hline B & 1.0468 & 28 & 2 Q \\
\hline & & & \\
\hline C & 0.5081 & 21 & 1 Q \\
\hline
\end{tabular}

Figure 4.27. Duncan's MRT Grouping of EFF_Q and RAS_OP for Mainstream NH4 as a Function of Effluent OP

For the dependent variable of mainstream $\mathrm{NO}_{3}$, the Duncan group and corresponding independent variable range shown in Figure 4.28 indicates that to minimize the mainstream $\mathrm{NO}_{3}$, the RAS $\mathrm{NO}_{3}$ should be kept within the first quartile range. From the Type I SS Covariance table we know that the RAS OP, WAS flowrate, and effluent flowrate did not contribute to the resultant effluent $\mathrm{NO}_{3}$ concentration and should not be examined further using Duncan's multiple range test results. 


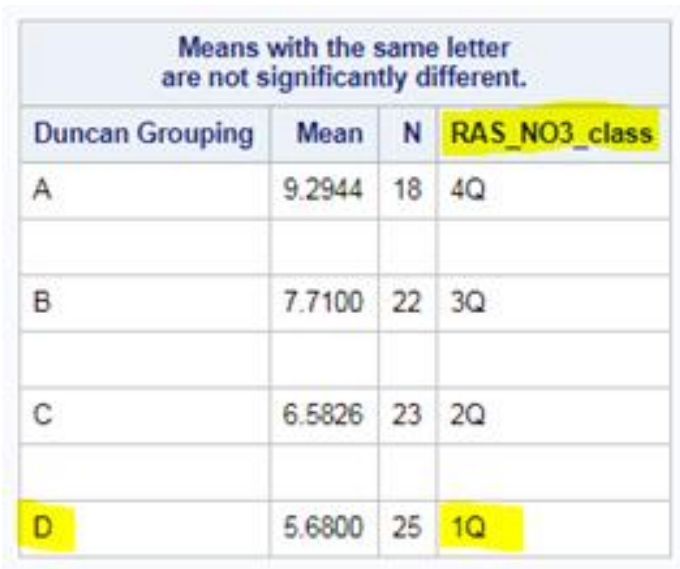

Figure 4.28. Duncan's MRT Grouping of RAS_NO3 for Mainstream NO3

Mainstream TSS as an additional variable had unbalanced data sets due to their temporal disjoints and making comparisons of the individual independent variables impossible. Because of this, background knowledge of how mixed liquor should be controlled in an activated sludge process was relied on.

For the dependent variable of sidestream effluent OP, the Duncan group and corresponding independent variable range that maximizes the dependent variable should be chosen so that the sidestream effluent OP is maximized. Figures 4.29 and 4.30 indicate which Duncan group and independent variable class to choose to achieve maximum sidestream effluent OP.

From the Duncan MRT results shown in Figure 4.29, to maximize the sidestream effluent OP, the RAS OP should be kept within the third quartile range, the fermentate OP should be kept within the fourth and third quartile range, and the SBPR flowrate should be kept in the first or third quartile ranges. From the Type I SS Covariance table we know that the SBPR OP did not contribute to the resultant effluent OP concentration and should not be examined further using Duncan's multiple range test results. 


\begin{tabular}{|l|l|r|r|l|}
\hline \multicolumn{5}{|c|}{$\begin{array}{l}\text { Means with the same letter } \\
\text { are not significantly different. }\end{array}$} \\
\hline Duncan Grouping & Mean & N & RAS_OP_class \\
\hline & A & 58.324 & 19 & 4 Q \\
\hline & A & & & \\
\hline B & A & 52.948 & 25 & 2 Q \\
\hline B & A & & & \\
\hline B & A & 49.290 & 26 & 1 Q \\
\hline B & & & & \\
\hline B & & 42.161 & 23 & 3 Q \\
\hline
\end{tabular}

\begin{tabular}{|l|r|r|r|}
\hline \multicolumn{4}{|c|}{$\begin{array}{c}\text { Means with the same letter } \\
\text { are not significantly different. }\end{array}$} \\
\hline Duncan Grouping & Mean & N & FERM_OP_class \\
\hline A & 66.881 & 10 & $4 Q$ \\
\hline A & & & \\
\hline A & 60.648 & 22 & 30 \\
\hline & & & \\
\hline B & 44.809 & 34 & 10 \\
\hline B & & & \\
\hline B & 42.835 & 27 & 20 \\
\hline
\end{tabular}

\begin{tabular}{|l|r|r|l|}
\hline \multicolumn{4}{|c|}{$\begin{array}{c}\text { Means with the same letter } \\
\text { are not significantly different. }\end{array}$} \\
\hline Duncan Grouping & Mean & N & SBPR_Q_class \\
\hline A & 65.515 & 16 & 1 Q \\
\hline A & & & \\
\hline A & 64.192 & 23 & $3 Q$ \\
\hline & & & \\
\hline B & 39.971 & 54 & 2 Q \\
\hline
\end{tabular}

Figure 4.29. Duncan's MRT Grouping of RAS_OP, FERM_OP and SBPR_Q for Sidestream EFF_OP

For the dependent variable of sidestream effluent $\mathrm{NO}_{3}$, and sidestream TSS as a function of sidestream OP, the results of the p-value in the ANOVA table indicate there is no collinearity between sidestream effluent $\mathrm{NO}_{3}$ and TSS with sidestream effluent OP values. Because of this no meaningful and reproducible interpretation of their relationships is possible.

For the dependent variable of sidestream effluent TSS as a function of SBPR TSS, the Duncan group and corresponding independent variable range that maximizes the dependent variable should be chosen so that the sidestream effluent TSS is maximized. Figure 4.30 
indicates which Duncan group and independent variable class to choose to achieve maximum sidestream effluent TSS.

From the Duncan MRT results shown in Figure 4.30, to maximize the sidestream TSS, the RAS TSS should be kept within the first quartile range, the fermentate TSS should be kept within the first, second, or third quartile range (i.e., not too extremely high), and the SBPR flowrate should be kept within the first quartile range.

\begin{tabular}{|l|l|r|r|l|}
\hline \multicolumn{5}{|c|}{$\begin{array}{c}\text { Means with the same letter } \\
\text { are not significantly different. }\end{array}$} \\
\hline & A & 8741.7 & 6 & 1 Q \\
\hline & A & & & \\
\hline Buncan Grouping & Mean & N & RAS_TSS_class \\
\hline B & A & 7256.7 & 6 & 4 Q \\
\hline B & & & & \\
\hline B & & 6834.0 & 5 & 3 Q \\
\hline B & & & & \\
\hline
\end{tabular}

\begin{tabular}{|l|r|r|l|}
\hline \multicolumn{4}{|c|}{$\begin{array}{c}\text { Means with the same letter } \\
\text { are not significantly different. }\end{array}$} \\
\hline Duncan Grouping & Mean & N & FERM_TSS_class \\
\hline A & 9118.3 & 6 & 4 Q \\
\hline & & & \\
\hline B & 6693.8 & 8 & 3 Q \\
\hline B & & & \\
\hline B & 6636.7 & 3 & 1 Q \\
\hline B & & & \\
\hline B & 5972.0 & 5 & 2 Q \\
\hline
\end{tabular}

\begin{tabular}{|l|r|r|l|}
\hline \multicolumn{4}{|c|}{$\begin{array}{c}\text { Means with the same letter } \\
\text { are not significantly different. }\end{array}$} \\
\hline Duncan Grouping & Mean & N & SBPR_Q_class \\
\hline A & 7810.0 & 18 & 1 Q \\
\hline & & & \\
\hline B & 4362.5 & 4 & 3 Q \\
\hline
\end{tabular}

Figure 4.30. Duncan's MRT Grouping of RAS_TSS, FERM_TSS and SBPR_Q for Sidestream EFF_TSS

Based on experimental design analysis results calculated by using SAS, the combination of independent variables that work best to produce low effluent mainstream OP are: RAS OP operating in the first quartile, and effluent flowrate in the second quartile. To minimize mainstream $\mathrm{NO}_{3}$, the RAS $\mathrm{NO}_{3}$ should be operated in the first quartile range. The combination of 
variables that work best to produce a maximum effluent sidestream OP are: RAS OP operating in the third quartile, fermentate OP operating in the third and fourth quartile, and SBPR flowrate operating in the first and third quartile. To maximize sidestream TSS, the RAS TSS should be operated in the first quartile, the fermentate TSS operated in the first, second, or third quartile, and the SBPR flowrate operated in the first quartile. By operating all these variables in the specified quartile ranges, the system will be optimized and produce the lowest effluent OP possible in the mainstream system in a reproducible manner under current experimental configuration at a $95 \%$ level of confidence.

Table 4.12 Summary Table for Duncan MRT Results

\begin{tabular}{|c|c|c|c|c|}
\hline & $\begin{array}{l}\text { Minimize } \\
\text { Effluent } \\
\text { Mainstream } \\
\text { OP }\end{array}$ & $\begin{array}{l}\text { Minimize } \\
\text { Mainstream } \\
\mathrm{NO}_{3}\end{array}$ & $\begin{array}{l}\text { Maximize Effluent } \\
\text { Sidestream OP }\end{array}$ & $\begin{array}{l}\text { Maximize } \\
\text { Sidestream TSS }\end{array}$ \\
\hline & \multicolumn{4}{|c|}{ Quartile Range } \\
\hline RAS OP mg/L & $\begin{array}{l}\text { Q1: } 0.14- \\
0.185\end{array}$ & & Q3: $1.62-2.89$ & \\
\hline $\begin{array}{l}\text { Effluent } \\
\text { Flowrate } \\
\text { L/min }\end{array}$ & Q2: 3.03-3.33 & & & \\
\hline $\mathrm{RAS} \mathrm{NO}_{3} \mathrm{mg} / \mathrm{L}$ & & $\begin{array}{l}\text { Q2: } 2.31- \\
4.79\end{array}$ & & \\
\hline $\begin{array}{l}\text { Fermentate } \\
\text { OP mg/L }\end{array}$ & & & $\begin{array}{l}\text { Q3: } 27.25-34.04 \\
\text { Q4: } 34.04-74.50\end{array}$ & \\
\hline $\begin{array}{l}\text { SBPR } \\
\text { Flowrate } \\
\text { L/min } \\
\end{array}$ & & & $\begin{array}{l}\text { Q1: } 0.13-0.40 \\
\text { Q3: } 0.7-0.8\end{array}$ & Q1: $0.13-0.40$ \\
\hline RAS TSS mg/L & & & & $\begin{array}{l}\text { Q1: } 2750.0- \\
4057.5\end{array}$ \\
\hline $\begin{array}{l}\text { Fermentate } \\
\text { TSS mg/L }\end{array}$ & & & & $\begin{array}{l}\text { Q1: } 66.0-389.5 \\
\text { Q2: } 389.5-612.5 \\
\text { Q3: } 612.5-904.5\end{array}$ \\
\hline
\end{tabular}

Based on the independent variables that were found to work best in producing the lowest effluent mainstream OP, and the highest effluent sidestream OP, a Stepwise regression model 
was then used to determine a pre-operational design tool to identify a target input condition to achieve a desired output (effluent OP condition) for future pilot studies.

Two stepwise regression models were conducted, the first using mainstream effluent OP concentration as the dependent variable, and the second using the sidestream RAS OP concentration as the dependent variable. For each of first and second stepwise regression models, a set of linearized independent variable combinations were prepared to define homogeneity subgroup models and then each was evaluated for the best predictive performance by using least squared-sum residual analysis. For example, the base subgroup model only consisted of the first-order linearized terms, then following variation subgroup models were formulated and analyzed (total of 12 stepwise regression models).

Subgroup model \#1: Base with $1^{\text {st }}$ order linearized terms

Subgroup model \#2: Base + cross-product terms

Subgroup model \#3: Base + cross-product + higher order terms

Subgroup model \#4: Base + cross-product + higher order + functional terms

Subgroup model \#5: Base + functional terms

Subgroup model \#6: Base + higher order terms

Each stepwise regression subgroup model was first evaluated at $\alpha=0.05$ level to determine whether it was a valid predictive model for the dependent variable at reproducible system level. The best performing model was then determined from a pool of resultant validated models. Lastly, the best performing model was evaluated to determine the independent variable that had the strongest collinearity toward the dependent variable. Once the independent variables with the strongest collinearity were determined, future plans for pilot studies could be determined and operated with relevant independent variables (=operating key control conditions) already known.

Results from the Stepwise regression models are shown in figures 4.31 and 4.32. Figures 4.31 and 4.32 depict the predicted values from the models versus the observed values from the raw data collection. If the values sit directly on the diagonal line, then the model is considered a 
perfect replication of the data. These graphs in junction with one's minimum least squared-sum residual indicate which combination of independent variables for the sidestream and mainstream regression models performed the best. Based on subgroup model-level ANOVA table p-values, the valid models for the sidestream are subgroup models 1,2,3, and 6, and for the mainstream subgroup models $1,2,3,4,5$, and 6 were valid models that can be used for predictive purpose.

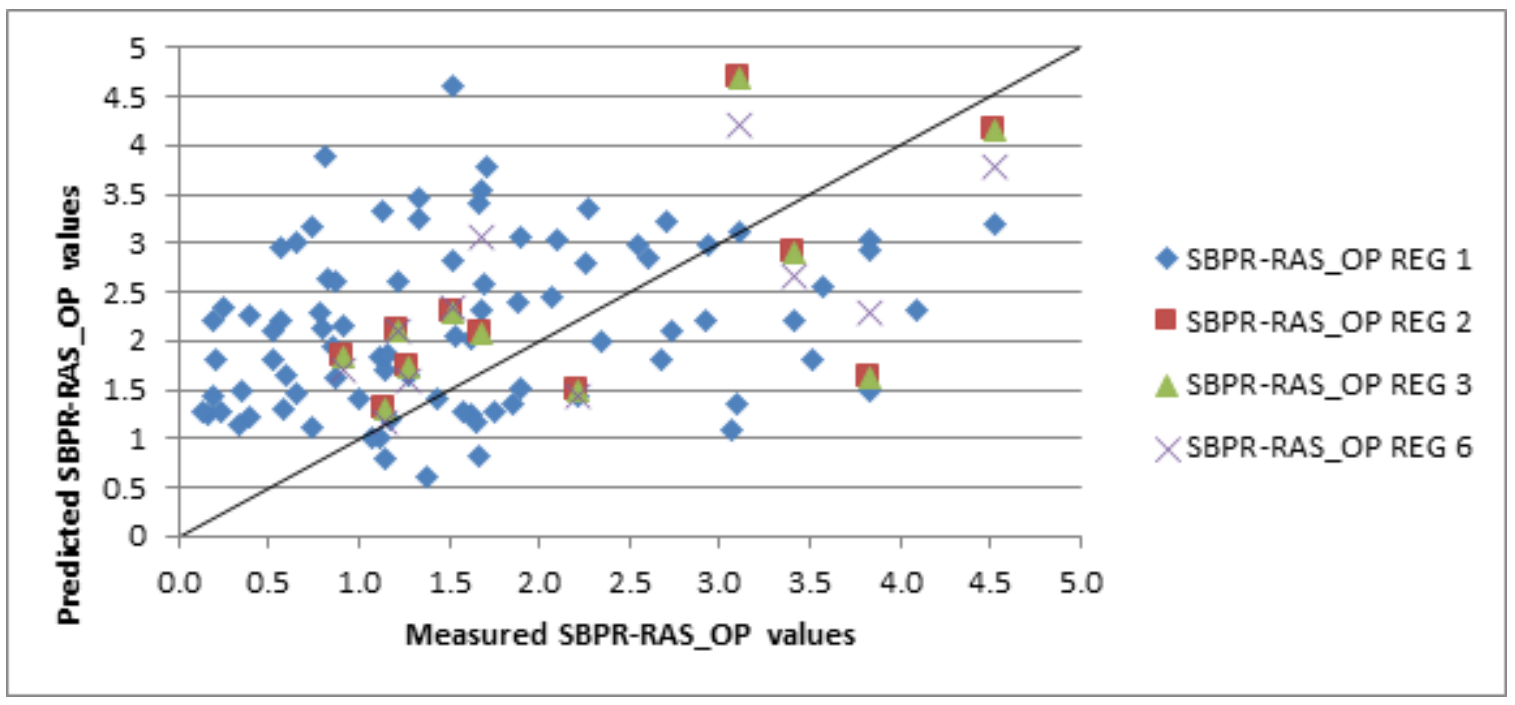

Figure 4.31. Sidestream Subgroup Models - Measured versus Predicted RAS OP Values

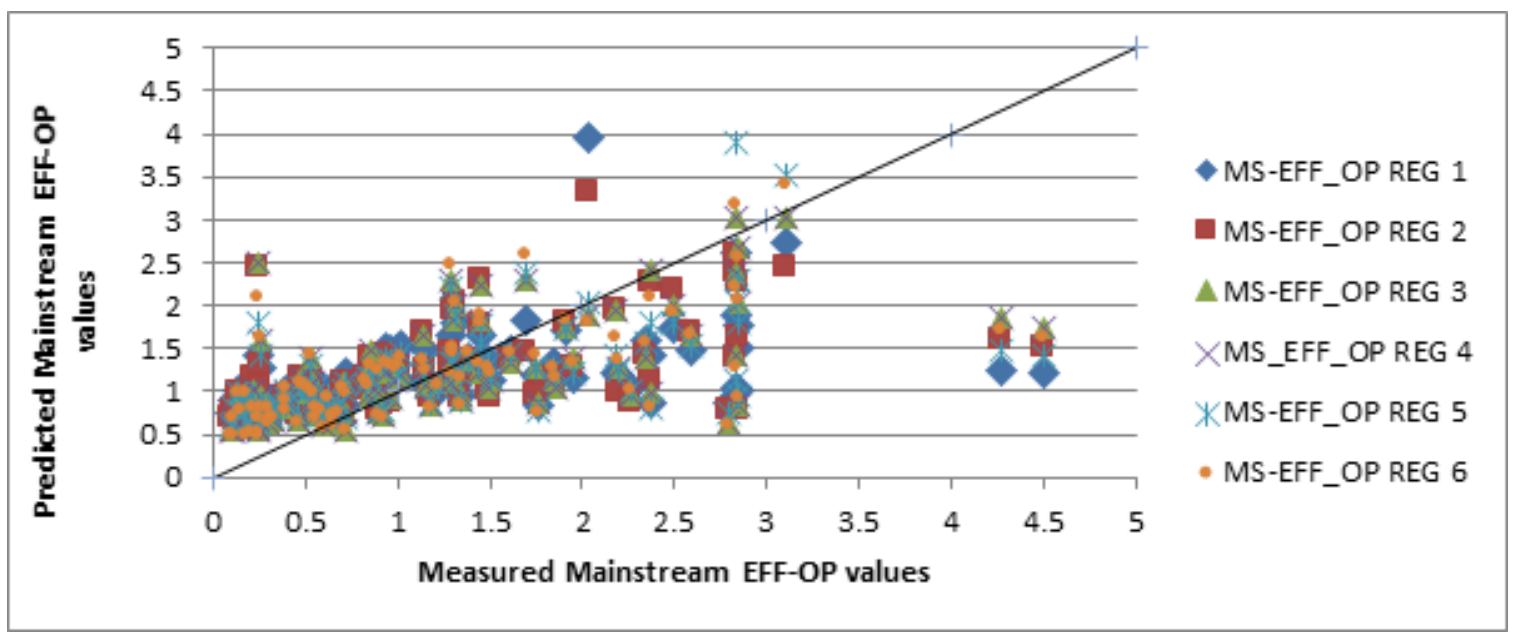

Figure 4.32. Mainstream Subgroup Models - Measured versus Predicted Effluent OP Values 
In the Figure 4.31 for the sidestream, regression model one tends to over-predict values below 2 and under-predict values above 3, making the more reproducible and accurate range between 2 and 3. Regression models 2 and 3 do not depict strong reproducibility. Regression model 6 shows the most reproducibility between ranges of 1.6 and 3.4. Overall for the sidestream, regression model 6 was selected as the best performing model based on the criteria of producing the minimum least squared-sum residual.

RAS $_{\mathrm{OP}}=(3.46 \mathrm{E}-8) \mathrm{RAS}_{\mathrm{TSS}}{ }^{2}+(2.64 \mathrm{E}-6)$ Fermentate $_{\mathrm{TSS}}{ }^{2}$

In the mainstream, Figure 4.32, regression model 1, 2, 3, and 4 were most reproducible between 1.2 and 1.5. Regression models 5 and 6 were most reproducible between range values of 1 and 2. Overall for the mainstream, regression model 3 was selected as the most accurate and best performing model.

Effluent $_{O P}=(0.195)$ RAS $_{Q}+(0.121)$ RAS $_{Q}$ RASOP $+(-9.8 E-3)$ RASOP $^{2}$

(Eqn. 4.2)

From Figures 4.31 and 4.32, for the sidestream regression models, the most reproducible model was regression model 6. This model utilized base level and higher order relationships among all independent variables used. From regression model 6, fermentate TSS proved to have a very strong collinearity to the dependent variable of RAS OP. For the mainstream regression model, the most reproducible model was 3. This model utilized base, products, cross products, and higher order terms for the relationships among all independent variables used. RAS OP as a product was the independent variable with the strongest collinearity to the dependent variable of mainstream effluent OP. 
Based on the valid predictive models and the variables with the strongest collinearity, future pilot studies could be conducted with known parameters and knowledge of how these variables will affect the operation.

\subsection{Final Conclusions}

It is clear from all the data and results presented that the optimal performance period for the system was during Phase IV of the experiment. During this phase of the study, the sidestream process was running with a 3.8-hour HRT, $27 \%$ of the RAS mass being sent to the sidestream reactor, and a large portion of VFA being sent to the sidestream reactor in terms of concentration and flow rate.

Phase IV of the experiment was successful for many reasons compared to the other phases of the experiment. The fermenter was operating at its optimal conditions, producing enough VFA to support the PAOs metabolisms, and the SBPR was operated in intermittent mixing, with a close eye being kept on the solids distribution between the mainstream and the sidestream. This allowed for the solids in the sidestream to contact fully with the VFA from the fermentate before being sent to the mainstream. The operational conditions in the sidestream reactor favored PAOs over GAOs.

Phase IV operated well until the pre-denite reactor was installed causing a change in population that favored GAOs. By looking at all the graphs depicting the effluent OP values, it is apparent that this is the same timeframe that good OP removal performance stopped. This shift in population encouraged the switch to Phase V. Phase V consisted of removing the predenite reactor, running a continuously mixed sidestream reactor, with an HRT of 20 hours, a 5\% RAS mass split, and very little to no VFA addition. This change was made, because PAOs are able to survive longer anaerobic retention times than their counterpart GAOs. During Phase V, the operation of the sidestream reactor may have started to change its dominant population back to PAOs, but no solid evidence has been produced at this time.

By combining the results from the experimental data collection and that of the experimental design data, there is a clear understanding of what the operational conditions were during the optimal operating period. These results allow for future work to replicate this project 
and from the experimental design work would be able to operate a similar system knowing the exact ranges each independent variable should operate within. 


\section{CHAPTER 5}

\section{FUTURE RECOMMENDATIONS}

Increasingly stringent phosphorus removal requirements dictate a more reliable $\mathrm{P}$ removal process from wastewater discharge. The EBPR process was found to be more beneficial than chemical P removal because of the decreased sludge volume production, reduced impact on $\mathrm{pH}$, the ability to recover $\mathrm{P}$ for secondary uses, and an overall reduction in cost. However, EBPR WRRFs usually struggle to keep the process stable and rely on backup chemical systems to reduce $\mathrm{P}$ to acceptable limits. One of the major problems with retaining a stable EBPR process is because of the influent rbCOD to $\mathrm{P}$ ratio being too low. Sidestream EBPR processes have been used to combat these low influent rbCOD concentrations. These processes allow for fermentation of RAS or MLSS in a sidestream reactor where the VFA rich effluent is sent back to the mainstream process.

The A/B process configuration with an A-stage WAS fermenter and SBPR reactor used in this study allowed for a controlled amount of carbon to be sent to the B-stage process for short-cut nitrogen removal, as well as, a controlled amount of carbon sent to the sidestream process in B-stage for more reliable EBPR. This process configuration allowed for shortcut nitrogen and phosphorus removal to be achievable in the same system.

Based on the data results from this project, the sidestream reactor optimal mixing regime and operation was discovered, along with determining the key parameters involved in the sidestream and mainstream process to achieve consistently low effluent OP values. Future studies would focus on the control variables found to work best in this study to further optimize effluent mainstream OP removal efficiency at a reproducible system level. To discontinue selfcontained sample-level experiments the results found in the experimental data should be utilized.

Based on the experimental design results from this project, a pre-operational design tool was created. This pre-operational tool consists of two Stepwise Regression models operated with relevant independent variables (=operating key control conditions) that were already 
identified in this study that can be used for future planning and optimal operating conditions for pilot studies. From these models and pre-identified key control conditions, future pilot studies would be able to find the optimal operating conditions at a system level reproducibility instead of sample level (i.e., numerous iterations of the same project would not be necessary). Prior to the creation of these models, these types of projects were conducted at sample level numerous times to achieve exact replicas of reproducible data. However, now with these models, easier design and scalability can be achieved because they provide a backwards approach to design. By starting with the influent characteristics and the intended effluent characteristics, the model will determine the achievable reactor volume and flowrate of the system, instead of these being the static variables. With the physical data collected at sample level for this project, the system level reproducible models were able to be created. 


\section{REFERENCES}

Andreasen, K., Petersen, G., Thomsen, H., \& Strube, R. (1997). Reduction of Nutrient Emission by Sludge Hydrolysis. Water Science and Technology, 35(10), 79-85.

APHA. (2012). Standard Methods for the Examination of Water and Wastewater. Washington, D.C.: APHA-AWWA-WEF.

Barnard, J. (1976). A review of biological phosphorus removal in activated sludge process. Water SA, 2(3), 136-144.

Barnard, J. (1985, June 23-28). The Role of Full Scale Research in Biological Phosphate Removal. Paper presented at the Proceedings of the University of British Columbia Conference on New Directions and Research in Waste Treatment and Residuals Management, Vancouver, Canada.

Barnard, J., \& Abraham, K. (2006). Key Features of Successful BNR Operation. Water Science and Technology, 53(12), 1-9.

Barnard, J., Dunlap, P., \& Steichen, M. (2017). Rethinking the Mechanisms of Biological Phosphorus Removal. Water Environment Research, 89(11), 2043-2054. doi:https://doi.org/10.2175/106143017X15051465919010

Barnard, J., Houweling, D., Analla, H., \& Steichen, M. (2010). Fermentation of Mixed Liquor for Phosphorus Removal. Paper presented at the WEFTEC 2010.

Barnard, J. L., \& Kobylinski, E. (2014). Fundamentals of Sludge Fermentation for Enhanced Biological Phosphorus Removal. Paper presented at the WEFTEC 2014, New Orleans, LA.

Brdjanovic, D., Logemann, S., Loosdrecht, M. C. M. V., Hooijmans, C. M., Alaerts, G. J., \& Heijnen, J. J. (1998). Influence of temperature on biological phosphorus removal: process and molecular ecological studies Water Research, 32(4), 1035-1048.

Cagnetta, C., Coma, M., Vlaeminck, S. E., \& Rabaey, K. (2016). Production of Carboxylates from High Rate Activated Sludge through Fermentation. Bioresource Technology, 217, 165-172.

Carson, K. (2012). Evaluation of performance for a novel side stream enhanced biological phosphorus removal configuration at a full-scale wastewater treatment plant. (Master of Science), University of Colorado at Boulder, ProQuest Dissertations Publishing. (1533385)

Carvalheira, M., Oehmen, A., Carvalho, G., Eusebio, M., \& Reis, M. A. M. (2014). The impact of aeration on the competition between polyphosphate accumulating organisms and glycogen accumulating organisms. Water Research, 66, 296-307.

Carvalheira, M., Oehmen, A., Carvalho, G., \& Reis, M. A. M. (2014). Survival strategies of polyphosphate accumulating organisms and glycogen accumulating organisms under conditions of low organic loading. Bioresource Technology, 172, 290-296.

Carvalho, G., Lemos, P. C., Oehmen, A., Crespo, M. T. B., \& Reis, M. A. M. (2006). Microbial diversity of the Candidatus Accumulibacter phosphatis clade in denitrifying phosphorus 
removal systems. Paper presented at the Proceedings of the 11th International Symposium on Microbial Ecology, Vienna, Austria.

Chen, Y., Liu, Y., Zhou, Q., \& Gu, G. (2005). Enhanced phosphorus biological removal from wastewater-effect of microorganism acclimatization with different ratios of short-chain fatty acids mixture. Biochemical Engineering Journal, 27, 24-32.

Chen, Y., Randall, A. A., \& Mccue, T. (2004). The efficiency of enhanced biological phosphorus removal from real wastewater affected by different ratios of acetic to propionic acid. Water Research, 38(1), 27-36.

Clark, K., \& Neethling, J. (2009). Operation of 5-Stage Bardenpho Process with Clarifier/Filters to achieve Low Effluent Phosphorus. WEFTEC 2009, Workshop W216- WEF/WERF Real World LOT.

Curto, P. (2001). Determining the potential for enhanced biological phosphorus removal based on the wastewater characteristics. (Master of Science), Cranfield University, UK.

Danesh, S., \& Oleszkiewicz, J. A. (1997). Volatile fatty acid production and uptake in biological nutrient removal systems with process separation. Water Environment Research, 69, 1106-1111.

de Graaff, M. S., van den Brand, T. P. H., Roest, K., Zandvoort, M. H., Duin, O., \& Van Loosdrecht, M. M. C. (2016). Full-scale highly-loaded wastewater treatment processes (A-stage) to increase energy production from wastewater: performance and design guidelines. Environmental Engineering Science, 33, 571-577.

Elefsionitis, P., \& Oldham, W. K. (1994). Anaerobic Acidogenesis of Primary Sludge: The Role of Solids Retention Time. Biotechnology and Bioengineering, 44, 7-13.

Erdal, U. G., Erdal, Z. K., \& Randall, C. W. (2003). The competition between PAOs (phosphorus accumulating organisms) and GAOs (glycogen accumulating organisms) in EBPR (enhanced biological phosphorus removal) systems at different temperatures and the effects on system performance. Water Science and Technology, 47(11), 1-8.

Filipe, C. D. M., Daigger, G. T., \& Grady, C. P. L. (2001a). Effects of pH on the Rates of Aerobic Metabolism of Phosphate-Accumulating and Glycogen-Accumulating Organisms. Water Environment Research, 73(2), 213-222.

Filipe, C. D. M., Daigger, G. T., \& Grady, C. P. L. J. (2001b). A metabolic model for acetate uptake under anaerobic conditions by glycogen accumulating organisms: stoichiometry, kinetics, and the effect of $\mathrm{pH}$. Biotechnology and Bioengineering, 76(1), 17-31.

Filipe, C. D. M., Daigger, G. T., \& Grady, C. P. L. J. (2001c). pH as a key factor in the competition between glycogen-accumulating organisms and phosphorus-accumulating organisms. Water Environment Research, 73(2), 223-232.

Flowers, J. J., He, S., Yilmaz, S., Noguera, D. R., \& McMahon, K. D. (2009). Denitrification capabilities of two biological phosphorus removal sludges dominated by different 'Candidatus Accumulibacter' clades. environmental microbiology reports, 1(6), 583-588.

Fuhs, G. W., \& Chen, M. (1975). Microbiological Basis of Phosphate Removal in the Activated Sludge Process for the Treatment of Wastewater. Microbial Ecology, 2(2), 119-138. 
Fukase, T., Shibata, M., \& Miyaji, Y. (1985). The role of the anaerobic stage on biological phosphorus removal. Water Science and Technology, 17, 69-80.

Ghasemi, A., \& Zahediasl, S. (2012). Normality tests for statistical analysis: a guide for nonstatisticians. International Journal of Endrocrinology and Metabolism, 10(2), 486-489.

Griffiths, P. C., Stratton, H. M., \& Seviour, R. J. (2002). Environmental factors contributing to the "G bacteria" population in full-scale EBPR plants. Water Science and Technology, 46(4-5), 185-192.

Gu, A. Z., Saunders, A. M., Neethling, J., Stensel, D., \& Blackall, L. (2008). Functionally relevant microorganisms to enhanced biological phosphorus emoval performance at fullscale wastewater treatment plants in the United States. Water Environment Research, 80, 688-698.

He, S., Gu, A. Z., \& McMahon, K. D. (2008). Progress Toward Understanding the Distribution of Accumulibacter Among Full-Scale Enhanced Biological Phosphorus Removal Systems. Microbial Ecology, 55(2), 229-236.

Houweling, D., Dold, P. L., \& Barnard, J. L. (2010). Theoretical Limits to Biological Phosphorus Removal: Rethinking the Influent COD:N:P Ratio. Paper presented at the WEFTEC 2010 Conference, New Orleans, LA.

Kang, D.-W., \& Noguera, D. R. (2014). Candidatus Accumulibacter Phosphatis: Elusive Bacterium Responsible for Enhanced Biological Phosphorus Removal. Journal of Environmental Engineering, 140(1), 2-10.

Kerrn-Jespersen, J. P., \& Henze, M. (1993). Biological Phosphorus Uptake Under Anoxic and Aerobic Conditions. Water Research, 27(4), 617-624.

Kobylinski, E., Barnard, J. L., Massart, N., Kleiwer, A., Crabtree, I., Wirth, M., . . Phillips, H. (2013). Starting up a 5-Stage Bardenpho Plant with In-line Fermentation- One Step at a Time. Paper presented at the WEFTEC 2013, Chicago, Illinois.

Kong, Y., Nielsen, J. L., \& Nielsen, P. H. (2005). Identity and Ecophysiology of Uncultured Actinobacterial Polyphosphate-Accumulating Organisms in Full-Scale Enahnced Biological Phosphorus Removal Plants. Applied and Environmental Microbiology, 71(7), 4076-4085.

Kristiansen, R., Nguyen, H. T. T., Saunders, A. M., Nielsen, J. L., \& Wimmer, R. (2013). A Metabolic Model for Members of the Genus Tetrasphaera involved in Enhanced Biological Phosphorus Removal. The ISME Journal, 7(3), 543-554.

Kuba, T., Smolders, G., Loosdrecht, M. C. M. v., \& Heijnen, J. J. (1993). Biological Phosphorus Removal from Wastewater by Anaerobic Anoxic Sequencing Batch Reactor. Water Science and Technology, 27(5-6), 241-252.

Lamb, J. (1994). United States Patent No.: U. S. Patent.

Lemaire, R., Meyer, R., Taske, A., Crocetti, G. R., Keller, J., \& Yuan, Z. (2006). Identifying causes for $\mathrm{N} 2 \mathrm{O}$ accumulation in a lab-scale sequencing batch reactor performing simultaneous nitrification, denitrification and phosphorus removal. Journal of Biotechnology, 122(1), 62-72. 
Levin, G. V., \& Shapiro, J. (1965). Metabolic Uptake of Phosphorus by Wastewater Organisms. Water Pollution Control Federation, 37(6), 800-821.

Li, G., Tooker, N. B., Wang, D., Srinivasan, V., Barnard, J., Schauer, P., . . Gu, A. Z. (2018). Investigate PAO-GAO Competition under Extended Anaerobic Conditions as in Sidestream Enhanced Biological Phosphorus Removal (S2EBPR) using Agent-based Model. Paper presented at the Water Environment Federation Technical Exhibition and Conference 2018 New Orleans, Louisiana.

Liu, W.-T., Mino, T., Matsuo, T., \& Nakamura, K. (1996). Biological Phosphorus Removal Processes- Effect of $\mathrm{pH}$ on Anaerobic Substrate Metabolism. Water Science and Technology, 34(1-2), 25-32.

Lopez-Vazquez, C. M., Oehmen, A., Hooijmans, C. M., Brdjanovic, D., Gijzen, H. J., Yuan, Z., \& Loosdrecht, M. C. M. v. (2008). Modeling the PAO-GAO competition: Effects of carbon source, $\mathrm{pH}$ and Temperature. Water Research, 43, 450-462.

Lopez-Vazquez, C. M., Oehmen, A., Hooijmans, C. M., Brdjanovic, D., Gijzen, H. J., Yuan, Z., \& Loosdrecht, M. C. M. v. (2009). Modeling the PAO-GAO competition: Effects of carbon source, $\mathrm{pH}$ and temperature. Water Research, 43, 450-462.

Lopez-Vazquez, C. M., Young-Il, S., Hooijmans, C. M., Brdjanovic, D., Moustafa S., M., Gijzen, H. J., \& Van Loosdrecht, M. M. C. (2007). Short-term temperature effects on the anerobic metabolism of glycogen accumulating organisms. Biotechnology and Bioengineering, 97(3), 483-495.

Martin, H. G., Ivanova, N., Kunin, V., Warnecke, F., Barry, K. W., \& al, e. (2006). Metagenomic analysis of two enhanced biological phosphorus removal (EBPR) sludge communities. Nature Biotechnology, 24(10), 1263-1269.

Meerburg, F. A., Boon, N., Van Winchel, T., Vercamer, J. A. R., Nopens, I., \& Vlaeminck, S. E. (2015). Toward energy-neutral wastewater treatment: a high-rate contact stabilization process to maximally recover sewage organics. Bioresource Technology, 179, 373-381.

Metcalf, \& Eddy. (2003). Wastewater Engineering Treatment and Reuse. India: McGraw-Hill.

Milbury, W. F., McCauley, D., \& Hawthorne, C. H. (1971). Operation of Conventional Activated Sludge for Maximum Phosphorus Removal. Water Pollution Control Federation, 43(9), 1890-1901.

Mino, T., Arun, V., Tsuzuki, Y., \& Matsuo, T. (1987). Effect of Phosphorus Accumulation on Acetate Metabolism in the Biological Phosphorus Removal Process. Paper presented at the Biological Phosphate Removal from Wastewaters, Rome, Italy.

Mino, T., loosdrecht, M. C. M. V., \& Heijnen, J. J. (1998). Microbiology and Biochemistry of the Enhanced Biological Phosphate Removal Process. Water Research, 32(11), 3193 3207.

Munch, E. v., \& Koch, F. A. (1999). A survey of prefermenter design, operation and performance in Australia and Canada. Water Science and Technology, 39(6), 105-112.

Nelder, J. A., \& Wedderburn, R. W. (1972). Generalized Linear Models. Journal of the Royal Statistical Society: Series A, 135, 370-384. 
Nguyen, H. T. T., Le, V. Q., Hansen, A. A., Nielsen, J. L., \& Nielsen, P. H. (2011). High diversity and abundance of putative polyphosphate accumulating Tetrasphaera related bacteria in activated sludge systems. FEMS Microbiology Ecology, 76(2), 256-267.

Nielsen, P. H., Mielczarek, A. T., Kragelund, C., Nielsen, J. L., Saunders, A. M., Kong, Y., . . . Vollertsen, J. (2010). A conceptual ecosystem model of microbial communities in enhanced biological phosphorus removal plants. Water Research, 44(17), 5070-5088.

Oehmen, A., Carvalho, G., Freitas, F., \& Reis, M. A. (2010). Assessing the abundance and activity of denitrifying polyphosphate accumulating organisms through molecular and chemical techniques. Water Science and Technology, 2061-2068.

Oehmen, A., Lemos, P. C., Carvalho, G., Yuan, Z., Keller, J., Blackall, L. L., \& Reis, M. A. M. (2007). Advances in enhanced biological phosphorus removal: From micro to macro scale. Water Research, 41(11), 2271-2300.

Oehmen, A., Saunders, A. M., Vives, M. T., Yuan, Z., \& Keller, J. (2006). Competition between polyphosphate and glycogen accumulating organisms in enhanced biological phosphorus removal systems with acetate and propionate as carbon sources. Journal of Biotechnology, 123(1), 22-32.

Oehmen, A., Vives, M. T., Lu, H., Yuan, Z., \& Keller, J. (2005). The effect of pH on the competition between polyphosphate-accumulating organisms and glycogen-accumulating organisms. Water Research, 39(15), 3727-3737.

Oehmen, A., Yuan, Z., Blackall, L. L., \& Keller, J. (2005). Comparison of Acetate and Propionate Uptake by Polyphosphate Accumulating Organisms and Glycogen Accumulating Organisms. Biotechnology and Bioengineering, 91(2), 162-168.

Oldham, W. K., \& Abraham, K. (1994). Use of Fermentation to Enhance Biological Nutrient Removal. Paper presented at the Overview of Full-Scale Fermenter Performance Water Environment Federation Conference Seminar, Chicago, Il.

Panswad, T., Doungchai, A., \& Anotai, J. (2003). Temperature effect on microbial community of enhanced biological phosphorus removal system. Water Research, 37(2), 409-415.

Rabinowitz, B. (1985). The Role of Specific Substrates in Excess Biological Phosphorus Removal. (Ph.D. Thesis), University of British Columbia, Vancouver, B.C.

Rabinowitz, B. (2011). WERF Compendium Fermenters.

Rahman, A., Yapuwa, H., Baserba, M. G., Rosso, D., Jimenez, J. A., Bott, C., . . De Clippeleir, H. (2017). Methods for quantification of biosorption in high-rate activated sludge systems. Biochemical Engineering Journal, 128, 33-44.

Sancho, I., Lopez-Palau, S., Arespacochaga, N., \& Cortina, J. L. (2019). New Concepts on Carbon Redirection in Wastewater Treatment Plants: A Review. Science of the Total Environment, 647, 1373-1384.

Satoh, H., Mino, T., \& Matsuo, T. (1992). Uptake of organic substrates and accumulation of polyhydroxyalkanoates linked with glycolysis of intracellular carbohydrates under anaerobic conditions in the biological excess phosphate removal processes. Water Science and Technology, 26(5-6), 933-942. 
Skalsky, D., \& Daigger, G. T. (1995). Wastewater solids fermentation for volatile acid production and enhanced biological phosphorus removal. Water Environment Research, 67(2), 230-237.

Smolders, G. J. F., Meij, J. V. D., Loosdrecht, M. C. M. V., \& Heijnen, J. J. (1994). Model of the anaerobic metabolism of the biological phosphorus removal process: Stoichiometry and pH influence. Biotechnology and Bioengineering, 43(6), 461-470.

Statistical Analysis System User's Guide: Statistics, Version 8.2. (2001).

Stevens, G., Ellsworth, A., Wyman, M., \& Lambrecht, A. (2015). BNR Process using RAS Anaerobic Zone. Proceedings of the Water Environment Federation, 1-3. doi:https://doi.org/10.2175/193864715819557641

Stroud, R., \& Martin, C. (2001). South Carey Water Reclamation Facility's Nutrient Removal Modifications and Reduction Success, Town of Carey, NC. Paper presented at the WEFTEC 2001, Atlanta, Georgia.

Tchobanoglous, G., Burton, F. L., \& Stensel, H. D. (2003). Wastewater Engineering: Treatment, Disposal, and Reuse 4th edition. New York: McGraw-Hill.

Thomas, M., Wright, P., Blackall, L., Urbain, V., \& Keller, J. (2003). Optimization of Noosa BNR plant to improve performance and reduce operating cost. Water Science and Technology, 47(12), 141-148.

Tooker, N. B., Li, G., Bott, C., Dombrowski, P., Schauer, P., Menniti, A., . . Gu, A. Z. (2017). Rethinking and Reforming Enhanced Biological Phosphorus Removal (EBPR) StrategyConcepts and Mechanisms of Side-Stream EBPR. Paper presented at the WEFTEC 2017.

Trzcinski, A. P., Wang, C., Zhang, D., Ang, S. W., Lin, L. L., Niwa, T., . . Ng Jern, W. (2017). Performance of A-stage process treating combined municipal-industrial wastewater. Water Science and Technology, 75, 228-238.

Turoviskiy, I. S., \& Mathai, P. K. (2006). Wastewater Sludge Processing. Hoboken, New Jersey: John Wiley \& Sons Inc.

Ullrich, A. H., \& Smith, M. W. (1951). The biosortion process of sewage and waste treatment process. Water Environment Federation, 23, 1248-1253.

Vale, P., Barnard, J., Thomas, D., \& Dold, P. (2008). RAS Fermentation to Enhance Biological Phosphorus Removal. Paper presented at the WEFTEC 2008, Chicago, Illinois.

Vollertsen, J., Petersen, B., \& Borregaard, V. R. (2006). Hydrolysis and Fermentation of Activated Sludge to Enhance Biological Phosphorus Removal. Water Science and Technology, 53(12), 55-64.

Wan, J., Gu, J., Zhao, Q., \& Liu, Y. (2016). COD capture: a feasible option towards energy selfsufficient domestic wastwater treatment. Science Reports, 6, 1-9.

Wang, D., Tooker, N. B., Srinivasan, V., Li, G., Schauer, P., Menniti, A., . . Gu, A. Z. (2018). A Full-Scale Comparative Study of Conventional and Side-Stream Enhanced Biological Phosphorus Removal Processes.

WEF. (2006). Biological Nutrient Removal (BNR) Operation in Wastewater Treatment Plants (Vol. MOP No. 30). New York, N.Y.: McGraw Hill. 
Yang, F., Kozak, J., \& Zhang, H. (2014). Shortcut Biological Nitrogen Removal Methodologies: Mainstream Partial Nitritation/Deammonification and Nitritation/Denitritation: A Literature Review. Retrieved from

Yuan, Q. (2012). Fermentation - Enhanced Sustainable Biological Phosphorus Removal. (Doctor of Philosophy), University of Manitoba. (978*0-494-79260-5)

Yuan, Z., Pratt, S., \& Batstone, D. (2012). Phosphorus recovery from wastewater through microbial processes. Current Opinion in Biotechnology.

Zeng, R. J., Van Loosdrecht, M. M. C., Yuan, Z. G., \& Keller, J. (2003). Metabolic model for glycogen-accumulating organisms in anaerobic/aerobic activated sludge systems. Biotechnology and Bioengineering, 81(1), 92-105.

Zeng, R. J., Yuan, Z., \& Keller, J. (2002). Enrichment of denitrifying glycogen-accumulating organisms in anaerobic/anoxic activated sludge system. Biotechnology and Bioengineering, 81(4), 397-404. doi:https://doi.org/10.1002/bit.10484 


\section{APPENDICES}

\section{APPENDIX A \\ LABORATORY ANALYSIS METHODS}

Table A-1. Chesapeake Elizabeth Pilot Analyses

\begin{tabular}{|c|c|c|}
\hline Parameter & Reference Method & Description \\
\hline TSS & SM 20th 2540D & $\begin{array}{l}\text { TSS - Total Suspended Solids Dried } \\
\text { at } 103-105^{\circ} \mathrm{C}\end{array}$ \\
\hline $\mathrm{NH} 4-\mathrm{N}$ & Hach 10205 & $\begin{array}{c}\text { Ammonia TNTplus ULR (0.015 to } \\
\left.2.00 \mathrm{mg} / \mathrm{L} \mathrm{NH} \mathrm{NH}_{4} \mathrm{~N}\right)\end{array}$ \\
\hline $\mathrm{NH} 4-\mathrm{N}$ & Hach 10205 & $\begin{array}{c}\text { Ammonia TNTplus LR (1 to } 12 \\
\left.\text { mg/L NH }{ }_{4}-\mathrm{N}\right)\end{array}$ \\
\hline NH4-N & Hach 10205 & $\begin{array}{c}\text { Ammonia TNTplus HR (2 to } 47 \\
\left.\mathrm{mg} / \mathrm{L} \mathrm{NH}_{4}-\mathrm{N}\right)\end{array}$ \\
\hline NO2-N & Hach 10207 & $\begin{array}{l}\text { Nitrite TNT LR }(0.015 \text { to } 0.600 \\
\left.\mathrm{mg} / \mathrm{L} \mathrm{NO}_{2}-\mathrm{N}\right)\end{array}$ \\
\hline NO2-N & Hach 10237 & $\begin{array}{l}\text { Nitrite TNTplus } \mathrm{HR}(0.6 \text { to } 6.0 \mathrm{mg} / \mathrm{L} \\
\left.\mathrm{NO}_{2}-\mathrm{N}\right)\end{array}$ \\
\hline NO3-N & Hach 10206 & $\begin{array}{c}\text { Nitrate TNTplus LR }(0.23 \text { to } 13.5 \\
\left.\mathrm{mg} / \mathrm{L} \mathrm{NO} \mathrm{NO}_{3}-\mathrm{N}\right)\end{array}$ \\
\hline NO3-N & Hach 10206 & $\begin{array}{l}\text { Nitrate TNTplus HR (5 to } 35 \mathrm{mg} / \mathrm{L} \\
\left.\qquad \mathrm{NO}_{3}-\mathrm{N}\right)\end{array}$ \\
\hline OP & Hach 8048 & $\begin{array}{l}\text { Reactive Phosphorus TNT LR }(0.06 \\
\left.\text { to } 5.0 \mathrm{mg} / \mathrm{L} \mathrm{PO}_{4^{3-}}\right)\end{array}$ \\
\hline $\mathrm{OP}$ & Hach 10214 & $\begin{array}{l}\text { Reactive Phosphorus TNT HR (1.6 } \\
\left.\text { to } 30 \mathrm{mg} / \mathrm{L} \mathrm{PO}_{4}{ }^{3-}\right)\end{array}$ \\
\hline COD & Hach 8000 & $\begin{array}{l}\text { COD TNTplus ULR (1 to } 60 \mathrm{mg} / \mathrm{L} \\
\text { COD) }\end{array}$ \\
\hline COD & Hach 8000 & $\begin{array}{c}\text { COD TNTplus LR (3 to } 150 \mathrm{mg} / \mathrm{L} \\
\text { COD) }\end{array}$ \\
\hline COD & Hach 8000 & $\begin{array}{l}\text { COD TNTplus HR (20 to } 1500 \mathrm{mg} / \mathrm{L} \\
\text { COD) }\end{array}$ \\
\hline VFA & Hach 10240 & $\begin{array}{l}\text { Volatile Acids TNTplus (50 to } 2500 \\
\text { mg/L CH3COOH) }\end{array}$ \\
\hline
\end{tabular}

Table A-2. Central Environmental Laboratory Analysis

\begin{tabular}{|c|c|c|}
\hline Parameter & Reference Method & Description \\
\hline VFA & $5560 \mathrm{D}$ & Gas Chromatography \\
\hline
\end{tabular}




\section{APPENDIX B}

\section{EXPERIMENTAL DESIGN RESULTS}

Table B-1. Supplemental Experimental Design Table of Contents

\begin{tabular}{|l|c|}
\hline \multicolumn{2}{|c|}{ Experimental Design Table of Contents } \\
\hline \multicolumn{1}{|c|}{ Section Title } & 1 \\
\hline Shapiro-Wilk Normality Check SAS Listing & 11 \\
\hline Mainstream Collected Data from Experimental Study & 17 \\
\hline Sidestream Collected Data from Experimental Study & 26 \\
\hline RCB and Factorial Analysis SAS Source Code & 34 \\
\hline RCB and Factorial Analysis SAS Listing & 224 \\
\hline Stepwise Selection GLM SAS Source Code & 232 \\
\hline Stepwise Selection GLM SAS Listing & \\
\hline
\end{tabular}

*The full experimental design appendix is included in a supplemental appendix file. 


\section{VITA}

\section{Department of Civil and Environmental Engineering}

Old Dominion University Norfolk, VA 23529

\section{Lindsey E. Ferguson, EIT}

2333 Number Ten Lane · Chesapeake, VA 23323 · (757) 692-0579·lferg008@odu.edu

\section{EDUCATION}

Old Dominion University

May 2019

Master of Science in Environmental Engineering

GPA: 3.75

Old Dominion University

Bachelor of Science in Civil Engineering

December 2017

GPA: 3.71

\section{Professional History}

Hampton Roads Sanitation District (HRSD), Virginia Beach, VA Water Research and Analysis Intern

Oct 2016- Present

- Conducted daily wastewater nutrient analysis

- Designed and built pilot scale reactors

- Researched effective EBPR using a side stream approach

Vanasse Hangen Brustlin (VHB), Virginia Beach, VA

Transportation Intern

Jan 2016 - Oct 2016

- Created cost estimates based on quantities

- Researched easements through deeds and plats

- Performed traffic counts and parking lot counts

- Wrote environmental pollution prevention plan documents

Innovations In Transportation (INIT), Chesapeake, VA Automatic Passenger Counting Civil Engineer Intern

May 2015- Aug 2015

- Learned specifications of INIT's sensors for each bus and train in each city

- Created presentations to teach new clients how to operate the APC system

- Assisted technicians in planning and building train models

\section{Conference Presentations:}

Sidestream RAS Fermentation for Stable Bio-P Combined with Short Cut Nitrogen Removal in an A/B Process. Nutrient Removal and Recovery 2018, Raleigh NC

Sidestream RAS Fermentation for Stable Bio-P Combined with Short Cut Nitrogen Removal in an A/B Process. WATERJAM 2018, Virginia Beach, VA

Sidestream RAS Fermentation for Stable Bio-P with A-stage Fermenter as Supplemental Carbon Source. WEFTEC 2018, New Orleans, LA 